\title{
DISTRIBUCIÓN DE LAS ESPECIES DE APHODIINAE (COLEOPTERA, SCARABAEOIDEA, APHODIIDAE) EN MÉXICO
}

\author{
Francisco José Cabrero-SAÑUdo', Marco Dellacasa², \\ Imelda MARTíneZ M. ${ }^{3}$, Jorge M. LOBO ${ }^{4}$ y Giovanni DELlACASA 5
}

1Universidad Complutense de Madrid, Departamento de Zoología y Antropología Física, Facultad de Ciencias Biológicas, José Antonio Novais 2, CP 28040, Madrid, ESPAÑA. fjcabrero@bio.ucm.es

2Università di Pisa, Museo di Storia Naturale e del Territorio, Via Roma 79, CP 56011 Calci, Pisa,

ITALIA. dellacasa@museo.unipit.it

3Instituto de Ecología A.C., Red de Ecoetología, km 2,5 carretera antigua a Coatepec 351, El Haya, 91070 Xalapa, Veracruz, MÉXICO. imelda.martinez@inecol.edu.mx

${ }^{4}$ Museo Nacional de Ciencias Naturales-CSIC, Departamento de Biodiversidad y Biología Evolutiva, José Gutiérrez Abascal 2, CP 28006 Madrid, ESPAÑA. mcnj117@mncn.csic.es

5Via Talamone 31/19, 16121 Génova, ITALIA. dellacasag@ alice.it

Cabrero-Sañudo, F. J., M. Dellacasa, I. Martínez M., J. M. Lobo \& G. Dellacasa. 2010. Distribución de las especies de Aphodiinae (Coleoptera, Scarabaeoidea, Aphodiidae) en México. Acta Zool. Mex. (n.s.), 26(2): 323-399.

RESUMEN. Se elaboró una base de datos (AphoMex) a partir de los registros disponibles sobre los Aphodiidae presentes en la República Mexicana, procedentes de la literatura, colecciones y colectas. A partir de ella y mediante una metodología dirigida a simular la distribución real de las especies, se obtuvieron mapas observados y predichos de los Aphodiinae mexicanos, así como un mapa que representa la riqueza de especies general de este grupo. Adicionalmente, se han examinado los posibles errores aportados por estas estimaciones. Teniendo en cuenta los patrones de distribución resultantes se discute cuáles son los factores que han determinado la distribución actual de los Aphodiinae en México. Palabras clave: Aphodiini, Didactyliini, Modelos de distribución, Escarabajos del estiércol, Mapas de distribución, México, Proctophanini, Riqueza de especies.

Cabrero-Sañudo, F. J., M. Dellacasa, I. Martínez M., J. M. Lobo \& G. Dellacasa. 2010. Distribution of Aphodiinae species (Coleoptera, Scarabaeoidea, Aphodiidae) in Mexico. Acta Zool. Mex. (n.s.), 26(2): 323-399.

ABSTRACT. A database (AphoMex) with the available records of Aphodiidae from the Mexican Republic was compiled, including data from literature, collections and surveys. Observed and simulated maps representing the realized distribution of Mexican Aphodiinae species were produced based on the observed records as well as on a species distribution modeling technique. Also, a map showing the general species richness of this group was obtained. The errors from these estimations were additionally examined. Considering the obtained distribution patterns, the most relevant factors which have influenced the distribution of Aphodiinae in Mexico are discussed.

Recibido: 22/09/2009; aceptado: 11/05/2010. 
Key Words: Aphodiini, Didactyliini, Distribution maps, Distribution models, Dung beetles, Mexico, Proctophanini, Species richness.

\section{INTRODUCCIÓN}

La subfamilia Aphodiinae constituye el grupo de especies de escarabajos más diversificado dentro de los Scarabaeoidea (clasificación sensu Dellacasa et al. 2001a) y presenta una distribución mundial. Una gran parte de las especies de Aphodiinae posee hábitos asociados a los excrementos de vertebrados, mostrando un comportamiento habitualmente endocóprido, es decir, comiendo y reproduciéndose en el interior de éstos, a diferencia de los Scarabaeinae y de los Geotrupinae, con costumbres generalmente telecópridas y/o paracópridas (Halffter \& Edmonds 1982, Cambefort 1991). Los Aphodiinae son el grupo predominante en las comunidades de escarabajos del estiércol de las zonas templado-frías de la región Paleártica (Hanski 1991) y, comúnmente, también en las de la región Neártica (Lobo 2000). En las regiones de influencia Neotropical, los Aphodiinae han sido escasamente estudiados, pero se ha observado que, aunque haya sólo una pequeña representación de estas especies en las comunidades, a veces pueden ser bastante abundantes (Andresen 2002).

En México, los Aphodiinae no han recibido una atención similar a la dirigida hacia otros grupos de coleópteros coprófagos (como Scarabaeinae o Geotrupinae) sino hasta la última década, en la que el interés por este grupo se ha incrementando notablemente (ver Cabrero-Sañudo et al. 2007b y referencias allí citadas). No obstante, el conocimiento acerca de la distribución geográfica de estas especies es bastante heterogéneo e incompleto, pues aún existe un buen número de regiones en México que requieren un mayor esfuerzo de prospección (Cabrero-Sañudo et al. 2007b).

Para determinar los patrones de distribución geográfica de los organismos, se han propuesto en los últimos años diferentes metodologías capaces de estimar las distribuciones potenciales y reales de las especies, a partir de los datos parciales georreferenciados y diversa información ambiental que actúa como predictora (Guisan \& Zimmermann 2000). Los mapas así obtenidos constituyen hipótesis de distribución que, dependiendo del tipo de datos usados (presencia, presencia/ausencia), la complejidad de la técnica de parametrización y la capacidad que tengan los predictores usados para dar cuenta de los factores históricos o geográficos, se acercarán más a la distribución potencial (el conjunto de localidades que pueden ser habitadas en un territorio según las caracteristicas de las áreas actualmente ocupadas) o a la distribución real (Soberón \& Peterson 2005, Peterson 2006, Jiménez-Valverde et al. 2008).

Utilizando una metodología de este tipo, similar a la de otros análisis previos realizados en México (Ortega-Huerta \& Peterson 2004, Domínguez-Domínguez et 
al. 2006, García 2006, Pineda \& Lobo 2009) e incluso utilizada anteriormente con otros grupos de escarabeidos coprófagos de México (Geotrupidae: Trotta-Moreu et al. 2008, Trotta-Moreu \& Lobo 2010; Scarabaeidae: Verdú \& Lobo 2008), el presente trabajo pretende ampliar el conocimiento biogeográfico sobre los Aphodiinae de México mediante: i) la creación de mapas que representen la distribución observada y predicha de todas aquellas especies con información georreferenciada disponible; ii) la obtención de un mapa general que muestre la posible distribución de la riqueza total de especies del grupo en la República Mexicana; y, iii) la estimación de la magnitud y localización de los errores de estas estimaciones. Finalmente, considerando los patrones así generados, se discutirán cuáles han podido ser los principales factores causales que han propiciado la actual distribución de la diversidad biológica de este grupo de insectos en México.

\section{MATERIAL Y MÉTODOS}

Origen de los datos biológicos y climáticos. Los datos utilizados en este trabajo proceden de una base de datos sobre los Aphodiidae mexicanos (AphoMex; CabreroSañudo et al. 2007b) elaborada mediante la compilación de la información contenida en los ejemplares depositados en diversas colecciones (destacando las de F. J. Cabrero-Sañudo, G. \& M. Dellacasa, G. \& V. Halffter, I. Martínez M., E. Montes de Oca, M. A. Morón, F. Vaz de Mello, y la colección del Instituto de Ecología, A. C., Xalapa, Veracruz, México), los datos procedentes de varias campañas de muestreo, así como aquéllos procedentes de una extensa búsqueda bibliográfica (ver Cuadro 1). Cada registro de la base de datos AphoMex contiene información contrastada de un total de 29 campos de información, relativos a las siguientes categorías: a) campos taxonómicos (subtribu, género, especie, autor, año de descripción); b) campos geográficos (localidad, estado, latitud, longitud, altitud); c) campos relacionados con la captura (número de ejemplares, día, mes y año de colecta, método de captura, colectores); d) campos eco-biológicos (sexo de los individuos, alimentación, hábitat, otras observaciones); y, e) otros campos relacionados con el manejo posterior de los ejemplares o de la información existente sobre éstos (persona que realizó la identificación, colección en la que se encuentra ingresado, bibliografía relacionada, otras anotaciones). AphoMex contiene en la actualidad alrededor de 4000 registros (11 de Septiembre de 2009), de los cuales 2588 corresponden a la subfamilia Aphodiinae (considerando las tribus Aphodiini, Didactyliini y Proctophanini). Esta base de datos está disponible bajo petición a los autores.

La taxonomía de esta subfamilia ha sufrido en los últimos años grandes modificaciones, especialmente en lo referente al cambio de estatus taxonómico de muchos subgéneros a géneros y a la reasignación de especies a diferentes géneros ya descritos o de nueva formación (Dellacasa et al. 1998, 2001a, 2002a, b, 2003, 2004a, b, 2007b, d, 2008, Bordat 1999, 2003, 2009, Dellacasa \& Dellacasa 2000a, b, 2005, 
Stebnicka 2000, Masumoto \& Kiuchi 2001, Ochi \& Kawahara 2001, Ziani 2002, Gordon \& Skelley 2007). Estos cambios taxonómicos no han sido arbitrarios, sino que se han propuesto con base en el examen morfológico de las más de 3000 especies asignadas a la subfamilia Aphodiinae (Dellacasa et al. 2001a) y en ausencia de hipótesis filogenéticas que abarquen toda la diversidad genérica o que ofrezcan una resolución determinante sobre las relaciones evolutivas dentro de la subfamilia, pese algunos trabajos preliminares realizados con un subconjunto regional de Aphodiinae (Cabrero-Sañudo \& Zardoya 2004; Cabrero-Sañudo 2007). Por tanto, se podría decir que los límites sistemáticos de cada género han sido subjetivamente establecidos por dichos autores (Dellacasa et al. 2001a), pero se encuentran basados en caracteres objetivos compartidos por las especies asignadas a cada género, y que los previos subgéneros han sido modificados en ausencia de criterios objetivos generales para establecer su inferioridad jerárquica frente a otros géneros que ya existían.

Muchos de estos cambios han afectado directamente a la taxonomía de Aphodiinae mexicanos, puesto que precisamente para este país se han descrito o sinonimizado últimamente diversos géneros y especies (Deloya \& Lobo 1996, Dellacasa et al. 1998, 2002b, 2003, 2007a, d, 2008, 2009, Deloya \& Ibáñez-Bernal 2000, Galante et al. 2003, Dellacasa \& Dellacasa 2005, Gordon \& Skelley 2007). Según las últimas actualizaciones de listados faunísticos (Cabrero-Sañudo et al. 2007b, Skelley et al. 2007) y los datos obtenidos en la elaboración de la base de datos AphoMex, México contaría actualmente con un total de 111 especies de Aphodiinae descritas y válidas (108 de Aphodiini, 2 de Didactyliini y 1 de Proctophanini), repartidas en un total de 43 géneros (41 de Aphodiini, 1 de Didactyliini y 1 de Proctophanini; Apéndice 1).

Para cada una de las especies mexicanas, se georreferenciaron (cuando fue posible) las localidades en las que se obtuvieron citas, teniendo en cuenta los datos del nomenclátor de localidades mexicanas ofrecido por el INEGI (Instituto Nacional de Estadística y Geografía; http://www.inegi.org.mx/inegi/default.aspx). Tanto los mapas de distribución observada como las predicciones de cada una de las especies modelizadas se realizaron a una resolución de $0.08^{\circ}\left(\approx 100 \mathrm{~km}^{2} ; 25.080\right.$ celdas para el territorio mexicano), utilizando para ello el programa Idrisi Kilimanjaro (Clark Labs 2003) y considerando que ésta era la mayor resolución posible a la que se podían utilizar los datos georreferenciados de las localidades de colecta de cada una de las especies. Del total de 2588 registros que actualmente posee esta base de datos, fue posible georreferenciar el $94 \%$ a esta resolución, careciendo los 150 registros restantes de información geográfica precisa. De las 111 especies consideradas, el $37 \%$ (41 especies) poseían cinco o más registros georreferenciados, el 37\% (41 especies) entre uno y cuatro registros, y el 26\% (29 especies) carecía de información georreferenciada fiable. 
Cuadro 1. Listado de artículos principales de los que se han obtenido registros relativos a la subfamilia Aphodiinae para la creación de la base de datos AphoMex.

\begin{tabular}{|c|c|c|}
\hline Allende \& Ramírez 2005 & Dellacasa et al. 2007c & Lobo 2000 \\
\hline Alvarado 2001 & Dellacasa et al. 2007d & Lobo \& Halffter 1994 \\
\hline Anduaga \& Halffter 1991 & Dellacasa et al. 2008 & Lobo \& Halffter 2000 \\
\hline Anduaga \& Halffter 2000 & Dellacasa et al. 2009 & Lobo \& Morón 1993 \\
\hline Arellano 2002 & Deloya 1987 & Márquez \& Asiain 2000 \\
\hline Arellano \& Halffter 2003 & Deloya 1988 & Martínez M. 2003 \\
\hline Balthasar 1946 & Deloya 1991 & Martínez M. 2005 \\
\hline Barrera 1969 & Deloya 1992a & Martínez M. \& Alvarado 2001 \\
\hline Bates 1887 & Deloya $1992 b$ & Martínez M. \& Cruz 2002 \\
\hline Blackwelder 1944 & Deloya 1994 & Martínez M. \& Suárez 2006 \\
\hline Blackwelder 1973 & Deloya 1995 & Martínez M. et al. 2000 \\
\hline Cabrero-Sañudo et al. 2007a & Deloya 1996 & Martínez M. et al. 2001 \\
\hline Cabrero-Sañudo et al. 2007b & Deloya 1998 & Martín-Piera \& Lobo 1993 \\
\hline Capistrán 1992 & Deloya 1999 & Morales 1998 \\
\hline Carrillo-Ruiz \& Morón 2003 & Deloya 2003a & Morales et al. 1998 \\
\hline Cartwright 1957 & Deloya 2003b & Morón 1979 \\
\hline Chacón 2005 & Deloya \& Ibáñez-Bernal 2000 & Morón 1994 \\
\hline Chapin 1940 & Deloya \& Lobo 1995 & Morón \& Deloya 1991 \\
\hline Cruz et al. 2002 & Deloya \& McCarty 1992 & Morón \& Zaragoza 1976 \\
\hline Dejean 1833 & Deloya \& Morón 1998 & Morón et al. 1985 \\
\hline Delgado 1989 & Deloya et al. 1993 & Morón et al. 1988 \\
\hline Delgado \& Márquez 2006 & Deloya et al. 1995 & Morón et al. 1998 \\
\hline Dellacasa 1986 & Deloya et al. 2007 & Morón et al. 2000 \\
\hline Dellacasa 1987a & Escoto 1984 & Muñoz 2003 \\
\hline Dellacasa $1987 \mathrm{~b}$ & Galante et al. 2003 & Muñoz et al. 2008 \\
\hline Dellacasa 1988a & García-Real 1995 & Navarrete-Heredia 2001 \\
\hline Dellacasa $1988 b$ & Gordon 1976 & Navarrete-Heredia 2006 \\
\hline Dellacasa 1991 & Gordon 1977 & Navarrete-Heredia \& Cortés 2004 \\
\hline Dellacasa 1995 & Gordon \& Howden 1973 & Navarrete-Heredia \& Deloya 2005 \\
\hline Dellacasa \& Dellacasa 2003 & Gordon \& Skelley 2007 & Navarrete-Heredia \& Quiroz-Rocha 2000 \\
\hline Dellacasa \& Dellacasa 2005 & Harold 1862 & Navarrete-Heredia et al. 2001 \\
\hline Dellacasa \& Gordon 1994 & Hinton $1934 \mathrm{a}$ & Ordóñez 2005 \\
\hline Dellacasa \& Stebnicka 2001 & Hinton $1934 b$ & Peraza 2004 \\
\hline Dellacasa et al. 1998 & Hinton 1938 & Percino-Figueroa 2002 \\
\hline Dellacasa et al. 2000 & Hinton \& Ancona 1934 & Rojas 1989 \\
\hline Dellacasa et al. 2001a & Hinton \& Ancona 1935 & Ruiz-Colorado 2001 \\
\hline Dellacasa et al. 2001b & Horn 1887 & Skelley et al. 2007 \\
\hline Dellacasa et al. 2002a & Islas 1945 & Smith 2003 \\
\hline Dellacasa et al. 2002b & Islas $1955 \mathrm{a}$ & Terrón et al. 1991 \\
\hline Dellacasa et al. 2003 & Islas $1955 b$ & Thomas 1993 \\
\hline Dellacasa et al. 2004a & Islas 1958 & Villalobos 1985 \\
\hline Dellacasa et al. 2004b & Koçak \& Kemal 2008 & Woodruff \& Cartwright 1967 \\
\hline Dellacasa et al. 2004c & Kohlmann 1991 & Zaragoza 1974 \\
\hline Dellacasa et al. 2007a & Lobo 1996 & Zunino \& Dellacasa 1989 \\
\hline
\end{tabular}


Como predictores se utilizaron un total de 19 variables climáticas obtenidas de la base de datos ambiental WorldClim también a una resolución de $\left(0.08^{\circ}\right)$ (Hijmans et al. 2006; ver Trotta-Moreu et al. 2008 y http://www.worldclim.org/).

Modelos predictivos. Para realizar la estimación de la distribución de las especies de Aphodiinae mexicanas se utilizó el programa MaxEnt 3.2 (Maximum Entropy; Phillips \& Dudik 2008), con los parámetros definidos por defecto en el programa, incluyendo características lineales y cuadráticas, así como un formato de salida acumulativo. La selección de este método, entre otras técnicas disponibles, se realizó como consecuencia de que sólo requiere los datos de presencia de las especies y porque ha sido recomendado en un análisis comparado entre las diversas técnicas de modelización de la distribución (Elith et al. 2006). MaxEnt utiliza un sistema de aprendizaje automático (machine learning) a través del cual se busca una distribución con una entropía máxima en la que todos los valores tienen la misma probabilidad de ocurrir, pero que se encuentra restringida según la información biológica de partida y las condiciones ambientales del área de estudio. El formato de salida es un mapa en el que cada celda del territorio posee un valor de favorabilidad entre 0 y 100.

MaxEnt únicamente fue utilizado en todas aquellas especies con datos de presencia en 5 ó más celdas de $0.08^{\circ}$ (37\%, 41 especies). Para aquellas especies con datos de presencia en 2,3 y 4 celdas de $0.08^{\circ}$ (19\%, 21 especies) las predicciones se realizaron calculando los valores máximos y minimos de diversas variables ambientales en las celdas con presencia conocidas, para después establecer el área de presencia probable como aquella compuesta por las celdas con valores climáticos dentro del rango de condiciones proporcionado por los datos de presencia conocidos (modelo de "cubierta bioclimática"). Este procedimiento simple es generalmente adecuado para realizar estimaciones de la distribución potencial de las especies (Jiménez-Valverde et al. 2008), de modo que asumimos que la representación geográfica así generada constituye una imagen provisional de la distribución en ausencia de limitantes de dispersión. Como los resultados de este procedimiento dependen del número de variables predictoras utilizadas (Beaumont et al. 2005), se eligió un conjunto mínimo de variables climáticas. Para ello se empleó el llamado método de Jollife (Rencher 2002) mediante el cual el conjunto completo de 19 variables climáticas predictoras se sometió a un Analisis de Componentes Principales, que proporcionó 4 componentes con valores propios (eigenvalues) mayores o próximos a la unidad $(7.86,4.83,3.62$ y 0.98 , respectivamente), que, en conjunto, fueron capaces de explicar el $91 \%$ de la variabilidad total. Para cada componente se eligió aquella variable original con una mayor correlación, de modo que las variables finalmente seleccionadas fueron: temperatura mínima del mes más frío, precipitación del cuatrimestre más seco, temperatura media del cuatrimestre más 
cálido y precipitación del mes más húmedo. Éstas serían, pues, las mejores variables con capacidad para representar las condiciones climaticas del territorio considerado.

Finalmente, para todas aquellas especies con datos de presencia en únicamente una celda de $0.08^{\circ}(18 \%, 20$ especies), la distribución potencial fue estimada ampliando un $30 \%$ los valores de las cuatro variables climáticas seleccionadas en la celda observada y considerando que todas las celdas con estas condiciones serían las más favorables para la presencia de cada especie (procedimiento también utilizado en Trotta-Moreu et al. 2008 y Trotta-Moreu \& Lobo 2010).

Validación de los modelos. Como ocurre generalmente en los grupos y regiones con alta diversidad biológica, la información georreferenciada disponible es muy escasa y sesgada, impidiendo la realización de modelos de distribución fiables (Cayuela et al. 2009). En nuestro caso, el número de registros georreferenciados disponibles es también escaso (media por especie \pm DS: $22 \pm 50$ ) y reducido el porcentaje de especies con más de 5 registros georreferenciados (37\%). Por ello, no es posible acudir a las técnicas de validación clásicas (Vaughan \& Omerod 2005) eligiendo, como medida de fiabilidad, la comparación entre los valores de riqueza observados en cada uno de los estados mexicanos con inventarios fiables y los valores de riqueza resultantes de la superposición de todos los modelos individuales de distribución generados (ver Pineda \& Lobo 2009 y Trotta-Moreu \& Lobo 2010).

Para estimar, en primer lugar, qué estados mexicanos poseían inventarios fiables, se valoraron sus inventarios faunísticos mediante dos estimadores no paramétricos de la riqueza de especies (ACE y Chao2; Colwell \& Coddington 1994, Chazdon et al. 1998), que aportan estimas del número total de especies en cada estado, asumiendo un esfuerzo de muestreo óptimo. Como medida del esfuerzo de muestreo se utilizó el número de registros de AphoMex para cada especie y para cada estado. Los análisis fueron realizados mediante el programa EstimateS (Colwell 2006). Aquellos estados para los que se estimó que la riqueza de especies observada era igual o superior al $70 \%$ de la predicha por cualquiera de estos dos estimadores se consideraron poseedores de inventarios fiables.

En las predicciones individuales realizadas con MaxEnt es necesario elegir un punto de corte adecuado en los valores de favorabilidad a fin de transformar éstos en binarios (presencia/ausencia). Para ello, se eligieron un total de 22 puntos de corte diferentes distribuidos a lo largo del intervalo de favorabilidad entre 0-100 (ver Pineda \& Lobo 2009 y Trotta-Moreu \& Lobo 2010): 100, 95, 90, 85, 80, 75, 70, 65, $60,55,50,45,40,35,30,25,20,15,10,5$ y 1. Además, se calculó para cada especie el punto óptimo de corte resultante de considerar, como área de presencia, al conjunto de todas aquellas celdas con favorabilidades iguales o superiores a la menor existente en una celda con presencia observada. Los valores de riqueza para cada estado, resultantes de la superposición de los modelos realizados con MaxEnt tras considerar 
cada uno de los 22 puntos de corte anteriormente mencionados, fueron comparados con la riqueza de especies observada en aquellos estados considerados como bien inventariados. Para decidir el umbral más favorable, se estimó la correlación entre ambos valores de riqueza mediante el coeficiente de correlación de Pearson y también la correlación entre la matriz de composición faunística observada (presencia/ausencia) en cada estado y la predicha según los modelos (test de Mantel). En estos analisis únicamente se utilizaron los datos provenientes de las 41 especies con presencia en 5 ó más celdas (ver Pineda \& Lobo 2009, para una descripción más detallada del procedimiento).

Una vez estimados los mapas de presencia/ausencia mediante MaxEnt y los modelos de "cubierta bioclimática", se generó una representación de la distribución de la riqueza de especies de Aphodinae en México, estimándose adicionalmente el número de especies erróneamente includos en cada estado y el número de especies omitidas de acuerdo a las predicciones y los inventarios de los estados con inventarios fiables (errores de comisión y omisión, respectivamente).

\section{RESULTADOS}

Selección de los estados con inventarios fiables. En el Cuadro 2 se resumen los 15 estados mexicanos cuyos inventarios fueron estimados fiables. Como se puede observar en la Figura 1, la mayor parte de los estados bien muestreados se encuentra distribuida a lo largo de la Sierra Madre Oriental, Sistema Volcánico Transversal, Sierra Madre del Sur y Sierra de Chiapas, mientras que, principalmente, los inventarios de los estados de la Península de Yucatán, del noroeste de México, Tamaulipas y algunos del centro de la República se encuentran insuficientemente muestreados.

Selección del umbral de favorabilidad. Las correlaciones entre la riqueza de especies observada en los estados con inventarios fiables y la predicha por la superposición de los modelos individuales sugieren que el mejor punto de corte es el que asigna como presencias las celdas con favorabilidades por encima de 80 (Figura 2) y que el punto de corte óptimo elegido individualmente para cada especie produce estimaciones poco fiables. Los valores del test de Mantel también sugieren un punto de corte similar (85). Por ello, a fin de obtener los mapas de presencia/ausencia predichos a partir de los modelos de MaxEnt, se eligió el punto de corte de 85 como el más apropiado para obtener los modelos de distribución de los Aphodiinae en México.

En las Figuras 3-16 se encuentran representados los mapas de distribución observados y predichos de las especies de Aphodiinae presentes en México. Estos mapas se encuentran también disponibles a una mejor resolución en la página http://www.biogeografia.org/. 
Cuadro 2. Riqueza de especies observadas por estado $\left(\mathrm{S}_{\mathrm{OBS}}\right)$ y riquezas predichas mediante los estimadores paramétricos $\mathrm{ACE}\left(\mathrm{S}_{\mathrm{ACE}}\right)$ y Chao2 $\left(\mathrm{S}_{\mathrm{CHAO} 2}\right)$ considerando los registros como medida de esfuerzo. Únicamente se incluyen los 15 estados en los que se observó que la riqueza de especies observada era, al menos, un $70 \%$ de la predicha por alguno de estos dos estimadores.

\begin{tabular}{|c|c|c|c|}
\hline \multirow[b]{2}{*}{ Estado } & \multirow{2}{*}{$\begin{array}{c}\text { Observada } \\
\mathbf{S}_{\mathrm{OBS}} \\
\end{array}$} & \multicolumn{2}{|c|}{ Predicha } \\
\hline & & $\mathbf{S}_{\mathrm{ACE}}$ & $\mathrm{S}_{\mathrm{CHAO2}}$ \\
\hline Chiapas & 13 & 16 & 14 \\
\hline Coahuila & 11 & 15 & 16 \\
\hline Durango & 38 & 51 & 51 \\
\hline Guerrero & 17 & 19 & 20 \\
\hline Hidalgo & 20 & 27 & 25 \\
\hline Jalisco & 18 & 26 & 25 \\
\hline México & 32 & 38 & 37 \\
\hline Michoacán & 22 & 30 & 29 \\
\hline Nuevo León & 17 & 26 & 21 \\
\hline Oaxaca & 28 & 30 & 29 \\
\hline Puebla & 22 & 25 & 25 \\
\hline Querétaro & 15 & 20 & 17 \\
\hline San Luis Potosí & 12 & 17 & 16 \\
\hline Veracruz & 27 & 31 & 37 \\
\hline Zacatecas & 7 & 7 & 7 \\
\hline
\end{tabular}

Comparación entre datos observados y predichos. La superposión de todos los modelos de distribución realizados (tanto utilizando MaxEnt, como los modelos de "cubierta bioclimática) produce valores de riqueza de especies claramente superiores a los observados (Cuadro 3). La sobrepredicción media es del 65\%, oscilando entre el $0 \%$ de Coahuila y el $186 \%$ de Zacatecas. A pesar de ello, la correlacion entre los valores predichos y observados es alta, positiva y significativa $(r=0.843, \mathrm{n}=15$, $\mathrm{P}<0.001)$. Como era de esperar, el porcentaje medio de los errores de comision (94 $\pm 52 ; \%$ medio \pm DS) es muy superior al de los errores de omision $(28 \pm 16 ; \%$ medio \pm DS), de modo que las técnicas de modelización empleadas tienden a incluir erróneamente un buen número de especies en cada estado, omitiendo además unas pocas de las observadas. 
Cuadro 3. Numero de especies de Aphodiinae observadas $\left(\mathrm{S}_{\mathrm{OBS}}\right)$ en cada uno de los estados mexicanos con inventarios fiables, numero de especies predichas por la superposición de los modelos individuales $\left(\mathrm{S}_{\mathrm{PRED}}\right)$, errores de comisión $(\mathrm{COM})$ y omisión $(\mathrm{OMI})$ y su porcentaje sobre el total de especies observadas en cada estado (\%COM y \%OMI).

\begin{tabular}{lcccccc}
\hline & S $_{\text {OBS }}$ & S $_{\text {PRED }}$ & COM & OMI & \% COM & \% OMI \\
\hline Chiapas & 13 & 23 & 15 & 5 & 115 & 38 \\
Coahuila & 12 & 12 & 4 & 4 & 33 & 33 \\
Durango & 32 & 48 & 23 & 7 & 72 & 22 \\
Guerrero & 17 & 26 & 12 & 3 & 71 & 18 \\
Hidalgo & 20 & 27 & 15 & 8 & 75 & 40 \\
Jalisco & 17 & 38 & 27 & 6 & 159 & 35 \\
México & 31 & 50 & 22 & 3 & 71 & 10 \\
Michoacán & 20 & 39 & 24 & 5 & 120 & 25 \\
Nuevo León & 13 & 14 & 6 & 5 & 46 & 38 \\
Oaxaca & 27 & 45 & 24 & 6 & 89 & 22 \\
Puebla & 23 & 56 & 33 & 0 & 143 & 0 \\
Querétaro & 15 & 20 & 13 & 8 & 87 & 53 \\
San Luis Potosí & 11 & 13 & 7 & 5 & 64 & 45 \\
Veracruz & 26 & 34 & 9 & 1 & 35 & 4 \\
Zacatecas & 7 & 20 & 16 & 3 & 229 & 43 \\
\hline
\end{tabular}

Características generales de las especies mexicanas de Aphodiinae. En el Cuadro 4 se encuentran resumidas las principales caracteristicas ambientales de las especies de Aphodiinae presentes en México, basadas en los valores de las celdas en las que se ha observado cada una de ellas. En general, las altitudes medias sobre el nivel del mar para las especies de Aphodiinae mexicanas oscilan entre los 250 a los 3200 metros, las temperaturas medias rondan desde los 9.7 hasta los $25.3^{\circ} \mathrm{C}$ y las precipitaciones medias de los 230 a los $2060 \mathrm{~mm}$. Estos resultados muestran que los Aphodiinae se encuentran presentes a lo largo de una amplia diversidad de ambientes, pese a que la mayoría de las especies posee preferencias por zonas montañosas, con climas templado/fríos y húmedos. 
Cuadro 4. Altitud, temperatura media anual (Tm) y precipitación anual (Pm) ( \pm DS) de las celdas de $0.08^{\circ}$ en las que se ha observado cada especie de Aphodiinae en México con datos georreferenciados y tamaño aproximado de su área de distribución predicha. Los datos de altitud provienen de un modelo digital del terreno a una resolución de $1 \mathrm{~km}^{2}$ (United Status Geological Survey 2006). Los datos climáticos provienen de WorldClim (Hijmans et al. 2006).

\begin{tabular}{|c|c|c|c|c|}
\hline Especies & $\begin{array}{l}\text { Altitud } \\
\text { (metros) }\end{array}$ & $\begin{array}{c}\text { Tm } \\
\left({ }^{\circ} \mathrm{C}\right)\end{array}$ & $\begin{array}{c}\text { Pm } \\
(\mathbf{m m})\end{array}$ & $\begin{array}{c}\text { Área } \\
\text { predicha } \\
\left(1^{3} \mathbf{k m}^{2}\right)\end{array}$ \\
\hline Agoliinus cruentatus & 2195 & 16.7 & 501 & 16.77 \\
\hline Agrilinellus abbonai & $2423 \pm 111$ & $14.4 \pm 1.8$ & $1149 \pm 240$ & 2.18 \\
\hline Agrilinellus antonioreyi & $2666 \pm 497$ & $13.4 \pm 2.2$ & $1157 \pm 191$ & 3.80 \\
\hline Agrilinellus azteca & $2293 \pm 1024$ & $14.4 \pm 5.9$ & $1435 \pm 627$ & 2.03 \\
\hline Agrilinellus chiapasensis & 2758 & 15.9 & 1278 & 35.81 \\
\hline Agrilinellus nuriae & 1927 & 12.8 & 625 & 1.48 \\
\hline Agrilinellus oaxacaensis & $1064 \pm 1371$ & $22.5 \pm 3.7$ & $1486 \pm 1149$ & 187.52 \\
\hline Agrilinellus ornatus & $2746 \pm 645$ & $11.6 \pm 3.0$ & $1171 \pm 333$ & 1.85 \\
\hline Aphodius fimetarius & 1382 & 18.9 & 499 & 5.55 \\
\hline Blackburneus charmionus & $1730 \pm 864$ & $15.8 \pm 4.0$ & $1410 \pm 454$ & 2.02 \\
\hline Blackburneus guatemalensis & $1792 \pm 568$ & $17.4 \pm 3.1$ & $1075 \pm 397$ & 19.71 \\
\hline Blackburneus saylorea & $1790 \pm 645$ & $18.4 \pm 3.5$ & $1261 \pm 618$ & 8.79 \\
\hline Blackburneus (s.l.) saylori & $2090 \pm 305$ & $16.9 \pm 2.3$ & $732 \pm 330$ & 20.07 \\
\hline Calamosternus colimaensis & $956 \pm 261$ & $23.7 \pm 2.2$ & $964 \pm 68$ & 7.08 \\
\hline Calamosternus granarius & 250 & 16.3 & 272 & 4.72 \\
\hline Cephalocyclus bordati & $2188 \pm 39$ & $13.6 \pm 2.1$ & $542 \pm 8$ & 2.72 \\
\hline Cephalocyclus carmenae & 2202 & 11.1 & 641 & 0.16 \\
\hline Cephalocyclus durangoensis & $2233 \pm 415$ & $14.3 \pm 2.4$ & $946 \pm 395$ & 3.14 \\
\hline Cephalocyclus fuliginosus & $2074 \pm 515$ & $15.6 \pm 3.0$ & $741 \pm 233$ & 23.26 \\
\hline Cephalocyclus gravidus & $2388 \pm 258$ & $14.7 \pm 2.1$ & $1040 \pm 232$ & 5.89 \\
\hline Cephalocyclus halffteri & $2800 \pm 659$ & $11.0 \pm 5.9$ & $1197 \pm 272$ & 7.58 \\
\hline Cephalocyclus hogei & $2516 \pm 547$ & $13.2 \pm 2.9$ & $1073 \pm 302$ & 3.16 \\
\hline Cephalocyclus howdenorum & $1826 \pm 977$ & $14.6 \pm 4.8$ & $726 \pm 144$ & 2.67 \\
\hline Cephalocyclus lagoi & $2230 \pm 419$ & $14.6 \pm 2.6$ & $631 \pm 358$ & 3.92 \\
\hline Cephalocyclus luridiventris & $2263 \pm 603$ & $15.1 \pm 2.5$ & $1114 \pm 552$ & 138.59 \\
\hline Cephalocyclus mexicanus & $2004 \pm 530$ & $16.8 \pm 2.9$ & $1093 \pm 296$ & 21.26 \\
\hline Cephalocyclus ordonezi & $3205 \pm 348$ & $9.7 \pm 1.8$ & $1025 \pm 60$ & 0.57 \\
\hline Cephalocyclus potosinus & $2307 \pm 441$ & $12.5 \pm 1.3$ & $577 \pm 97$ & 1.24 \\
\hline Cephalocyclus pullatus & $2015 \pm 760$ & $14.8 \pm 3.6$ & $1044 \pm 315$ & 2.17 \\
\hline Cephalocyclus puncticeps & $2159 \pm 1651$ & $16.8 \pm 7.5$ & $997 \pm 347$ & 398.76 \\
\hline Cephalocyclus rockefelleri & $1956 \pm 416$ & $15.3 \pm 2.8$ & $533 \pm 114$ & 24.15 \\
\hline Cephalocyclus stebnickae & $2217 \pm 168$ & $14.3 \pm 0.7$ & $1223 \pm 140$ & 0.66 \\
\hline Cephalocyclus villosipes & $2013 \pm 139$ & $16.8 \pm 2.8$ & $819 \pm 359$ & 14.00 \\
\hline Cesamexico constricticollis & 2300 & 18.5 & 1456 & 35.34 \\
\hline Coelotrachelus burgosi & 1045 & 23.7 & 987 & 61.96 \\
\hline Coelotrachelus ixtapalapaensis & 2323 & 16.0 & 679 & 30.49 \\
\hline Coelotrachelus kuntzeni & $2362 \pm 442$ & $14.8 \pm 2.5$ & $940 \pm 306$ & 6.42 \\
\hline Coelotrachelus rudis & $1992 \pm 203$ & $16.3 \pm 2.8$ & $540 \pm 120$ & 31.54 \\
\hline
\end{tabular}


Cabrero-Sañudo et al.: Distribución de Aphodiinae en México

\begin{tabular}{|c|c|c|c|c|}
\hline Especies & $\begin{array}{c}\text { Altitud } \\
\text { (metros) }\end{array}$ & $\begin{array}{l}\text { Tm } \\
\left({ }^{\circ} \mathrm{C}\right)\end{array}$ & $\underset{(\mathbf{m m})}{\mathbf{P m}}$ & $\begin{array}{c}\text { Área } \\
\text { predicha } \\
\left(\mathbf{1 0}^{3} \mathbf{k m}^{2}\right)\end{array}$ \\
\hline Coelotrachelus symbius & $1986 \pm 587$ & $15.0 \pm 3.0$ & $763 \pm 264$ & 11.20 \\
\hline Coelotrachelus venustus & 2323 & 16.0 & 679 & 30.49 \\
\hline Crypstoscatomaseter durangoi & $2573 \pm 334$ & $12.9 \pm 3.3$ & $992 \pm 429$ & 53.36 \\
\hline Crypstoscatomaseter epulus & $2763 \pm 93$ & $11.0 \pm 0.2$ & $1237 \pm 83$ & 0.16 \\
\hline Dellacasiellus concavus & $1820 \pm 530$ & $18.3 \pm 2.3$ & $752 \pm 355$ & 11.57 \\
\hline Diapterna dugesi & $1673 \pm 332$ & $18.8 \pm 1.4$ & $832 \pm 309$ & 7.65 \\
\hline Drepanocanthoides (s.l.) larreae & $1049 \pm 224$ & $20.4 \pm 1.5$ & $236 \pm 32$ & 9.21 \\
\hline Flaviellus perfimbriatus & 2354 & 12.9 & 622 & 12.35 \\
\hline Geomyphilus (s.l.) barrerai & $2336 \pm 451$ & $13.9 \pm 4.2$ & $1172 \pm 259$ & 57.18 \\
\hline Geomyphilus (s.l.) coronadoi & $2365 \pm 252$ & $13.6 \pm 0.9$ & $1141 \pm 318$ & 1.46 \\
\hline Geomyphilus (s.l.) macgregori & 2186 & 12.9 & 1366 & 4.29 \\
\hline Geomyphilus (s.l.) pierai & $1973 \pm 854$ & $13.4 \pm 5.0$ & $1402 \pm 369$ & 13.02 \\
\hline Gonaphodiellus bimaculosus & $2032 \pm 938$ & $16.1 \pm 5.4$ & $1711 \pm 1066$ & 1.30 \\
\hline Gonaphodiellus hoffmanni & $1620 \pm 1024$ & $17.6 \pm 4.6$ & $2060 \pm 1042$ & 37.77 \\
\hline Gonaphodiellus opisthius & $2025 \pm 531$ & $16.2 \pm 3.0$ & $1184 \pm 364$ & 14.91 \\
\hline Haroldiellus lansbergei & $1268 \pm 723$ & $19.4 \pm 3.1$ & $1483 \pm 482$ & 4.84 \\
\hline Haroldiellus sallei & $1019 \pm 779$ & $21.3 \pm 3.7$ & $1280 \pm 646$ & 21.04 \\
\hline Jalisco plumipes & 2411 & 19.1 & 1195 & 58.05 \\
\hline Labarrus pseudolividus & $1428 \pm 792$ & $19.2 \pm 4.0$ & $1071 \pm 553$ & 43.79 \\
\hline Liothorax innexus & $2106 \pm 446$ & $15.7 \pm 3.0$ & $911 \pm 353$ & 13.26 \\
\hline Liothorax levatus & $2215 \pm 516$ & $15.4 \pm 3.9$ & $1255 \pm 146$ & 1.30 \\
\hline Melinopterus (s.l.) consentaneus & 2195 & 16.7 & 501 & 16.77 \\
\hline Neotrichonotulus inurbanus & 2828 & 10.8 & 1296 & 0.54 \\
\hline Neotrichonotulus perotensis & $2453 \pm 275$ & $10.6 \pm 1.5$ & $1227 \pm 293$ & 0.57 \\
\hline Neotrichonotulus urangai & 2543 & 14.2 & 916 & 8.87 \\
\hline Nialaphodius nigrita & $710 \pm 707$ & $22.4 \pm 4.3$ & $1497 \pm 766$ & 9.23 \\
\hline Oscarinus crassuloides & $2272 \pm 344$ & $14.4 \pm 2.9$ & $824 \pm 109$ & 24.34 \\
\hline Oscarinus indutilis & $1986 \pm 484$ & $16.3 \pm 2.8$ & $1017 \pm 376$ & 12.98 \\
\hline Oscarinus spiniclypeus & $2485 \pm 538$ & $15.1 \pm 3.6$ & $1132 \pm 294$ & 42.05 \\
\hline Otophorus haemorrhoidalis & $2114 \pm 326$ & $14.4 \pm 2.9$ & $650 \pm 191$ & 16.86 \\
\hline Oxyomus setosopunctatus & $2662 \pm 820$ & $11.8 \pm 4.2$ & $1305 \pm 553$ & 1.78 \\
\hline Pardalosus (s.l.) pumilio & $2201 \pm 354$ & $15.5 \pm 2.2$ & $598 \pm 346$ & 6.92 \\
\hline Pardalosus (s.l.) serval & 1927 & 12.8 & 625 & 1.48 \\
\hline Pharaphodius (s.l.) oleosus & $2078 \pm 409$ & $16.1 \pm 2.8$ & $992 \pm 237$ & 6.16 \\
\hline Planolinellus vittatus & $2027 \pm 617$ & $15.6 \pm 3.4$ & $1033 \pm 420$ & 14.15 \\
\hline Planolinus tenellus & $2161 \pm 1076$ & $15.7 \pm 7.4$ & $1119 \pm 37$ & 15.79 \\
\hline Pseudagolius caballeroi & 724 & 25.3 & 922 & 61.33 \\
\hline Pseudagolius coloradensis & $2090 \pm 356$ & $16.4 \pm 2.1$ & $661 \pm 230$ & 23.27 \\
\hline Pseudagolius warneri & $283 \pm 287$ & $23.8 \pm 2.3$ & $558 \pm 98$ & 15.67 \\
\hline Pseudogonaphodiellus zdzislawae & $2347 \pm 307$ & $17.1 \pm 2.3$ & $1353 \pm 147$ & 2.13 \\
\hline Tetraclipeoides (s.l.) giulianii & 1331 & 17.2 & 228 & 18.35 \\
\hline Trichonotuloides glyptus & $2599 \pm 706$ & $13.0 \pm 4.2$ & $1167 \pm 498$ & 2.82 \\
\hline Xeropsamobeus (s.l.) asellus & 2195 & 16.7 & 501 & 16.77 \\
\hline Aidophus notatus & $249 \pm 766$ & $24.4 \pm 4.0$ & $1433 \pm 293$ & 11.98 \\
\hline
\end{tabular}


Autoecologia y biogeografía de los Aphodiinae mexicanos. En los siguientes apartados se muestran los valores ambientales de las localidades de presencia conocidas para cada una de las especies de Aphodiinae mexicanas, así como las representaciones cartográficas obtenidas mediante los modelos predictivos de distribución realizados. La información relativa a la distribución de los géneros, el número de especies descritas o los detalles sobre la ecología de las especies han sido tomados, principalmente, de las siguientes referencias bibliográficas: Dellacasa 1987a, b, 1988a, b, 1991, 1995, Dellacasa et al. 2001 a, 2002b, 2003, 2007c, d, 2009, Dellacasa \& Dellacasa 2003, 2005, Cabrero-Sañudo et al. 2007b, Gordon \& Skelley 2007, Skelley et al. 2007. Las regiones biogeográficas se basan en las definidas por Cox \& Moore (1993).

Distribución de las especies de Aphodiinae en México. De las 111 especies observadas de Aphodiinae presentes en México, el grupo más numeroso es el de la tribu Aphodiini, con 108 especies. De la tribu Didactyliini se encuentran dos especies de un mismo género y de Proctophanini sólo hay una especie.

Aphodiini. Las 108 especies de esta tribu están comprendidas en 41 géneros diferentes.

Género Agoliinus Schmidt, 1913

El género Agoliinus se encuentra distribuido en la región Holártica y está representado por alrededor de 40 especies, de las cuales sólo dos han sido citadas en México: A. cruentatus y A. plutonicus (Figs. 3a-b). Ambas especies extienden su área por el noroeste de México y sur/suroeste de Estados Unidos.

En general, las especies de Agoliinus suelen habitar localidades de altitudes elevadas. Así, Agoliinus cruentatus se ha observado en México a una altitud media (Am) de 2195 metros, en una zona relativamente cálida (temperatura anual media; $\mathrm{Tm} 16.1^{\circ} \mathrm{C}$ ) y seca (precipitación anual media; Pm $527 \mathrm{~mm}$ ) (Cuadro 4). En cuanto a A. plutonicus, se desconocen sus afinidades topográficas y ambientales en México. Ambas especies han sido observadas en excrementos de caballo y humanos, entre los meses de junio y agosto; $A$. cruentatus también ha sido capturada a la luz (Morón \& Deloya 1991, Gordon \& Skelley 2007).

Sólo se ha podido realizar un modelo de distribución en el caso de $A$. cruentatus, puesto que se carecía de datos georreferenciados en México para $A$. plutonicus. El mapa de distribución predicho para A. cruentatus muestra que su área de distribución podría incluir algunas localizaciones de la Sierra Madre Occidental, especialmente de Durango y Zacatecas, así como algunos puntos en el estado de Sonora (Fig. 3a). 
Género Agrilinellus M. Dellacasa,

G. Dellacasa \& Gordon, 2008

Se trata de un género endémico casi exclusivo de México, para el que se han descrito un total de siete especies (Figs. 3c-h, 4a); sólo una de ellas (A. chiapasensis) se extiende hasta El Salvador. Las especies de Agrilinellus se encuentran distribuidas por las sierras mexicanas. Así, A. abbonai y A. antonioreyi han sido observadas en el Sistema Volcánico Transversal (Figs. 3c, 3d); A. azteca, en el Sistema Volcánico Transversal, la región meridional de la Sierra Madre Oriental y en la Sierra Madre del Sur (Fig. 3e); A. chiapasensis, en la Sierra de Chiapas (Fig. 3f); A. nuriae, en las estribaciones septentrionales de la Sierra Madre Oriental (Fig. 3g); A. oaxacaensis, en la Sierra Madre del Sur y la zona meridional de la Sierra Madre Oriental (Fig. 3h); y, A. ornatus, en el Sistema Volcánico Transversal, el sur de la Sierra Madre Oriental y la Sierra Madre Occidental (Fig. 4a).

Agrilinellus es un género con preferencia por altitudes medias hasta muy altas, cuyas especies están presentes habitualmente desde los 1000 hasta los 2800 metros (Cuadro 4). Suelen preferir desde temperaturas frescas a moderadas que oscilan entre $11.6^{\circ} \mathrm{C}$ y $15.9^{\circ} \mathrm{C}$ (exceptuando A. oaxacaensis, con una Tm observada más alta de $22.5^{\circ} \mathrm{C}$, a consecuencia, probablemente, de las localizaciones colindantes) y lluvias moderadas de entre 625 a $1486 \mathrm{~mm}$ de precipitación anual (Cuadro 4). La mayoría de las especies de Agrilinellus han sido observadas durante los meses de julio a agosto, aunque $A$. chiapasensis ha sido capturada en mayo y A. azteca y A. ornatus pueden colectarse durante todo el año. Son especies coprófagas de amplio espectro, puesto que se han observado en estiércol vacuno, equino y ovino; únicamente, $A$. nuriae y $A$. oaxacaensis han sido citadas de vacuno y equino, respectivamente, lo que, no obstante, puede deberse a la ausencia de otro tipo de excremento (observaciones personales y Martín-Piera \& Lobo 1993, Martínez 2005, Gordon \& Skelley 2007, Dellacasa et al. 2008).

Las distribuciones predichas para estas especies amplían su actual rango a lo largo de las sierras mexicanas; así, se aumenta la distribución de A. abbonai hacia la Sierra Madre del Sur (Fig. 3c); la de A. antonioreyi hacia algunos puntos adicionales del Sistema Volcánico Transversal y de la Sierra Madre del Sur (Fig. 3d); la de A. azteca hacia algunas localizaciones adicionales del Sistema Volcánico Transversal y de la Sierra Madre del Sur (Fig. 3e); la de A. chiapasensis hacia la Sierra Madre del Sur, el Sistema Volcánico Transversal, la Sierra Madre Occidental y otras localidades de la Sierra de Chiapas (Fig. 3f); la de A. nuriae a otras localidades del norte de la Sierra Madre Occidental (Fig. 3g); la de A. oaxacaensis en la Sierra de Chiapas, la Sierra Madre del Sur, la Sierra Madre Occidental, la Sierra Madre Oriental, el Sistema Volcánico Transversal y algunas localizaciones presentes en el Golfo de México y la Península de Yucatán (Fig. 3h); y la de A. ornatus hasta algún punto más de la Sierra Madre Occidental y del Sistema Volcánico Transversal (Fig. 4a). 
Género Aphodius Illiger, 1798

El género Aphodius presenta una distribución Holártica, así como Oriental y Australiana. Se encuentra representado por 13 especies, de las cuales una, A. fimetarius, ha sido introducida en México (Horn 1887). La especie ha sido citada en el estado de Puebla, al sur del Sistema Volcánico Transversal (Fig. 4b).

En México, A. fimetarius se encuentra a una Am de 1382 metros, con una Tm de $18.9^{\circ} \mathrm{C}$ y una precipitación de $499 \mathrm{~mm}$ (Cuadro 4). Ha sido citada del mes de agosto en México, pero en otras regiones se encuentra presente durante todo el año. Se trata de una especie eurífaga, que no es estrictamente coprófaga, sino que también se alimenta de material orgánico en descomposición, materia vegetal y micelios de hongos (Dellacasa \& Dellacasa 2006).

Según el mapa de distribución predicho para esta especie, su actual rango de distribución podría ampliarse hasta la Sierra Madre del Sur, la Sierra Madre Occidental y algunas localizaciones del Altiplano (Fig. 4b).

Género Blackburneus (sensu lato) Schmidt, 1913

El género Blackburneus (s.l.) muestra una distribución Neártica, Neotropical, Oriental y Afrotropical. Se han descrito alrededor de 71 especies, de las cuales cinco se encuentran distribuidas en México (Figs. 4c-g). Blackburneus charmionus ha sido citada de Costa Rica, El Salvador y México; B. guatemalensis de Guatemala, Costa Rica, El Salvador, México y Panamá; B. (s.l.) rubeolus del sudeste de Canadá, México y este de Estados Unidos; $B$. saylorea del suroeste de Estados Unidos; y, $B$. (s.l.) saylori es la única especie aparentemente endémica de México. En México, las especies de Blackburneus (s.l.) suelen habitar zonas de montaña. Así, B. charmionus se ha capturado en el Sistema Volcánico Transversal, la Sierra Madre del Sur, la Sierra Madre Occidental y el sur de la Sierra Madre Oriental (Fig. 4c); $B$. guatemalensis, aparte de en las anteriores sierras, se extiende también por la Sierra de Chiapas (Fig. 4d); B. saylorea habita el Sistema Volcánico Transversal, el sur de la Sierra Madre Oriental y la Sierra Madre del Sur (Fig. 4f); y, B. (s.l.) saylori, el Sistema Volcánico Transversal y la Sierra Madre Occidental (Fig. 4g). Blackburneus (s.l.) rubeolus ha sido citada de Oaxaca y Tamaulipas, pero no se tienen referencias precisas de su localización (Fig. 4e).

Las especies de Blackburneus (s.l.) suelen encontrarse en México en altas elevaciones, de modo que han sido citadas de alturas entre los 1730 y los 2090 metros (Cuadro 4). Parecen preferir localidades con temperaturas medias relativamente elevadas (entre $15.8^{\circ} \mathrm{C} \mathrm{y} 18.4^{\circ} \mathrm{C}$ ) y precipitaciones moderadas que oscilan entre los 732 y los $1410 \mathrm{~mm}$ (Cuadro 4). Blackburneus charmionus, B. guatemalensis y B. saylorea están activas durante todo el año, mientras que $B$. (s.l.) saylori sólo se ha observado durante julio y agosto, y B. (s.l.) rubeolus entre los meses de abril y octubre. Todas muestran hábitos coprófagos y se han encontrado en excrementos de 
caballo, vaca y oveja; $B$. charmionus y B. (s.l.) rubeolus son también atraídas por material orgánico en descomposición y B. guatemalensis y B. (s.l.) rubeolus han sido capturadas a la luz (observaciones personales y Ruiz-Colorado 2001, Galante et al. 2003, Gordon \& Skelley 2007).

Según las distribuciones predichas, B. charmionus extendería su presencia por diversos puntos del este del Sistema Volcánico Transversal y el sur de la Sierra Madre Oriental (Fig. 4c); B. guatemalensis estaría presente en más localidades del Sistema Volcánico Transversal, la Sierra Madre Oriental, la Sierra Madre Occidental y la Sierra Madre del Sur (Fig. 4d); B. saylorea aumentaría su distribución hacia más puntos del Sistema Volcánico Transversal, la Sierra Madre del Sur, la Sierra de Chiapas y sur de la Sierra Madre Oriental (Fig. 4f); y, B. (s.l.) saylori hacia algún punto más de la Sierra Madre Occidental, muchos otros del Sistema Volcánico Transversal y el sur de la Sierra Madre Oriental, la Sierra Madre del Sur y la Sierra de Chiapas (Fig. 4g). No se ha podido estimar la distribución de B. (s.l.) rubeolus puesto que se carecía de información georreferenciada para México (Fig. 4e).

\section{Género Calamosternus Motschulsky, 1859}

Calamosternus es un género de distribución mundial compuesto actualmente por 25 especies, dos de las cuales se encuentran en México (Figs. 4h, 5a). Calamosternus colimaensis es la única especie de este género endémica de Norteamérica, en concreto de México, y se encuentra distribuida a lo largo del Sistema Volcánico Transversal (Fig. 4h); C. granarius es una especie subcosmopolita que ha sido introducida desde Europa y aparece en el noroeste de México, el resto de la región Neártica (Cánada y Estados Unidos) y también en la región Neotropical (Fig. 5a; Dellacasa 1988a, Dellacasa \& Dellacasa 2006, Gordon \& Skelley 2007).

Calamosternus colimaensis suele encontrarse a media altitud, alrededor de los 956 metros, mientras que $C$. granarius se ha observado en México a altitudes inferiores ( $\approx 250$ metros, Cuadro 4). La Tm de los puntos en los que se ha encontrado C. colimaensis es moderada-alta $\left(23.7^{\circ} \mathrm{C}\right)$, y la Pm moderada $(964 \mathrm{~mm})$; para $C$. granarius, la Tm donde se ha observado es menor, de $16.3^{\circ} \mathrm{C}$, y la Pm escasa, de 272 $\mathrm{mm}$ (Cuadro 4). Calamosternus colimaensis ha sido colectada durante el mes de abril, mientras que $C$. granarius ha sido observada durante todo el año. No se tienen referencias sobre los hábitos alimenticios de $C$. colimaensis, pero de $C$. granarius se sabe que se trata de una especie eurífaga, capaz de alimentarse de todo tipo de excrementos, así como de material orgánico en descomposición y materia vegetal (Dellacasa \& Dellacasa 2006).

La distribución predicha para $C$. colimaensis indica que esta especie puede encontrarse también por otros puntos del Sistema Volcánico Transversal, así como en la Sierra Madre del Sur y la Sierra de Chiapas (Fig. 4h). En el caso de C. granarius, 
ésta podría encontrarse también en algunos otros puntos de la Sierra de Baja California y en la provincia biogeográfica Sonorense (Fig. 5a).

Género Cephalocyclus M. Dellacasa, Gordon \& G. Dellacasa, 1998 El género Cephalocyclus es endémico de la zona meridional de la región Neártica y algunas de sus especies se adentran hacia las montañas de la región Neotropical en Centroamérica. Se trata del género con un mayor número de especies en México y con un mayor número de endemismos; así, de las 21 especies descritas en total para este género, 18 han sido citadas de México (Figs. 5b-h, 6a-h, 7a-c), 15 de las cuales presentan una distribución restringida a las sierras de México. En cuanto a las especies mexicanas, Cephalocyclus bordati, C. pullatus y C. rockefelleri han sido observadas en la Sierra Madre Occidental (Fig. 5b, 6g, 7a); C. carmenae, C. howdenorum, C. lagoi y C. potosinus, en la Sierra Madre Oriental (Fig. 5c, 6a-b, f); C. durangoensis, en la Sierra Madre Occidental, la Sierra Madre Oriental, el Sistema Volcánico Transversal y la Sierra Madre del Sur (Fig. 5d); C. fuliginosus, C. hogei y C. mexicanus, en la Sierra Madre Occidental, la Sierra Madre Oriental, el Sistema Volcánico Transversal, la Sierra Madre del Sur y la Sierra de Chiapas hacia Guatemala (Figs. 5e, h, 6d); C. gravidus, en la Sierra Madre Occidental, en el sur de la Sierra Madre Oriental y en el Sistema Volcánico Transversal (Fig. 5f); C. halffteri, C. luridiventris y $C$. puncticeps, en el Sistema Volcánico Transversal y la Sierra Madre del Sur (Figs. 5g, 6c, h); C. ordonezi, en el Sistema Volcánico Transversal (6e); C. stebnickae, en la Sierra de Chiapas (Fig. 7b); y, C. villosipes, en el sur de la Sierra Madre Oriental, el Sistema Volcánico Transversal y la Sierra Madre del Sur (Fig. 7c; existe otra especie similar, algunas de cuyas citas pueden haberse confundido con ésta; a la espera de dicha confirmación, las citas se han asignado a esta especie).

Las especies de Cephalocyclus son moradoras de cotas altas-muy altas, que van de 1826 a los 3205 metros (Cuadro 4). Por ello, suelen preferir unas temperaturas medias que oscilan entre frescas y moderadas (entre $\operatorname{los} 9.3^{\circ} \mathrm{C}$ y $\operatorname{los} 16.8^{\circ} \mathrm{C}$ ) y unas precipitaciones bajas o moderadas que pueden rondar entre los 533 a los $1223 \mathrm{~mm}$ (Cuadro 4). Los imagos muestran una actividad restringida habitualmente a los meses entre mayo y agosto, especialmente en junio y julio, coincidiendo con la aparición de las primeras precipitaciones de la estación de lluvias. Los individuos de estas especies suelen encontrarse en excrementos equinos con una mayor frecuencia, así como en vacunos y ovinos, e incluso atraídos por la luz (observaciones personales y Morón \& Deloya 1991, Galante et al. 2003, Martínez 2005, Dellacasa et al. 2007a).

Los modelos de distribución predichos para estas especies aumentan su distribución, en general, hacia diversos puntos situados en las cadenas montañosas donde éstas se encuentran o hacia otras sierras. De esta manera, C. bordati, $C$. durangoensis y $C$. rockefelleri podrían estar presentes en otros puntos de la Sierra 
Madre Occidental (Figs. 5b, d, 7a); C. carmenae, C. howdenorum y C. potosinus tendrían una distribución un poco más amplia a lo largo de la Sierra Madre Oriental (Figs. 5c, 6a, f); C. fuliginosus podría encontrarse en otras localizaciones de la Sierra Madre Occidental, del Sistema Volcánico Transversal, de la Sierra Madre del Sur e incluso de la Sierra de Chiapas (Fig. 5e); C. gravidus podría extenderse más aún por la Sierra Madre Occidental, por el Sistema Volcánico Transversal y por la Sierra de Chiapas (Fig. 5f); $C$. halffteri se encontraría también en otros puntos de la Sierra Madre del Sur (Fig. 5g); C. hogei muestra otras zonas favorables en el Sistema Volcánico Transversal y en la Sierra de Chiapas, hacia Guatemala (Fig. 5h); C. lagoi muestra puntos adicionales de presencia en la Sierra Madre Oriental, en el Sistema Volcánico Transversal y en la Sierra de Chiapas (Fig. 6b); $C$. luridiventris y $C$. puncticeps podrían extenderse por otros enclaves de la Sierra Madre del Sur, el Sistema Volcánico Transversal, la Sierra Madre Occidental, la Sierra Madre Oriental y la Sierra de Chiapas (Fig. 6c, h); C. mexicanus aumentaría su presencia en diversas localizaciones de la Sierra Madre Oriental, del Sistema Volcánico Transversal y de la Sierra Madre del Sur (Fig. 6d); C. ordonezi y C. stebnickae no modificarían mucho más su distribución, quedando restringidas aparentemente a los puntos en los que han sido observadas (Figs. 6e, 7b); C. pullatus tendría localidades favorables adicionales en la Sierra Madre Occidental, la Sierra de Chiapas e incluso en la Sierra de Baja California (Fig. 6g); y, C. villosipes podría extenderse también por algunos puntos al sur de la Sierra Madre Oriental, del Sistema Volcánico Transversal, de la Sierra Madre del Sur y de la Sierra de Chiapas (Fig. 7c).

\section{Género Cesamexico Koçaz \& Kemal, 2008 \\ (= Imelda Dellacasa, Dellacasa \& Gordon 2002)}

Cesamexico es un género monoespecífico, cuya única especie es endémica de México, en concreto, de la Sierra Madre del Sur, en el estado de Guerrero (Fig. 7d).

Se encuentra a una Am de 2300 metros y muestra preferencia por precipitaciones moderadas (Pm de $1456 \mathrm{~mm}$ ) y localidades con una $\mathrm{Tm}$ moderada-alta de $18.5^{\circ} \mathrm{C}$ (Cuadro 4). Aunque se ha capturado diversas veces durante el mes de julio, no han sido registrados sus hábitos alimentarios.

El mapa de distribución predicho muestra que C. constricticollis podría encontrarse presente en otros puntos de la Sierra Madre del Sur, el Sistema Volcánico Transversal, la vertiente occidental de la Sierra Madre Occidental y la Sierra de Chiapas (Fig. 7d).

\section{Género Cinacanthus Schmidt, 1913}

El género Cinacanthus es endémico de la región Neártica. Hasta el momento, se han asignado seis especies a este género, de las cuales sólo dos, $C$. crenicollis y $C$. militaris, han sido citadas para México, en el estado de Baja California (Figs. 7e-f). 
Se distribuyen a lo largo de las sierras norteamericanas occidentales, ligadas a zonas desérticas y asociadas a las madrigueras de roedores.

Se desconocen las condiciones ambientales y la topografía de las localizaciones donde se han observado estas especies en México. En Estados Unidos, C. crenicollis y $C$. militaris han sido capturadas en zonas áridas de alta montaña, entre los 1500 y los 2750 metros de altitud; $C$. crenicollis se ha observado activa desde abril a junio, mientras que $C$. militaris ha sido colectada desde marzo a septiembre. Ambas especies muestran actividad nocturna y se alimentan del estiércol de diversos roedores, como tuzas (Thomomys Wied-Neuwied, 1839), ardillas de tierra (Spermophilus Cuvier, 1825) y perros de las praderas (Cynomys Rafinesque, 1817; Gordon \& Skelley 2007).

No se obtuvieron mapas de distribución predicha para estas especies, puesto que se carecía de información georreferenciada para México.

Género Coelotrachelus Schmidt, 1913

Se trata de un género endémico de la región Neártica, para el que se han descrito un total de seis especies, presentes todas en México y cinco de ellas endémicas para el país (Figs. 7g-h, 8a-d). Son especies asociadas a madrigueras de roedores, que se localizan a lo largo de las cadenas montañosas, poseyendo su límite meridional de distribución en el Sistema Volcánico Transversal. Así, C. burgosi y $C$. ixtapalapaensis han sido colectadas en el Sistema Volcánico Transversal (Figs. 7gh); C. kuntzeni, C. symbius y C. venustus, en la Sierra Madre Occidental y en el Sistema Volcánico Transversal (Figs. 8a, c-d); y, C. rudis en la Sierra Madre Occidental (Fig. 8b).

Sus localidades de presencia poseen altitudes medio-altas (entre los 1045 y los 2362 metros), con temperaturas moderadas-cálidas (entre $14.8^{\circ} \mathrm{C}$ y $23.7^{\circ} \mathrm{C}$ ) y lluvias escasas o moderadas (entre los 679 y los $987 \mathrm{~mm}$ ) (Cuadro 4). La actividad más destacada de estas especies ocurre durante los meses de junio y julio, coincidiendo con el comienzo de la época de lluvias, aunque también se ha citado $C$. kuntzeni durante los meses de febrero y abril, y $C$. ixtapalapaensis y $C$. venustus durante noviembre. Se alimentan de los excrementos de tuzas (por ejemplo, Thomomys sp. o Cratogeomys Merriam, 1895) con las que están asociadas, siendo comunes en los bosques de pinos y encinos. Son capturadas también a la luz (C. burgosi y C. rudis), probablemente debido a sus hábitos nocturnos (observaciones personales y Gordon \& Skelley 2007, Dellacasa et al. 2009).

Según los mapas de distribución predicha, C. burgosi podría ampliar su distribución hacia otros puntos del Sistema Volcánico Transversal y estar presente también en la vertiente occidental de la Sierra Madre Occidental, en la Sierra Madre del Sur y en la Sierra de Chiapas (Fig. 7g); C. ixtapalapaensis y C. venustus podrían encontrarse en otros puntos del Sistema Volcánico Transversal, el sur de la Sierra 
Madre Oriental, la Sierra Madre Occidental y la Sierra Madre del Sur (Fig. 7h, 8d); C. kuntzeni y $C$. symbius estarían presentes en un número mayor de localidades de la Sierra Madre Occidental y el Sistema Volcánico Transversal, así como en la Sierra de Chiapas y la Sierra de Baja California (Figs. 8a, c); y, C. rudis podría estar también presente en otros puntos de la Sierra Madre Occidental y del noroeste del Sistema Volcánico Transversal (Fig. 8b).

\section{Género Cryptoscatomaseter (sensu lato) Gordon \& Skelley, 2007}

El género Cryptoscatomaseter (s.l.) reúne un total de 29 especies distribuidas por la región Neártica, de las cuales dos $(C$. durangoi y $C$. epulus) se encuentran en México y son endémicas (Figs. 8e-f). Son especies de alta montaña, que se encuentran asociadas a nidos de roedores; ambas especies han sido colectadas en la Sierra Madre Occidental, no más al sur del estado de Durango (Figs. 8e-f).

Las altitudes medias en las que están presentes oscilan entre los 2573 y los 2763 metros (Cuadro 4). Las temperaturas medias anuales de estas localidades son frescas (entre $\operatorname{los} 11.0^{\circ} \mathrm{C}$ y $\operatorname{los} 12.9^{\circ} \mathrm{C}$ ), mientras que las precipitaciones son moderadas (entre los 992 y los $1237 \mathrm{~mm}$; Cuadro 4). Los adultos han sido colectados durante los meses de junio y julio, en madrigueras de tuzas (Thomomys sp.) y muestran una actividad diurna (Gordon \& Howden 1973, Gordon \& Skelley 2007).

La distribución predicha para $C$. durangoi muestra que la especie podría estar presente en otros puntos de la Sierra Madre Occidental, así como en el Sistema Volcánico Transversal y en algunos puntos al sur de la Sierra Madre Oriental y el noreste de la Sierra Madre del Sur (Fig. 8e). En cuanto a C. epulus, su distribución predicha parece bastante restringida a las localidades donde ha sido capturada en la Sierra Madre Occidental (Fig. 8f).

\section{Género Dellacasiellus Gordon \& Skelley, 2007}

Dellacasiellus es un género endémico de la región Neártica, en el que se han incluido doce especies, seis de ellas distribuidas en México (Figs. 8g-h, 9a-d). Son especies de montaña, ligadas a nidos de roedores. En México, D. claudus y D. concavus han sido citadas de la Sierra Madre Occidental y del Sistema Volcánico Transversal (Figs. 8g-h); D. fucosus se ha observado en el Sistema Volcánico Transversal y en la Sierra de Baja California (Fig. 9a); D. kirni, en la Sierra Madre Occidental (Fig. 9b); D. pseudofucosus, en la Sierra de Baja California (Fig. 9c); y, D. ruficlarus, en la Sierra Madre Occidental y en la Sierra de Baja California (Fig. 9d).

Para México, no se tienen otros datos georreferenciados más que los de $D$. concavus. Según estos datos, la Am para esta especie es de alrededor de 1820 metros prefiriendo zonas cálidas $\left(\mathrm{Tm}\right.$ de $18.3^{\circ} \mathrm{C}$ ) y con precipitaciones escasas o moderadas (Pm de $752 \mathrm{~mm}$ ) (Cuadro 4). Las especies del género Dellacasiellus se alimentan de estiércol de tuzas (Thomomys sp.), ardillas de tierra (Spermophilus sp.) y perros de 
las praderas (Cynomys sp.; Gordon \& Skelley 2007). Presentan actividad nocturna y pueden ser atraídas por las trampas de luz (Morón \& Deloya 1991, Deloya et al. 1993). Se han observado activas durante los meses de junio a agosto, coincidiendo con el comienzo de la época de lluvias.

El mapa de distribución predicho para $D$. concavus muestra que la especie podría estar presente en otros muchos puntos de la Sierra Madre Occidental y del Sistema Volcánico Transversal, así como en la Sierra Madre del Sur (Fig. 8h).

\section{Género Diapterna Horn, 1887}

Se trata de un género de distribución Neártica, en el que se incluyen seis especies conocidas, una de las cuales, D. dugesi, se encuentra exclusivamente en México, distribuida por el Sistema Volcánico Transversal y por la Sierra Madre del Sur (Fig. 9e).

Diapterna dugesi se distribuye a una Am de 1673 metros, en enclaves cálidos (Tm de $18.8^{\circ} \mathrm{C}$ ) con lluvia moderada (Pm de $832 \mathrm{~mm}$ ) (Cuadro 4). Ha sido capturada entre los meses de junio y septiembre, al inicio y durante la época de lluvias. Las especies del género Diapterna son detritívoras; en concreto, D. dugesi ha sido observada en acumulaciones de desechos procedentes de nidos de hormigas cortadoras de hojas (Atta Fabricius, 1805; Galante et al. 2003, Gordon \& Skelley 2007).

La distribución estimada para esta especie aumenta su rango hacia diversos puntos del Sistema Volcánico Transversal y de la Sierra Madre del Sur (Fig. 9e).

Género Drepanocanthoides (sensu lato) Schmidt, 1913

El género Drepanocanthoides (s.l.) posee una distribución Neártica y dos especies descritas, de las cuales una, D. (s.l.) larreae, extiende su distribución hacia México desde latitudes más septentrionales, apareciendo en el Altiplano del Norte (Fig. 9f).

Las citas para esta especie muestran que tiene afinidad por localidades de altitud moderada (Am de 1049 metros), temperatura elevada $\left(\mathrm{Tm}\right.$ de $\left.20.4^{\circ} \mathrm{C}\right)$ y escasas precipitaciones (Pm de $236 \mathrm{~mm}$ ) (Cuadro 4). En México se han realizado capturas de $D$. (s.l.) larreae durante los meses de mayo y junio, coincidiendo con el comienzo de la época de lluvias. Se ha capturado en trampas de luz y se cree que es una especie detritívora, de carácter psammófilo (observaciones personales y Gordon \& Skelley 2007).

El mapa de distribución predicho para esta especie, obtenido a partir de los datos georreferenciados mexicanos, indica que $D$. (s.l.) larreae estaría presente en otros puntos del Altiplano del Norte, así como al norte del Golfo de California, en zonas áridas de la provincia biogeográfica Sonorense (Fig. 9f).

Género Flaviellus (sensu lato) Gordon \& Skelley, 2007

Seis especies Neárticas han sido incluidas dentro del género Flaviellus (s.l.), dos de las cuales han sido citadas para México, F. perfimbriatus y $F$. (s.l.) subtruncatus, aunque se desconoce si ésta última se encuentra realmente distribuida por el país 
(Figs. 9g-h). Flaviellus perfimbriatus ha sido colectada en algún punto sin precisar de la Sierra Madre Occidental (Fig. 9g).

Las especies de Flaviellus suelen distribuirse en cotas altas; así, F. perfimbriatus se encuentra en México a una Am de 2354 metros (Cuadro 4). Presenta afinidad por temperaturas frescas $\left(\mathrm{Tm}\right.$ de $\left.12.9^{\circ} \mathrm{C}\right)$ y precipitaciones escasas $(\mathrm{Pm}$ de $622 \mathrm{~mm}$ ) (Cuadro 4). Esta especie se ha capturado durante el mes de junio, al inicio de la temporada de lluvias. Se desconocen cuáles pueden ser los hábitos alimenticios de estas especies, aunque se ha especulado que podrían ser detritívoras, de carácter psammófilo (Gordon \& Skelley 2007).

La distribución predicha para $F$. perfimbriatus amplia su rango hacia otras localidades de la Sierra Madre Occidental (Fig. 9g). No se estimó ningún mapa de distribución predicho para $F$. (s.l.) subtruncatus, puesto que se carecía de datos confirmados para México.

Género Geomyphilus (sensu lato) Gordon \& Skelley, 2007

El género Geomyphilus (s.l.) es endémico de la región Neártica. Se han asignado 16 especies a este género, cuatro de las cuales están presentes en México y son endémicas de las cadenas montañosas, como el Sistema Volcánico Transversal o la Sierra Madre Oriental, asociándose a nidos de roedores (Figs. 10a-d). De esta manera, G. (s.l.) barrerai ha sido colectada en el Sistema Volcánico Transversal y al sur de la Sierra Madre Oriental (Fig. 10a); G. (s.l.) coronadoi y G. (s.l.) macgregori, en el Sistema Volcánico Transversal (Figs. 10b-c); y, G. (s.l.) pierai, al sur de la Sierra Madre Oriental (Fig. 10d).

En México, las especies de Geomyphilus (s.l.) parecen seleccionar enclaves situados en elevaciones altas, con una Am que oscila entre los 1973 y los 2365 metros (Cuadro 4). Así mismo, tienen afinidad por temperaturas y precipitaciones moderadas, con $\mathrm{Tm}$ que oscilan entre $\operatorname{los} 12.9^{\circ} \mathrm{C}$ y $13.9^{\circ} \mathrm{C}$, y Pm que varían entre los 1141 y los $1402 \mathrm{~mm}$ (Cuadro 4). Se han colectado ejemplares de estas especies desde agosto hasta febrero, especialmente durante octubre y diciembre. Este género se alimenta de excrementos presentes en madrigueras de geomíidos, esencialmente tuzas (como Cratogeomys o Pappogeomys Merriam, 1895; Gordon \& Skelley 2007).

Los mapas de distribución predichos muestran que G. (s.l.) barrerai y G. (s.l.) pierai se podrían encontrar también en puntos adicionales del Sistema Volcánico Transversal, así como en la Sierra Madre Occidental, en la Sierra Madre Oriental, en la Sierra Madre del Sur y en la Sierra de Chiapas (Figs. 10a, d); G. (s.l.) coronadoi ampliaría sólo ligeramente su distribución conocida hacia algunos puntos del Sistema Volcánico Transversal (Fig. 10b); y, G. (s.l.) macgregori podría estar también presente en algunos puntos del Sistema Volcánico Transversal, de la Sierra Madre Occidental y de la Sierra de Chiapas (Fig. 10c). 
Género Gonaphodiellus (sensu lato) Schmidt, 1913

Gonaphodiellus (s.l.) es un género cuyas especies se distribuyen por la región Neotropical, incluyendose en él un total de 17 especies, de las cuales tres se distribuyen en México, penetrando a través de las cadenas montañosas (Figs. 10e-g). Así, G. bimaculosus ha sido observada exclusivamente en la zona meridional de la Sierra Madre Oriental, en la zona oriental del Sistema Volcánico Transversal, en la Sierra Madre del Sur y en la Sierra de Chiapas (Fig. 10e); G. hoffmanni, otra especie autóctona de México, se distribuye por la Sierra Madre del Sur y la Sierra de Chiapas (Fig. 10f); y, G. opisthius, la de distribución más amplia, se localizaría en la Sierra Madre Occidental, la Sierra Madre Oriental, el Sistema Volcánico Transversal, la Sierra Madre del Sur y la Sierra de Chiapas (Fig. 10g).

Estas especies suelen encontrarse en cotas altas, presentando una Am que oscila entre los 1620 y los 2032 metros (Cuadro 4). Parecen preferir localidades con temperaturas y precipitaciones moderado-altas $\left(\mathrm{Tm}\right.$ entre $16.1^{\circ} \mathrm{C}$ y $17.6^{\circ} \mathrm{C}$ y Pm entre los $1184 \mathrm{~mm}$ y los $2060 \mathrm{~mm}$ ) (Cuadro 4). Los adultos presentan una fenología que oscila entre los meses de abril a noviembre en el caso de G. bimaculosus, de junio a agosto en $G$. hoffmanni, o todo el año, especialmente en junio y julio, para $G$. opisthius. Gonaphodiellus bimaculosus se ha capturado en excrementos de vacuno y a la luz, mientras que, aparte de éstos, G. opisthius ha sido también capturado en restos orgánicos en descomposición y excrementos equinos y ovinos; para $G$. hoffmanni no se tienen referencias sobre sus hábitos de alimentación (observaciones personales y Deloya et al. 1993, Morón 1994, Alvarado 2001, Ruiz-Colorado 2001, Cruz et al. 2002, Allende \& Ramírez 2005, Delgado \& Márquez 2006, CabreroSañudo et al. 2007).

Según los modelos de distribución, G. bimaculosus se extendería por diversas localizaciones adicionales situadas en el sur de la Sierra Madre Oriental, en el Sistema Volcánico Transversal, en la Sierra Madre del Sur y en la Sierra de Chiapas en Guatemala (Fig. 10e); G. hoffmanni podría encontrarse presente en más puntos de la Sierra Madre del Sur y de la Sierra de Chiapas, así como en el Sistema Volcánico Transversal, la Sierra Madre Occidental y la Sierra Madre Oriental (Fig. 10f); G. opisthius ampliaría su distribución hacia algunas localidades del sur de la Sierra Madre Oriental, del Sistema Volcánico Transversal y de la Sierra Madre del Sur (Fig. 10g).

\section{Género Haroldiellus Gordon \& Skelley, 2007}

El género Haroldiellus se encuentra integrado por dos especies, $H$. lansbergei y $H$. sallei, las cuales se encuentran distribuidas en México (Figs. 10h, 11a). La primera especie es endémica de México y se extiende a media altura por diversas localizaciones de la Sierra Madre Oriental, del Sistema Volcánico Transversal y de la Sierra Madre del Sur (Fig. 10h); H. sallei, por el contrario, es una especie euritópica que se distribuye 
desde Centroamérica hasta Texas, ocupando en México enclaves montañosos de la Sierra Madre Oriental, de la Sierra Madre Occidental, del Altiplano, del Sistema Volcánico Transversal, de la Sierra Madre del Sur y de la Sierra de Chiapas, pero que también se encuentra en enclaves de menor altitud de las provincia Sonorense, la Depresión del Balsas, el Golfo de México, Yucatán y Petén (Fig. 11a).

La altitud media para ambas especies oscila entre los 1019 y los 1268 metros (Cuadro 4). Son especies que parecen requerir temperaturas moderado-altas (Tm de entre $\operatorname{los} 19.94^{\circ} \mathrm{C}$ y $\operatorname{los} 21.3^{\circ} \mathrm{C}$ ) y precipitaciones moderadas (Pm entre los $1280 \mathrm{~mm}$ y los $1483 \mathrm{~mm}$ ) (Cuadro 4). Tanto la distribución de estas especies como sus preferencias climáticas sugieren un origen Neotropical para este género. Los adultos de $H$. lansbergei han sido observados activos durante los meses de febrero a agosto, especialmente en julio, mientras que los adultos de $H$. sallei se encontrarían activos durante todo el año, especialmente en junio y julio. Haroldiellus lansbergei se ha capturado en excrementos de vaca y a la luz; $H$. sallei también ha sido colectada en otros excrementos (de caballo y de oveja) y en material orgánico en descomposición (observaciones personales y Delgado 1989, Lobo \& Deloya 1993, Percino-Figueroa 2002, Galante et al. 2003).

El mapa de distribución predicho para $H$. lansbergei indica que esta especie podría ampliar su distribución hacia el sur de la Sierra Madre Oriental y el este del Sistema Volcánico Transversal (Fig. 10h); H. sallei tendría una mayor presencia en las zonas occidentales y orientales del Sistema Volcánico Transversal, el sur de la Sierra Madre Oriental, la Sierra Madre del Sur y la Sierra de Chiapas, así como en algunas localidades del sur del Golfo de México (Fig. 11a).

\section{Género Jalisco M. Dellacasa, Gordon \& G. Dellacasa, 2004}

Se trata de un género monoespecífico, endémico de México, presente en el estado de Jalisco, en las estribaciones occidentales del Sistema Volcánico Transversal (Fig. 11b).

Jalisco plumipes es una especie de altura (Am de 2411 metros), que tiene afinidad por temperaturas medias-altas $\left(\mathrm{Tm}\right.$ de $19.1^{\circ} \mathrm{C}$ ) y precipitaciones moderadas (Pm de $1195 \mathrm{~mm}$ ) (Cuadro 4). La única captura de adultos de la que se dispone se realizó durante el mes de julio. Fue realizada en bosque mesófilo y los individuos fueron colectados mediante una coprotrampa, por lo que posiblemente tiene hábitos coprófagos (Dellacasa et al. 2003).

Según su mapa de distribución predicho, J. plumipes podría extenderse hacia otros puntos del Sistema Volcánico Transversal, de la Sierra Madre Occidental, de la Sierra Madre del Sur y de la Sierra de Chiapas (Fig. 11b).

\section{Género Labarrus Mulsant \& Rey, 1870}

Labarrus es un género de amplia distribución mundial, presente en todas las regiones biogeográficas. Consta de alrededor de 20 especies actualmente aceptadas como 
válidas, aunque según algunos autores el género se puede tratar en realidad de un complejo de especies con un patrón polimórfico (Petrovitz 1961, Stebnicka \& Howden 1995). En cualquier caso, Angus et al. (2004) confirmó que al menos $L$. lividus y L. pseudolividus serían especies diferenciadas, basándose en sus respectivos cariotipos y en la morfología de la genitalia masculina. En Norteamérica conviven ambas especies e, incluso, se pueden reconocer sin lugar a dudas, puesto que las diferencias observadas en las respectivas genitalias masculinas se correlacionan con la apariencia morfológica externa de las especies (Gordon \& Skelley 2007). En México, se han citado estas dos especies, aunque es probable que sólo una de ellas se encuentre realmente distribuida por el país (Figs. 11c-d). Así, L. pseudolividus, que se extiende ampliamente por México por todas las regiones, podría ser propia de la región Neotropical (Fig. 11d); sin embargo, L. lividus, una especie originalmente Paleártica pero introducida en numerosas partes del mundo, tiene su presencia confirmada en otras localidades de Norteamérica y de Centroamérica, como Panamá, pero, por el momento, como se ha demostrado, todos los ejemplares mexicanos observados parecen pertenecer realmente a L. pseudolividus (Fig. 11c; Dellacasa et al. 2002b).

Como las demás especies del género Labarrus, L. pseudolividus es una especie euritópica que se puede encontrar en ambientes muy diversos, habitualmente de carácter Neotropical. Según los registros observados para esta especie, su altitud media se sitúa alrededor de los 1428 metros (Cuadro 4). Selecciona localidades con temperaturas moderado-cálidas $\left(19.2^{\circ} \mathrm{C}\right)$ y precipitaciones moderadas $(1071 \mathrm{~mm})$ (Cuadro 4). Ha sido observada durante todo el año. Es una especie polífaga que se alimenta de diversos tipos de excrementos, preferentemente bovino, aunque también se ha colectado a la luz y en material orgánico en descomposición (observaciones personales y Kohlmann 1991, Deloya et al. 1995, Ruiz-Colorado 2001, Arellano \& Halffter 2003, Galante et al. 2003, Peraza 2004, Allende \& Ramírez 2005, Delgado \& Márquez 2006, Gordon \& Skelley 2007, Muñoz et al. 2008).

Según el mapa de distribución predicho, el rango de L. pseudolividus podría ser todavía mayor, entendiéndose por localidades elevadas del Sistema Volcánico Transversal, la Sierra Madre Oriental, la Sierra Madre del Sur y la Sierra de Chiapas (Fig. 11d).

Género Liothorax Motschulsky, 1859

Liothorax es un género de origen Holártico, que se distribuye también por las regiones Oriental y Neotropical, utilizando como corredores las cadenas montañosas. Se han incluido en este género un total de diez especies, de las cuales tres se encuentran en la región Neártica. Se han citado las tres especies para México, aunque aún estaría por confirmar una de ellas, L. alternatus (Figs. 11e-g). Esta especie habría sido colectada en el Distrito Federal, pero no se ha logrado confirmar su 
identificación (Fig. 11e). Liothorax innexus se extiende por la Sierra Madre Occidental, la Sierra Madre Oriental, el Sistema Volcánico Transversal y la Sierra Madre del Sur (Fig. 11f); por otra parte, L. levatus es autóctona de la Sierra Madre Occidental, del Sistema Volcánico Transversal, del sur de la Sierra Madre Oriental, de la Sierra Madre del Sur y de la Sierra de Chiapas (Fig. 11g).

Son especies propias de altas elevaciones (Am entre los 2106 y los 2215 metros), que prefieren localidades con temperaturas medio-altas (Tm entre $15.4^{\circ} \mathrm{C}$ y $15.7^{\circ} \mathrm{C}$ ) y precipitaciones moderadas (Pm entre los $911 \mathrm{~mm}$ y $\operatorname{los} 1255 \mathrm{~mm}$ ) (Cuadro 4). Se muestran activas durante todo el año, principalmente durante los meses de junio a agosto, coincidiendo con el inicio de la temporada de lluvias. Liothorax alternatus ha sido colectada cerca de cuerpos de agua, no en excrementos, lo que puede indicar un carácter saprófago (Gordon \& Skelley 2007); L. innexus y L. levatus son especies coprófagas, que se han encontrado en diversos tipos de estiércol; ésta última también ha sido colectada a la luz y en material orgánico en descomposición (observaciones personales y Ruiz-Colorado 2001, Allende \& Ramírez 2005, Martínez 2005).

No se realizó ningún modelo de distribución para L. alternatus, puesto que se contaba únicamente con una cita sin confirmar para México. El mapa de distribución predicho para L. innexus muestra que esta especie podría estar presente en enclaves adicionales del Sistema Volcánico Transversal, el sur de la Sierra Madre Oriental, la Sierra Madre del Sur y la Sierra de Chiapas en Guatemala (Fig. 11f). El mapa de distribución predicho para L. levatus muestra una distribución similar a la anterior, pero mucho más restringida, que podría extenderse a otros puntos del Sistema Volcánico Transversal, el sur de la Sierra Madre Oriental y la Sierra Madre del Sur (Fig. 11g).

\section{Género Melinopterus (sensu lato) Mulsant, 1842}

Se trata de un género Holártico con alrededor de 20 especies descritas, tres de las cuales están presentes en la región Neártica, dos de ellas endémicas y una introducida. En México, se ha capturado una de las especies endémicas para Norteamérica, $M$. consentaneus, en la Sierra Madre Occidental, al sureste del estado de Durango (Fig. 11h).

Melinopterus (s.l.) consentaneus es una especie de cotas altas (2195 metros de $\mathrm{Am})$, que busca enclaves templado-cálidos $\left(16.7^{\circ} \mathrm{C}\right.$ de $\left.\mathrm{Tm}\right)$, con escasas precipitaciones (501 mm de Pm) (Cuadro 4). En México ha sido colectada durante el mes de junio, pero según se ha observado a latitudes mayores, podría estar presente entre los meses de junio a agosto. Aunque las observaciones en México indican que posee hábitos coprófagos, al haber sido colectada en excrementos de vaca (Morón \& Deloya 1991), se presume que podría estar asociada a las madrigueras de tuzas (Geomyidae) y alimentarse de dicho estiércol (Gordon \& Skelley 2007). 
Aunque sólo ha sido capturada en una localidad de México, el mapa de distribución predicho sugiere que podría estar extendida por otros puntos de la Sierra Madre Occidental, así como en la provincia biogeográfica Sonorense (Fig. 11h).

\section{Género Mendidius (sensu lato) Harold, 1868}

El género Mendidius (s.l.) está integrado por alrededor de 40 especies distribuidas por las regiones Afrotropical, Paleártica, Oriental y Neártica. En esta última región, sólo se encuentra una especie, $M$. (s.l.) aculeatus, que ha sido también citada de México, probablemente de la Sierra Madre Occidental en Chihuahua (Fig. 12a).

No se posee información topográfica ni ambiental para esta especie en México, pero en Estados Unidos ha sido capturada en cotas altas, entre los 1500 y los 1850 metros, en enclaves áridos o semiáridos, durante los meses de julio y agosto. Se cree que podría tener hábitos psammófilos y ser detritívora; ha sido colectada siempre a la luz (Gordon \& Skelley 2007).

Como no se dispone de información georreferenciada para M. (s.l.) aculeatus en México, no se ha elaborado un mapa de distribución predicho para esta especie.

\section{Género Neotrichonotulus M. Dellacasa, Gordon \& G. Dellacasa, 2004}

Este género Neártico posee tres especies descritas, todas ellas presentes en México y dos de las cuales endémicas del país (Figs. 12b-d). Las tres especies están asociadas a nidos de roedores y se encuentran localizadas en diferentes cadenas montañosas, de modo que $N$. inurbanus se distribuye por la Sierra Madre Occidental, subiendo por ella hasta Arizona (Fig. 12b); N. perotensis, en la intersección entre la Sierra Madre Oriental y el Sistema Volcánico Transversal (Fig. 12c); y, N. urangai, en el Sistema Volcánico Transversal (Fig. 12d).

Por consiguiente, las tres son especies propias de elevaciones altas o muy altas, cuyas Am oscilan entre los 2453 y los 2828 metros (Cuadro 4). Muestran afinidad por localizaciones con temperaturas frescas $\left(\mathrm{Tm}\right.$ entre $\operatorname{los} 10.6^{\circ} \mathrm{C}$ y $\left.\operatorname{los} 14.2^{\circ} \mathrm{C}\right)$ y precipitaciones moderadas (Pm entre los $916 \mathrm{~mm}$ y los $1296 \mathrm{~mm}$ ) (Cuadro 4). Neotrichonotulus inurbanus ha sido observada durante el mes de junio, mientras que $N$. perotensis se encuentra activa durante los meses de agosto a octubre y $N$. urangai en octubre. Han sido colectadas dentro de nidos de tuzas (Geomyidae), como cleptoparásitas de algunas especies de Onthophagus sp. (O. cuboidalis Bates, 1887 para N. inurbanus y O. hippopotamus Harold, 1869 para N. perotensis; Islas 1955, Gordon \& Howden 1973, Deloya \& Lobo 1995, Dellacasa et al. 2004b; Gordon \& Skelley 2007).

El mapa de distribución predicho para $N$. inurbanus ofrece algunas localizaciones adicionales para esta especie a lo largo de la Sierra Madre Occidental (Fig. 12b). Para $N$. perotensis, se incrementaría su distribución en algún otro punto de la zona de unión entre la Sierra Madre Oriental y el Sistema Volcánico Transversal, así como 
del Sistema Volcánico Transversal (Fig. 12c). Por último, N. urangai se encontraría presente en diversos puntos adicionales del Sistema Volcánico Transversal y de la Sierra Madre Occidental (Fig. 12d).

\section{Género Nialaphodius Kolbe, 1908}

El género Nialaphodius se compone de dos especies distribuidas por la región Afrotropical. Una de estas especies, $N$. nigrita, se distribuye en México a lo largo de las pendientes de las cadenas montañosas (Sierra Madre Occidental, Sierra Madre Oriental, Sistema Volcánico Transversal, Sierra Madre del Sur y Sierra de Chiapas), así como en zonas más bajas (Yucatán, Petén; Fig. 12e). Gordon \& Skelley (2007) afirman que esta especie ha sido probablemente importada desde África a las regiones Neártica y Neotropical, donde se ha establecido con éxito.

La altura media observada para esta especie es de 710 metros, seleccionando hábitats con temperaturas moderado-cálidas $\left(22.4^{\circ} \mathrm{C}\right.$ de $\left.\mathrm{Tm}\right)$ y precipitaciones moderadas (1497 mm de Pm) (Cuadro 4). Nialaphodius nigrita se encuentra activa todo el año, especialmente durante los meses de mayo a julio. Ha sido capturada frecuentemente en estiércol bovino y a la luz, pero también es atraída por otros tipos de excremento, como el ovino (observaciones personales y Morón et al. 1985, Morón \& Deloya 1991, Lobo \& Morón 1993, Morón 1994, Lobo 1996, Galante et al. 2003, Delgado \& Márquez 2006).

Según el mapa de distribución predicho, N. nigrita podría aumentar su distribución hacia localidades adicionales situadas al sur de la Sierra Madre Oriental y este del Sistema Volcánico Transversal, así como hacia la Sierra Madre del Sur y algunos puntos del Golfo de México próximos a las citas que actualmente se poseen para esta especie (Fig. 12e).

\section{Género Oscarinus Gordon \& Skelley, 2007}

Oscarinus es un género fundamentalmente Neártico, aunque alguna de sus especies puede localizarse también dentro de la región Neotropical. Se han asignado un total de 18 especies a este género, cuatro de las cuales se encuentran distribuidas por las sierras mexicanas (Figs. 12f-h, 13a). Oscarinus bottimeri ha sido citada de la Sierra Madre Oriental (Fig. 12f); O. crassuloides, también de la Sierra Madre Occidental y del Sistema Volcánico Transversal (Fig. 12g); O. indutilis, aparte de en dichas cadenas montañosas, también se distribuye por la Sierra Madre del Sur y por la Sierra de Chiapas (Fig. 12h); y, O, spiniclypeus, la única especie propiamente endémica de México, ha sido observada en el Sistema Volcánico Transversal y en la Sierra Madre del Sur (Fig. 13a).

Son especies que se encuentran presentes en elevaciones altas (Am entre los 1986 y los 2485 metros) y que se distribuyen en localidades con temperaturas moderadocálidas y cálidas $\left(\mathrm{Tm}\right.$ que oscila entre $\operatorname{los} 14.4^{\circ} \mathrm{C}$ y $\left.\operatorname{los} 16.3^{\circ} \mathrm{C}\right)$ y precipitaciones 
moderadas (Pm entre los $824 \mathrm{~mm}$ y los $1132 \mathrm{~mm}$ ) (Cuadro 4). No se tiene referencia sobre la fenología de $O$. bottimeri en México, aunque en latitudes superiores se puede observar durante los meses de marzo a mayo; las demás especies han sido colectadas en México principalmente durante los meses de junio y julio, coincidiendo con el comienzo de la época de lluvias, aunque también se ha observado cierta actividad de $O$. indutilis durante los demás meses del año. Las especies de Oscarinus son coprófagas; así, $O$. bottimeri se alimenta de excrementos de ciervo, al igual que $O$. crassuloides, que también ha sido capturada a la luz y en estiércol de vaca y caballo; $O$. indutilis se ha colectado en diversos excrementos (vaca, caballo y ovino) y a la luz; y, O. spiniclypeus, en estiércol ovino (observaciones personales y Morón 1994, Gordon \& Skelley 2007).

A falta de registros georreferenciados para $O$. bottimeri, no se ha podido modelizar su distribución. Los mapas de distribución predichos para $O$. crassuloides y $O$. indutilis muestran que estas especies podrían encontrarse en diversos puntos adicionales de la Sierra Madre Occidental, el sur de la Sierra Madre Oriental, el Sistema Volcánico Transversal, la Sierra Madre del Sur y la Sierra de Chiapas (Fig. 12g-h); O. spiniclypeus aumentaría su distribución hacia alguna localidad del sur de la Sierra Madre Oriental, otros puntos del Sistema Volcánico Transversal y de la Sierra Madre del Sur, así como hacia la Sierra Madre Occidental y la Sierra de Chiapas (Fig. 13a).

\section{Género Otophorus Mulsant, 1842}

Se trata de un género monoespecífico Paleártico que ha sido probablemente introducido en la región Neártica (Gordon \& Skelley 2007). En México, $O$. haemorrhoidalis se distribuye por la Sierra Madre Occidental, el Altiplano y la Sierra Madre Oriental (Fig. 13b).

Otophorus haemorrhoidalis es una especie que habita cotas altas, a una Am de 2114 metros (Cuadro 4). Selecciona hábitats con temperaturas moderado-cálidas $\left(22.4^{\circ} \mathrm{C}\right.$ de $\mathrm{Tm}$ ) y precipitaciones moderadas (1497 $\mathrm{mm}$ de Pm) (Cuadro 4). Ha sido observada en México durante los meses de junio a septiembre. Es una especie coprófaga de amplio espectro, observada habitualmente en excrementos de vaca o caballo (observaciones personales y Lobo 1996, Gordon \& Skelley 2007).

El mapa de distribución predicho ofrece diversos puntos adicionales de aparición para esta especie en la Sierra Madre Occidental y en la Sierra Madre Oriental, aparte de que podría extenderse su distribución a la zona de intersección entre el sur de la Sierra Madre Oriental y el este del Sistema Volcánico Transversal (Fig. 13b).

\section{Género Oxyomus Dejean, 1833}

El género Oxyomus tiene una amplia distribución mundial, con 23 especies repartidas por las regiones Paleártica, Oriental, Afrotropical y Neártica. El único endemismo 
Neártico es $O$. setosopunctatus, que solamente está presente en México (Fig. 13c). Se distribuye por zonas de montaña del Sistema Volcánico Transversal, el sur de la Sierra Madre Oriental y la Sierra Madre del Sur (Fig. 13c).

Esta especie suele encontrarse en alta montaña (2662 metros de Am), bajo temperaturas frescas $\left(11.8^{\circ} \mathrm{C}\right.$ de $\left.\mathrm{Tm}\right)$ y precipitaciones moderadas $(1305 \mathrm{~mm}$ de $\mathrm{Pm})$ (Cuadro 4). Ha sido colectada durante todo el año, pero más frecuentemente durante los meses de junio y julio, coincidiendo con el inicio de la temporada de lluvias. Sus hábitos son coprófagos y se ha observado en excrementos de vaca, caballo y oveja (observaciones personales y Martínez 2005, Cabrero-Sañudo et al. 2007).

El modelo de distribución predicho para $O$. setosopunctatus no ofrece muchas más localidades adicionales de presencia aparte de las observadas, extendiendo su distribución hacia enclaves próximos conocidos de la especie (Fig. 13c).

\section{Género Pardalosus (sensu lato) Gordon \& Skelley, 2007}

El género Pardalosus (s.l.) está integrado por siete especies de distribución Neártica, cuatro de las cuales penetran en México a través de las cadenas montañosas (Figs. 13d-g). Pardalosus pardalis y P. pseudopardalis han sido citadas en México en el norte de la Sierra Madre Occidental (Figs. 13d-e); P. (s.l.) pumilio es la que presenta una distribución más amplia en México, extendiéndose por la Sierra Madre Occidental, la Sierra Madre Oriental, el Altiplano y la intersección del Sistema Volcánico Transversal con la Sierra Madre Oriental (Fig. 13f). P. (s.l.) serval se ha colectado en la zona norte de la Sierra Madre Oriental (Fig. 13g).

No se poseen datos georreferenciados para México de $P$. pardalis ni de $P$. pseudopardalis, por lo que se desconocen sus preferencias climáticas y altitudinales. Probablemente, éstas son muy parecidas a las de $P$. (s.l.) pumilio y $P$. (s.l.) serval, que suelen encontrarse en localidades de altitudes elevadas (Am entre los 1927 y los 2201 metros), con temperaturas moderadas o moderado-cálidas (Tm entre los $12.8^{\circ} \mathrm{C} \mathrm{y} \mathrm{los}$ $15.5^{\circ} \mathrm{C}$ ) y precipitaciones escasas o moderadas (Pm entre los $598 \mathrm{~mm}$ y los $625 \mathrm{~mm}$ ) (Cuadro 4). Pardalosus pardalis y P. pseudopardalis han sido colectadas en latitudes más altas durante todo el año; $P$. (s.l.) pumilio, ha sido capturada en México durante los meses de junio y julio; y, $P$. (s.l.) serval se ha observado durante el mes de abril, aunque podría tener una distribución temporal más amplia, como la observada en Estados Unidos, desde octubre a junio. Se especula que estas especies puedan tener hábitos detritívoros, aunque $P$. (s.l.) pumilio ha sido observada también en excrementos equinos y en materia orgánica en descomposición (observaciones personales y Martín-Piera \& Lobo 1993, Gordon \& Skelley 2007).

Por carencia de datos precisos de localización para México no se han obtenido mapas de distribución predichos para $P$. pardalis ni para $P$. pseudopardalis. El modelo de distribución obtenido para $P$. (s.l.) pumilio muestra una probable ampliación de rango de distribución de esta especie hacia 
puntos adicionales del norte de la Sierra Madre Oriental, la intersección de ésta con el Sistema Volcánico Transversal y el Altiplano (Fig. 13f); P. (s.l.) serval aumentaría su extensión ligeramente hacia otros puntos situados al norte de la Sierra Madre Oriental (Fig. 13g).

Género Pharaphodius (sensu lato) Reitter, 1892

Pharaphodius (s.l.) es un género compuesto por más de cien especies con una distribución Paleártica, Afrotropical, Oriental y Neártica. Aunque es posible que no pertenezca a este género, la única especie presente en el Neártico, endémica además de México, es Pharaphodius (s.l.) oleosus, que se extiende por la Sierra Madre Occidental y el Sistema Volcánico Transversal (Fig. 13h).

Se trata de una especie de montaña, que se suele encontrarse a una Am de 2078 metros (Cuadro 4). Selecciona enclaves con una temperatura moderado-cálida (Tm de $16.1^{\circ} \mathrm{C}$ ) y precipitaciones moderadas (Pm de $992 \mathrm{~mm}$ ) (Cuadro 4). Tiene una fenología de mayo a octubre, especialmente activa durante los meses de junio y julio. Tiene hábitos coprófagos y ha sido colectada en excremento equino (observaciones personales).

El mapa de distribución predicho para esta especie sugiere localidades adicionales de presencia localizados en la Sierra Madre Occidental y el Sistema Volcánico Transversal (Fig. 13h).

Género Planolinellus M. Dellacasa \& G. Dellacasa, 2005

El género Planolinellus contiene únicamente a una especie, $P$. vittatus, presente en la región Holártica, salvo en el Paleártico Occidental, aunque se extiende solamente hasta Rodas. Ésta es una distribución inusual por lo que se piensa que podría ser una especie nativa norteamericana que hubiera sido introducida en el Paleártico (Dellacasa \& Dellacasa 2005, Gordon \& Skelley 2007). En México, se extiende por zonas elevadas de la Sierra Madre Occidental, Altiplano, Sierra Madre Oriental, Sistema Volcánico Transversal, Sierra Madre del Sur y Sierra de Chiapas, aunque también se ha observado en algunas localidades del Golfo de México (Fig. 14a).

Suele estar presente en elevaciones altas (2027 metros de Am; Cuadro 4), prefiriendo temperaturas moderado-cálidas $\left(15.6^{\circ} \mathrm{C}\right.$ de $\left.\mathrm{Tm}\right)$ y precipitaciones moderadas (1033 mm de Pm) (Cuadro 4). Los adultos están activos durante todo el año y presentan varias generaciones anuales. Tiene hábitos coprófagos de amplio espectro, puesto que se ha encontrado en excrementos diversos (vaca, caballo, oveja, roedores) y es atraída a la luz y por materia orgánica en descomposición (observaciones personales y Morón 1994, Ruiz-Colorado 2001, Arellano 2002, Delgado \& Márquez 2006, Martínez \& Suárez 2006, Cabrero-Sañudo et al. 2007).

El mapa de distribución predicho para $P$. vittatus muestra que la especie podría estar presente en enclaves adicionales del Sistema Volcánico Transversal, de la Sierra 
Madre Oriental, de la Sierra Madre del Sur y de la Sierra de Chiapas, incluso en algún punto de Guatemala, donde aún no ha sido colectada (Fig. 14a).

Género Planolinoides M. Dellacasa \& G. Dellacasa, 2005

Planolinoides es un género de distribución Holártica, al cual se han asignado cinco especies, todas ellas presentes en el Neártico. En México han sido citadas dos especies, $P$. duplex y $P$. neotomae, presentes en cadenas montañosas y asociadas a madrigueras de roedores. Planolinoides duplex ha sido citada del estado de Durango, mientras que P. neotomae ha sido citada del estado de Veracruz (Figs. 14b-c).

No se posee información precisa de localización para estas especies en México, pero se ha observado que en latitudes mayores suele encontrarse en localidades de altitud elevada. Planolinoides duplex se ha colectado durante los meses de abril a julio, mientras que $P$. neotomae se ha colectado entre febrero y mayo. Dentro del género Planolinoides, estas dos especies son las únicas que se alimentan de excrementos de roedores; las demás suelen estar asociadas a excrementos de rumiantes forestales, como ciervo o alce. Así, $P$. duplex se ha colectado en nidos de ardillas de tierra (Spermophilus sp.) y $P$. neotomae en los de ratas selváticas (Neotoma Say \& Ord, 1825; Gordon \& Skelley 2007).

A falta de información georreferenciada, no se han elaborado modelos de distribución para estas especies.

Género Planolinus Mulsant \& Rey, 1870

Cuatro especies han sido incluidas dentro del género Holártico Planolinus, sólo una de las cuales, $P$. tenellus, se extiende por la región Neártica. Esta especie de amplia distribución en Canadá y Estados Unidos ha sido citada para México de la Sierra Madre del Sur y del sur de la Sierra Madre Oriental (Fig. 14d).

La especie se localiza en montañas, a una Am de 2161 metros, seleccionando ambientes moderado-cálidos $\left(15.7^{\circ} \mathrm{C}\right.$ de $\left.\mathrm{Tm}\right)$ con precipitaciones moderadas (1119 $\mathrm{mm}$ de Pm) (Cuadro 4). En México ha sido capturada durante el mes de mayo, pero podría extender su fenología durante los meses de abril a octubre. Sus hábitos alimenticios incluyen excrementos de caballo, oveja y ciervo (Lobo \& Halffter 2000, Gordon \& Skelley 2007).

Según el mapa de distribución predicho, $P$. tenellus podría ampliar su distribución hacia otras localizaciones del Sistema Volcánico Transversal y del sur de la Sierra Madre Oriental, así como por la Sierra Madre Occidental, la Sierra Madre del Sur y la Sierra de Chiapas (Fig. 14d).

Género Pseudagolius (sensu lato) Schmidt, 1913

Pseudagolius (s.l.) es un género Neártico compuesto por cuatro especies, todas ellas presentes en México (Figs. 14e-h). Una de ellas es endémica, $P$. caballeroi, presente 
en las pendientes occidentales del Sistema Volcánico Transversal (Fig. 14f); P. (s.l.) bicolor ha sido citada de Sonora, sin mayor información sobre la localidad, aunque probablemente pueda encontrarse en las estribaciones septentrionales de la Sierra Madre Occidental (Fig. 14e); P. coloradensis se extiende por la Sierra Madre Occidental, el Altiplano, la Sierra Madre Oriental, el Sistema Volcánico Transversal y la Sierra Madre del Sur (Fig. 14g); y, P. warneri ha sido colectada en la llanura costera del Pacífico y en la zona norte de la Sierra Madre Occidental (Fig. 14h).

Así pues, tres especies de este género se encontrarían a baja-media altura (P. (s.l.) bicolor, $P$. caballeroi y $P$. warneri), mientras que una de ellas habría colonizado alturas mayores ( $P$. coloradensis). No se poseen datos georreferenciados de las localizaciones de $P$. (s.l.) bicolor en México, pero $P$. caballeroi y $P$. warneri se sitúan a Am que oscilan entre los 283 y los 724 metros, en enclaves con temperaturas moderado-cálidas o cálidas ( $\mathrm{Tm}$ entre $\operatorname{los} 23.8^{\circ} \mathrm{C}$ y $\operatorname{los} 25.3^{\circ} \mathrm{C}$ ) y precipitaciones escasas o moderadas que oscilan entre los 558 y los $922 \mathrm{~mm}$ de Pm (Cuadro 4). A diferencia de estas especies, $P$. coloradensis se encuentra a una Am de 2090 metros, en zonas de temperatura moderado-cálida $\left(16.4^{\circ} \mathrm{C}\right.$ de $\left.\mathrm{Tm}\right)$ y precipitaciones escasas (661 mm de Pm) (Cuadro 4). Todas las especies se han observado entre los meses de mayo y octubre. Se desconocen los hábitos alimentarios de $P$. caballeroi; las otras tres especies son coprófagas, mostrando $P$. (s.l.) bicolor una preferencia por excrementos más pequeños y secos (ciervo, ardilla) y las otras dos una mayor preferencia por excrementos de vaca, caballo u oveja, siendo capturadas también a la luz (observaciones personales y Morón \& Deloya 1991, Lobo \& Morón 1993, Gordon \& Skelley 2007).

No se desarrolló un modelo de distribución para P. (s.l.) bicolor, por falta de datos precisos de localización para México. El mapa para $P$. caballeroi indica que la especie podría tener un área de distribución extendida hacia zonas litorales o bajas de las regiones Sonorense y de la Costa del Pacífico, así como en la Depresión del Balsas (Fig. 14f); P. coloradensis ampliaría su área hacia la Sierra Madre Occidental, así como hacia el Sistema Volcánico Transversal, algún punto al sur de la Sierra Madre Oriental y la Sierra Madre del Sur (Fig. 14g); P. warneri se encontraría más extendida por la región Sonorense y las vertientes occidentales de la Sierra Madre Occidental (Fig. 14h).

\section{Género Pseudogonaphodiellus}

M. Dellacasa, Gordon \& G. Dellacasa, 2007

Se trata de un género integrado por una sola especie, $P$. zdzislawae, autóctona de la Sierra Madre del Sur, en México (Fig. 15a).

Se distribuye por zonas altas (2347 metros de Am), con temperaturas moderadocálidas $\left(17.1^{\circ} \mathrm{C}\right.$ de $\left.\mathrm{Tm}\right)$ y precipitaciones moderadas (1353 mm de Pm) (Cuadro 4). Se han capturado individuos adultos en actividad durante los meses de junio a 
septiembre, siendo más frecuentes al comienzo de la época de lluvias. Es una especie coprófaga y saprófaga, puesto que se ha encontrado tanto en excrementos de vaca o caballo, como en material vegetal y fúngico en descomposición (Dellacasa et al. 2007d).

El mapa de distribución predicho muestra que la especie sería más común en la Sierra Madre del Sur, en localidades próximas a los lugares donde ha sido recolectada anteriormente de Guerrero y Oaxaca, así como en la Sierra de Chiapas, en Guatemala (Fig. 15a).

Género Rugaphodius Gordon \& Skelley, 2007

El género Rugaphodius se compone sólo de una especie, $R$. rugatus, distribuida por el sudoeste de Estados Unidos. Ha sido citada también de Baja California, aunque no se ha precisado mucho más este dato (Fig. 15b).

No se tienen datos georreferenciados para $R$. rugatus, pero se ha observado que selecciona hábitats costeros, durante los meses de septiembre a mayo. Aunque se ha encontrado en excrementos equinos, es posible que se trate de una especie detritívora, puesto que es común en suelos ricos en materia orgánica y también se ha encontrado a la entrada de madrigueras de roedores (Gordon \& Skelley 2007).

A falta de datos localizados para México, no se elaboró ningún mapa de distribución predicho para esta especie.

Género Schaefferellus Gordon \& Skelley, 2007

Se trata de un género monoespecífico distribuido por la zona sur de las Montañas Rocosas. En México, Schaefferellus arizonensis se ha citado del estado de Durango, probablemente de la Sierra Madre Occidental (Fig. 15c).

No se poseen más datos sobre la localización de esta especie en México, pero en latitudes superiores suele encontrarse alrededor de los 1500 metros de altitud, en el ecotono entre sabinares y bosques de pino. Su actividad fenológica abarcaría los meses entre junio y agosto, al comienzo del período de lluvias. Se cree que puede estar asociada a excrementos de roedores, pero no se tienen datos fidedignos que lo corroboren; también ha sido colectada a la luz (Gordon \& Skelley 2007).

No se elaboró ningún mapa de distribución predicho para esta especie, puesto que se carecía de datos georreferenciados.

Género Stenotothorax Schmidt, 1913

Stenotothorax es un género ampliamente distribuido por la región Neártica y con presencia en el Paleártico Oriental. Está compuesto por 24 especies, de las cuales una, S. sparsus, penetra en México (Fig. 15d).

No se tienen datos georreferenciados para esta especie en México, salvo por la mención de su presencia en el estado de Chihuahua. En el resto de Norteamérica 
suele establecerse cerca de las costas y con afinidades por un clima mediterráneo; por tanto, es posible que en Chihuahua pueda localizarse en las zonas bajas de la Sierra Madre Occidental, actuando ésta como barrera para que la especie se extienda hacia el este. Se ha observado que los adultos se encuentran activos durante todo el año. Stenotothorax sparsus se encuentra asociada a nidos de ratas selváticas (Neotomae), alimentándose de sus excrementos; también es atraída hacia la luz (Gordon \& Skelley 2007).

No se ha elaborado ningún mapa de distribución predicho para esta especie, pues no se disponía de datos georreferenciados.

Género Tetraclipeoides (sensu lato) Schmidt, 1913

El género Tetraclipeoides (s.l.) está formado por 16 especies, con una distribución Neártica y Afrotropical. En la región Neártica están presentes 14 especies y tres de ellas se extienden por el norte de México, en Chihuahua (Figs. 15e-g). No se poseen referencias geográficas precisas para $T$. (s.l.) aemulus ni para $T$. dentiger, pero sí para T. (s.l.) giulianii, localizada al norte de la Sierra Madre Occidental (Fig. 15g).

Tetraclipeoides (s.l.) giulianni ocupa zonas de dunas arenosas a media altitud (1331 metros de Am), áridas o semiáridas (17.2 de Tm C y 228 mm de Pm) (Cuadro 4). Esta especie ha sido colectada durante el mes de abril; en México, no se poseen datos fenológicos para T. (s.l.) aemulus ni para T. dentiger, pero en Estados Unidos suelen aparecer durante los meses de abril a agosto o entre abril y noviembre, respectivamente. Tetraclipeoides (s.l.) giulianni es atraída hacia la luz, pero se desconocen sus hábitos alimentarios; es muy probable que éstos sean similares a los de $T$. (s.l.) aemulus y $T$. dentiger, que también son atraídas a la luz y suelen asociarse a nidos de ratas selváticas (Neotoma sp.; Gordon 1977, Gordon \& Skelley 2007).

Aunque no se obtuvieron mapas de distribución predichos para T. (s.l.) aemulus y T. dentiger, por falta de datos georreferenciados para México, sí se obtuvo uno para $T$. (s.l.) giulianni, según el cual esta especie aumentaría su rango de distribución hacia otras zonas bajas presentes al norte de la Sierra Madre Occidental y hacia otras localidades de las Montañas Rocosas en Estados Unidos (Fig. 15g).

Género Trichaphodiellus Schmidt, 1913

Se trata de un género monoespecífico Neotropical que se encuentra bien distribuido por toda Sudamérica. Su especie, T. brasiliensis, ha sido citada como una posible especie introducida en México, pero su presencia está aún pendiente de confirmación, de modo que no se elaboró ningún mapa de distribución predicho para esta especie (Fig. 15h).

En Sudamérica es una especie euritópica, colectada en pastizales a diferentes alturas. En general, selecciona enclaves con temperaturas moderado-cálidas y precipitaciones que oscilan entre moderadas y abundantes. En el hemisferio sur, 
suele estar activa entre los meses de enero a junio, mostrando una afinidad por excrementos de vaca y, sobre todo, equinos (Verdú \& Galante 1997).

Género Trichonotuloides Balthasar, 1945

Trichonotuloides es un género presente en Centro y Norteamérica, con dos especies repartidas por México y Guatemala. En México, se encuentra la especie endémica $T$. glyptus, distribuida por las montañas de la Sierra Madre Occidental, el Sistema Volcánico Transversal, el sur de la Sierra Madre Oriental y la Sierra Madre del Sur (Fig. 16a).

La especie se encuentra distribuida a gran altitud, a una $\mathrm{Am}$ de 2599 metros (Cuadro 4). Está presente en enclaves frescos $\left(13.0^{\circ} \mathrm{C}\right.$ de $\left.\mathrm{Tm}\right)$ con precipitaciones moderadas (1167 mm de Pm) (Cuadro 4). Ha sido colectada entre los meses de abril a diciembre, con una mayor frecuencia durante junio y julio, coincidiendo con el inicio de la temporada de lluvias. La especie presenta hábitos coprófagos de amplio espectro, habiendo sido encontrada en excrementos de diversos tipos (vaca, caballo, oveja, ciervo), e incluso en materia orgánica en descomposición (observaciones personales y Martín-Piera \& Lobo 1993).

El mapa de distribución predicho para T. glyptus indica algunos puntos adicionales de presencia en la Sierra Madre Occidental, el Sistema Volcánico Transversal, el sur de la Sierra Madre Oriental y la Sierra Madre del Sur (Fig. 16a).

\section{Género Xeropsamobeus (sensu lato) Saylor, 1937}

El género Xeropsamobeus (s.l.) presenta una distribución Neártica. Diez especies han sido asignadas a este género, de las cuales tres se extienden también por el norte de México. Así, X. (s.l.) asellus ha sido observada en la Sierra Madre Occidental, en el estado de Durango, mientras que $X$. desertus y X. (s.l.) scabriceps se han colectado en Sonora y Nuevo León, respectivamente (Figs. 16b-d).

No se dispone de datos ambientales ni topográficos sobre las citas de $X$. dentatus y $X$. (s.l.) scabriceps en México, pero las referencias para X. (s.l.) asellus indican que se trata de una especie propia de altitudes elevadas (2195 metros de Am), que selecciona temperaturas moderado-cálidas $\left(16.7^{\circ} \mathrm{C}\right.$ de $\left.\mathrm{Tm}\right)$ y precipitaciones bajas $(501 \mathrm{~mm} \mathrm{de} \mathrm{Pm})$ (Cuadro 4). Se ha colectado esta especie sólo durante el mes de junio, pese a que citas más septentrionales muestran que estaría presente desde diciembre a julio; las otras dos especies, $X$. dentatus y $X$. (s.l.) scabriceps, estarían activas de diciembre a abril y de abril a julio, respectivamente. Las tres especies son atraídas por la luz, siendo arenícolas y considerándoselas psammófilo-detritívoras, aunque también se ha encontrado a $X$. (s.l.) scabriceps en madrigueras de perros de las praderas (Cynomys sp.), asociada a sus desechos (morón \& Deloya 1991, Gordon \& Skelley 2007).

El mapa de distribución predicho para X. (s.l.) asellus muestra que, aparte de las zonas de la Sierra Madre Occidental en las que está presente, se podría encontrar en otros enclaves de estas montañas, en el Altiplano y en la región Sonorense (Fig. 16b). 


\section{Didactyliini}

Dos especies de esta tribu han sido citadas para México, ambas incluidas dentro del género Aidophus.

Género Aidophus Balthasar, 1963

El género Aidophus se compone de diez especies repartidas ampliamente por la región Neotropical y con otras dos especies distribuidas en la región Neártica, al norte de México, A. flaveolus y A. notatus, la primera de las cuales precisa aún confirmación. Aidophus flaveolus es una especie extendida por Argentina y Chile, con referencias en Yucatán pendientes de ser corroboradas (Fig. 16e); A. notatus se distribuye por las zonas costeras del Golfo de México, siendo también colectada en el estado de México (Fig. 16f).

Sólo se poseen datos georreferenciados para A. notatus, los cuales muestran que se trata de una especie distribuida por las zonas arenosas de baja altitud (249 metros de $\mathrm{Am})$, con temperaturas cálidas $\left(24.4^{\circ} \mathrm{C}\right.$ de $\left.\mathrm{Tm}\right)$ y precipitaciones moderadas (1433 mm de Pm) (Cuadro 4). Los ejemplares de esta especie han sido colectados durante los meses de mayo a julio; por otra parte, A. flaveolus ha sido observada en actividad entre los meses de noviembre y marzo en Sudamérica, lo que podría, estacionalmente, coincidir con un periodo estival de lluvias para México. Son especies habitualmente atraídas por la luz, que se alimentan probablemente de materia orgánica en descomposición (Dellacasa et al. 2001b).

A falta de datos confirmados para México de A. flaveolus no se elaboró ningún mapa de distribución predicho. El modelo de distribución para A. notatus muestra que la especie podría estar presente en otras zonas adicionales del Golfo de México y en la Llanura Costera del Pacífico, pero también en Yucatán y diversos puntos de Belice y Guatemala situados en la Península de Yucatán (Fig. 16f).

\section{Proctophanini}

El único género citado de Proctophanini para las regiones Neártica y Neotropical es Australaphodius, con una especie no autóctona que ha sido introducida.

Género Australaphodius Balthasar, 1942

Se trata de un género compuesto por cuatro especies, tres de las cuales son Afrotropicales y otra, A. frenchi, distribuida por las regiones Afrotropical, Australiana, Neotropical y Neártica. Esta última especie ha sido citada de México, de la región del Golfo de México en Tamaulipas, lo cual aún habría que confirmar (Fig. 16g). Se especula que habría sido introducida en California y, quizás en México, desde la región Australiana (Dellacasa et al. 2001b).

Se desconocen las preferencias de esta especie en México, pero en otros lugares suele seleccionar enclaves cálidos a baja altura. En California ha sido observada 
durante los meses de febrero y marzo. Aunque ha sido colectada en excrementos secos de caballo, se cree que puede ser una especie generalista (Dellacasa et al. 2001b).

No se ha obtenido un mapa de distribución predicho para esta especie, puesto que se carecía de datos georreferenciados y confirmados.

Distribución predicha de la riqueza y de la endemicidad de Aphodiinae en México. Según el mapa de riqueza obtenido (Figura 17), alrededor del 62\% del territorio mexicano no poseería ninguna especie de Aphodiinae, el 38\% (unos $750.000 \mathrm{~km}^{2}$ ) contendría al menos una especie y el $4.4 \%$ (alrededor de $86.000 \mathrm{~km}^{2}$ ) cinco o más especies. Los puntos de mayor riqueza de especies coincidirían, en general, con los enclaves de mayor altitud del país, presentes a lo largo del Sistema Volcánico Transversal y el sur de la Sierra Madre Oriental, en los estados de Veracruz, Puebla, México, Distrito Federal y Michoacán (Fig. 17). También se muestra una alta riqueza de especies en algunos puntos de la Sierra Madre del Sur (en los estados de Guerrero y Oaxaca). Destacan, así mismo, aunque con menor riqueza, algunas localizaciones de la Sierra Madre Occidental (en los estados de Durango, Jalisco y Zacatecas) y de la Sierra Madre Oriental (en los estados de Nuevo León y Coahuila; Fig. 17). Por el contrario, los lugares con una menor o nula riqueza de Aphodiinae se encontrarían en las Penínsulas de Baja California y de Yucatán, noroeste de México y Llanura Costera del Pacífico, Altiplano mexicano, noreste de México y Golfo de México (Fig. 17).

Considerando únicamente aquellas especies con distribuciones limitadas al territorio mexicano, se obtuvo un mapa de la endemicidad de Aphodiinae en México (Figura 18). Según este mapa, los mayores núcleos de endemicidad se encontrarían en enclaves situados en altitudes superiores, observándose, por tanto, una relación coincidente con los puntos de mayor riqueza de Aphodiinae $(r=0.794, \mathrm{P}<0.001)$. Así pues, los lugares con una mayor endemicidad se distribuirían principalmente por el Sistema Volcánico Transversal, Sierra Madre Occidental, Sierra Madre del Sur y, en menor grado, por la Sierra de Chiapas, zonas norte y sur de la Sierra Madre Oriental y norte de la Sierra de California (Fig. 18).

\section{DISCUSIÓN}

Los mapas que aquí se presentan son la primera aproximación que pretende describir la distribución de las especies y la variación geográfica de la riqueza de Aphodiinae en México, así como la tercera ocasión en que se predice la distribución de un grupo de coleópteros coprófagos en México, habiéndose realizado también anteriormente para todos los Geotrupidae y para algunos Scarabaeidae (Coleoptera, Scarabaeoidea; Trotta-Moreu et al. 2008, Verdú \& Lobo 2008, Trotta-Moreu \& Lobo 2010). La cartografía proporcionada en este trabajo debe considerarse una representación provisional del área de distribución de las especies de Aphodiinae mexicanas, que 
podrá mejorarse y validarse ulteriormente, a medida que se obtengan nuevas citas faunísticas de las especies actualmente reconocidas e incluso de otras afines filogenéticamente, que podrían estar ocupando las areas predichas.

Para la realización de este tipo de modelos suele utilizarse información biológica procedente de grupos y regiones no tan insuficientemente prospectados como en nuestro caso, pero es indudable que los resultados de estas técnicas, aunque deben siempre considerase con precaución (Jiménez-Valverde et al. 2008), adquieren un interés especial cuando son capaces de realizar predicciones bajo las condiciones de carencia de información que generalmente abundan en los grupos y en las regiones mas diversificadas (Soberón \& Peterson 2004, Whittaker et al. 2005, Cayuela et al. 2009). El procedimiento metodológico seguido en este trabajo permite corregir la frecuente sobrepredicción de este tipo de modelizaciones (Fielding \& Haworth 1995, Araújo \& Williams 2000, Stockwell \& Peterson 2002, Brotons et al. 2004, Segurado \& Araújo 2004, Stockman et al. 2006), especialmente cuando los valores de riqueza se obtienen a través del sumatorio de mapas estimados individuales (Hortal \& Lobo 2006), y también validar las predicciones de riqueza obtenidas utilizando los resultados de diversos estimadores no-paramétricos. Pese a ello, puede decirse que la aproximación seguida en éste y en otros trabajos (Trotta-Moreu et al. 2008, Verdú \& Lobo 2008, Pineda \& Lobo 2009, Trotta-Moreu \& Lobo 2010) es atrevida y de dudosa eficiencia ya que, como nosotros mismos estimamos, proporciona un error de comisión promedio del $94 \%$ y un error de omisión medio del $28 \%$ (71\% y 18\%, respectivamente, en Geotrupidae; Trotta-Moreu \& Lobo 2010). Ello implica que, en los estados mexicanos con un inventario a priori fiable, el número de especies observadas prácticamente se duplica y, además, que una de cada cuatro especies verdaderamente observada es omitida. Aunque el número de especies observado en cada estado esté subestimado y buena parte de estas especies erróneamente incluidas o excluidas posean áreas de distribución predichas reducidas (ver Pineda \& Lobo 2009), no cabe duda que estos resultados no permiten confiar en la composición faunística predicha para cada estado y localidad. Siendo conscientes que éstos y otros resultados ponen en duda la utilidad de este tipo de modelizaciones cuando la información de partida es escasa y sesgada, consideramos, no obstante, que la fuerte correlación existente entre los valores de riqueza observaos y predichos sugiere que la sobrepredicción de los modelos no altera sustancialmente el patrón de variación espacial en la riqueza observado. Así, aunque no podamos confiar en la identidad de las especies existentes en cada localidad, sí podemos suponer que hemos capturado el patrón de variación en la riqueza para este grupo. Será necesario poseer información sobre la presencia de cada una de las especies que, aunque escasa, esté bien repartida a lo largo del espectro de condiciones ambientales y geográficas del territorio mexicano (ver Hortal et al. 2007), e información fiable sobre las localidades en las que cada una de las especies esté ausente (Jiménez-Valverde et al. 
2008), para obtener modelos de distribución más fiables capaces de considerar los factores que limitan la presencia de una especie bajo condiciones climáticas favorables (Pulliam 2000).

Estos factores de naturaleza histórico-geográfica son, a nuestro juicio, vitales a la hora de explicar la composición de la fauna mexicana de Aphodiinae que, básicamente, seguiría un modelo de "colonización horizontal" tal y como han propuesto Lobo y Halffter (2000). La mayor parte de los Aphodiinae pertenecen a patrones de dispersión Paleoamericanos o Neárticos (Halffter 1987) y formarían parte de líneas filogenéticas de origen Holártico o Neártico que se habrían diversificado en la Zona de Transición Mexicana. Así, algunas de estas especies procederían originalmente de grupos Laurásicos compartidos entre Eurasia y Norteamérica (Cabrero-Sañudo \& Lobo 2009), tierras conectadas intermitentemente desde finales del Cretácico hasta el Eoceno (hace 66-38 millones de años; Scotese 2003). De este período podrían proceder varias líneas de Aphodiinae con carácter orófilo, que habrían comenzado a coevolucionar con diversas especies de roedores, a falta de otros excrementos de los que nutrirse; luego, a partir del Mioceno, el surgimiento de un clima árido-semiárido podría haber sido el factor desencadenante para la diversificación de muchos roedores y, por tanto, de especies de Aphodiinae asociadas a éstos en regiones montañosas y altiplanicies del Neártico y de la Zona de Transición Mexicana (Lobo \& Halffter 1994). El contacto entre continentes volvería a reanudarse desde el Mioceno y durante el Plioceno y Pleistoceno; la presencia de puentes de tierra en el estrecho de Bering habría permitido el paso de bóvidos y de otros grandes mamíferos desde Eurasia hacia Norteamérica (Potts \& Behrensmeyer 1993) y, con ellos, la introducción de líneas de Aphodiinae adaptadas a sus excrementos, que también divergirían en Norteamérica dando lugar a nuevas líneas Neárticas, algunas de las cuales habrian alcanzado la Zona de Transición Mexicana.

La colonización del territorio mexicano por especies Neotropicales de Aphodiinae habría sido más reciente (Cabrero-Sañudo \& Lobo 2009). La introducción de estas líneas se podría haber producido a partir de finales del Mioceno y durante el Plioceno, con el cierre del estrecho de Panamá (hace 13-7 millones de años; Coates et al. 2004). Este evento provocó el Gran Intercambio Americano de fauna y flora (Webb 1985), que también favoreció la expansión de especies de Scarabaeinae (Davis \& Scholtz 2001). Gradualmente, numerosas especies de Aphodiinae Neotropicales habrían colonizado tierras más septentrionales hasta llegar a ambientes cálidos de Norteamérica e, incluso, derivando hacia nuevas líneas de Aphodiinae, como posiblemente ocurrió con el género Haroldiellus. Las especies presentes en México de Proctophanini y Didactyliini podrían ser el resultado de colonizaciones recientes propiciadas por el hombre desde la región Neotropical, salvo acaso Aidophus notatus, que habría penetrado en México de igual manera que las otras especies de Aphodiini Neotropicales. 
Al igual que los Geotrupidae, y más concretamente dentro de ellos los Geotrupinae, los Aphodiinae presentan sus valores máximos de riqueza en las áreas más elevadas del Sistema Volcánico Transversal y de la Sierra Madre del Sur (TrottaMoreu \& Lobo 2010; Figura 17). En nuestra opinión, ello se debe a que la inmensa mayoría de los grupos de Aphodiinae presentes en México proceden de la región Neártica, siendo la Zona de Transición Mexicana el punto principal de diversificación de esta subfamilia en México (Cabrero-Sañudo et al. 2007b). La preferencia general de los Aphodiinae mexicanos por los enclaves montañosos y templado-fríos se corrobora al observar que los principales centros de endemicidad coinciden significativa y positivamente con los puntos de mayor riqueza de especies (Fig. 18). Además, esta tendencia también se observa al ubicar los datos de preferencia climática conocidos de estas especies (presentes en el Cuadro 4) en una representación climática del territorio mexicano, creada simplemente a partir de los datos de temperatura media anual y de precipitación anual para cada una de las celdas del territorio, a una resolución de $0.08^{\circ}$ (Figura 19). En esta representación se aprecia que la mayoría de especies de Aphodiinae gravitarían hacia puntos de temperaturas menores y precipitaciones superiores a la media de los puntos del territorio mexicano, es decir tenderían a seleccionar localizaciones con un cierto carácter orófilo.

Así, una gran parte de las especies presentes en México serían representantes de grupos con una distribución más amplia que abarcaría latitudes más septentrionales, como Agoliinus, Cinacanthus, Cryptoscatomaseter (s.l.), Dellacasiellus, Diapterna, Drepanocanthoides (s.l.), Flaviellus (s.l.), Geomyphilus (s.l.), Oscarinus, Pardalosus (s.l.), Pseudagolius (s.l.), Rugaphodius, Schaefferellus, Stenotothorax, Tetraclipeoides (s.l.) o Xeropsammobeus; mientras que otra serie de especies pertenecen a grupos endémicos o primordialmente endémicos de la Zona de Transición Mexicana, guardando aún afinidades Neárticas, como Agrilinellus, Cephalocyclus, Cesamexico, Coelotrachelus, Jalisco, Neotrichonotulus, Pseudogonaphodiellus o Trichonotuloides. Con afinidades ambientales análogas, también son comunes en México aquellas especies ampliamente extendidas por la región Holártica, pertenecientes a grupos de origen típicamente Paleártico o compartidas con el conjunto Paleártico-Afrotropical-Oriental (Cabrero-Sañudo \& Lobo, 2009), como sería el caso de los géneros Liothorax, Melinopterus (s.l.), Mendidius (s.l.), Otophorus, Oxyomus, Pharaphodius (s.l.), Planolinellus, Planolinoides o Planolinus. Existen, además, especies pertenecientes a géneros de amplia distribución, como Aphodius o Calamosternus, suficientemente generalistas, pero con afinidades también Laurásicas.

Por otra parte, se pueden observar algunas especies que requerirían, en general, mayores temperaturas o incluso menores precipitaciones que aquellas otras que muestran afinidades Neárticas, como consecuencia de tener un origen posiblemente 
Neotropical (Fig. 19). De esta manera, los géneros Neotropicales de Aphodiinae con especies en México serían Gonaphodiellus (s.l.), Trichaphodiellus (si se confirma su presencia) y Aidophus (una de sus especies introducida desde Sudamérica). Un género, Haroldiellus, aunque autóctono de la Zona de Transición Méxicana y Centroamérica, muestra también afinidades Neotropicales. Similares a los anteriores, también se encontrarían algunos géneros extendidos por la región Afrotropical o, en general, con afinidades Gondwánicas, como Blackburneus (s.l.), Nialaphodius o Australaphodius (los dos últimos, introducidos en México). También existen especies (una de ellas por confirmar) pertenecientes al género Labarrus, de amplia distribución mundial, pero con afinidades Gondwánicas.

Otro de los factores que puede haber influido en la distribución de las especies de Aphodiinae mexicanas, aparte de los ambientales, son las interacciones bióticas de éstas con otros organismos. Hasta cierto punto, la distribución de las especies de Aphodiinae se encuentra parcialmente condicionada por la presencia de vertebrados rumiantes domesticados (vaca, caballo, oveja y cabra) o, a veces, salvajes (ciervo), que suelen encontrarse en zonas de pastizales o bosques, habitualmente en montaña. Sin embargo, si la preferencia por las condiciones ambientales templado-frías de las cadenas montañosas puede considerarse la característica más sobresaliente de la fauna de Aphodiinae mexicana, no lo es menos la existencia de un buen número de especies adaptadas hacia el consumo especializado de heces de roedores y detritos vegetales, una característica que distingue las comunidades de Scarabaeoidea coprófagas de las regiones Neártica y Paleártica (Martín-Piera \& Lobo 1996). En México, el porcentaje de especies de Aphodiinae con hábitos psammófilo-detritívoros es importante (superior al 25\%, considerando las especies con hábitos psammófilos obligados y facultativos), algunas de ellas incluso asociadas a nidos de hormigas Atta sp. (por ejemplo, especies de los géneros Diapterna, Drepanocanthoides (s.l.), Flaviellus (s.l.), Planolinoides, Xeropsamobeus (s.l.) y posiblemente Mendidius (s.l.) y Pardalosus (s.l.); Gordon \& Skelley 2007). No obstante, la característica más significativa, en cuanto a interacciones bióticas, de los Aphodiinae Neárticos es la asociación obligada de muchas especies con madrigueras de roedores, donde se alimentan directamente de sus excrementos, de la materia orgánica en descomposición presente en ellos o incluso cleptoparasitando a otras especies de coleópteros coprófagos Scarabaeinae también presentes en las madrigueras, como Onthophagus sp. Alrededor de un tercio de las especies de Aphodiinae presentes en México se encuentran adaptadas a la explotación de los nidos de tuzas (Geomyidae), ratas selváticas (Neotomae), ardillas de tierra (Spermophilus sp.) o perros de las praderas (Cynomys sp.; ver, por ejemplo, Gordon \& Skelley 2007), aunque se desconoce el grado de especificidad de cada especie de Aphodiinae a especies concretas de roedores. Así, se han observado preferencias hacia estos nidos de roedores en especies de Aphodiinae pertenecientes a los géneros Cinacanthus, Coelotrachelus, Cryptoscatomaseter (s.l.), Dellacasiellus, Geomyphilus 
(s.l.), Neotrichonotulus, Stenotothorax, Tetraclipeoides (s.l.), Xeropsamobeus (s.l.) y posiblemente también en Melinopterus (s.l.) consentaneus y Schaefferellus arizonensis.

Otra particularidad de la fauna mexicana de Aphodiinae es el importante porcentaje de especies invasoras que puede encontrase en algunos ensambles (ver Lobo 1996), un patrón comun en las especies de esta subtribu presentes en la region Neártica (Lobo 2000). Especies como Aphodius fimetarius, Calamosternus granarius, Labarrus lividus y posiblemente Nialaphodius nigrita, Otophorus haemorrhoidalis, Trichaphodiellus brasiliensis, Aidophus flaveolus y Australaphodius frenchi se encuentran distribuidas en México como consecuencia de introducciones accidentales propiciadas por el hombre desde otras regiones biogeográficas. Estas especies no deberían hallarse en México, pero han encontrado en su territorio condiciones adecuadas para su establecimiento y para el mantenimiento de sus poblaciones.

La predicción de la distribución espacial de las especies es una herramienta útil en biogeografía y en conservación. Aunque provisionales, los resultados de estos modelos pueden permitir mejorar nuestro conocimiento sobre la distribución probable de las especies, pero también ayudar a inferir los principales procesos implicados en su conformación, así como ayudar a diseñar nuevas estrategias de colecta más eficientes. Su utilización y descripción, tal y como hemos realizado en este estudio, constituye en esencia una continuación de los imprescindibles trabajos faunísticos clásicos que, con la ayuda de nuevas técnicas, han pretendido y pretenden describir la variación geografica y ambiental de la biota.

AGRADECIMIENTOS. Agradecemos a Gonzalo y Violeta Halffter, Carmen Huerta, Enrique Montes de Oca, Miguel Ángel Morón, César Vicente Rojas (Instituto de Ecología, A.C., Xalapa, Veracruz, México), Fernando Vaz de Mello (Universidade Federal de Mato Grosso, UFMT, Brasil) y Daniel Curoe por permitirnos examinar sus colecciones y/o por el material brindado. A Teresa Suárez del equipo de Imelda Martínez M. y, en general, a la Red de Ecoetología del Instituto de Ecología A.C. (Xalapa, Veracruz, México) por el apoyo ofrecido durante las diversas estancias realizadas. A dos revisores anónimos que nos ayudaron a enriquecer la presentación de este trabajo.

\section{LITERATURA CITADA}

Allende, J. \& A. Ramírez. 2005. Fauna de Coleópteros Lamelicornios de Santiago Xiacui, Sierra Norte, Oaxaca, México. Tesis de Licenciatura. Dirección General de Educación Tecnológica Agropecuaria. México D.F., México.

Alvarado, M. 2001. Datos sobre la biología y la reproducción de Aphodius (Trichaphodius) opisthius Bates, 1887 (Coleoptera: Scarabaeidae: Aphodiinae). Tesis de Licenciatura. Universidad Veracruzana, Facultad de Biología. Xalapa, Veracruz, México.

Andresen, E. 2002. Dung beetles in a Central Amazonian rainforest and their ecological role as secondary seed dispersers. Ecological Entomology, 27: 257-270. 
Anduaga, S. \& G. Halffter. 1991. Micofagia en Scarabaeidae. Pp. 151-169. In: J.L. Navarrete-Heredia and G. A. Quiroz-Rocha (Eds.). Memorias del I Simposio Nacional sobre la Interacción InsectoHongo, S. M. E., Facultad de Ciencias, IGU, Veracruz, México.

Anduaga, S. \& G. Halffter. 2000. Escarabajos coprófagos (Coleoptera: Scarabaeoidea) asociados a hongos en la Sierra Madre Occidental, Durango, México: con una compilación de las especies micetófagas. Acta Zoológica Mexicana (n.s.), 80: 119-130.

Angus, R. B., C. J. Wilson \& D. J. Mann. 2004. Chromosomal and aedeagal distinction between Aphodius (Labarrus) lividus Olivier, 1789 and A. (L.) pseudolividus Balthasar, 1941 (Col., Scarabaeidae, Aphodiinae). Entomologist's Monthly Magazine, 140: 255-261.

Araújo, M. B. \& P. H. Williams. 2000. Selecting areas for species persistence using occurrence data. Biological Conservation, 96: 331-345.

Arellano, L. 2002. Evaluación de la diversidad alfa, beta y gamma de Scarabaeoidea y Silphidae (Insecta: Coleoptera) en la región Cofre de Perote, Veracruz, México. Tesis de Maestría. Universidad Nacional Autónoma de México, México D.F., México.

Arellano, L. \& G. Halffter. 2003. Gamma diversity: derived from and a determinant of alpha diversity and beta diversity. An analysis of three tropical landscapes. Acta Zoológica Mexicana (n.s.), 90: 27-76.

Balthasar, V. 1946. De novis generis Aphodius speciebus. Acta Entomologica Musei Pragae, 24: 53-68.

Barrera, A. 1969. Coleoptera Lamellicornia en la Colección Nacional. Acta Zoológica Mexicana, 6: 1-94.

Bates, H. W. 1887. Fam. Copridae, Aphodiidae, Orphnidae, Hybosoridae, Geotrupidae, Trogidae, Aclopidae, Chasmatopteridae, Melolonthidae. Pp. 25-160. In: F.D. Godman and O. Salvin (Eds.). Biologia Centrali-Americana. Insecta, Coleoptera. Vol. II, Part 2, Pectinicornia and Lamellicornia. Porter, London.

Beaumont, L., L. Hughes \& M. Poulsen. 2005. Predicting species distributions: use of climatic parameters in BIOCLIM and its impact on predictions of species' current and future distributions. Ecological Modelling, 186: 250-269.

Blackwelder, R. E. 1944. Checklist of the coleopterous insects of Mexico, Central America, the West Indies, and South America. Bulletin of the United States Natural Museum, 185: 189-341.

Blackwelder, R. E. 1973. Checklist of the Scarabaeidae of Canada, United States, Mexico, Central America and the West Indies. Biological Research Institute of America Inc., Latham, New York, USA.

Bordat, P. 1999. Ammoecioides, nouveau genre et ses espèces (Coleoptera, Scarabaeoidea, Aphodiidae). Nouvelle Revue d'Entomologie, 16: 161-182.

Bordat, P. 2003. Haroldaphodius et Euhemicyclium nouveaux genres d'Aphodiinae et leurs espèces (Coleoptera, Scarabaeoidea). Nouvelle Revue d'Entomologie, 19: 235-248.

Bordat, P. 2009. Nouveaux taxons afrotropicaux dans la famille Aphodiidae (Coleoptera, Scarabaeoidea). Nouvelle Revue d'Entomologie, 25: 123-144.

Brotons, L., W. Thuiller, M. B. Araújo \& A. H. Hirzel. 2004. Presence-absence versus presence-only modelling methods for predicting bird habitat suitability. Ecography, 27: 437-448.

Cabrero-Sañudo, F. J. 2007. The phylogeny of Iberian Aphodiini species (Coleoptera, Scarabaeoidea, Scarabaeidae, Aphodiinae) based on morphology. Systematic Entomology, 32: 156-175.

Cabrero-Sañudo, F. J. \& J. Lobo. 2009. Biogeography of Aphodiinae dung bettles based on the regional composition and distribution patterns of genera. Journal of Biogeography, 36: 1474-1492.

Cabrero-Sañudo, F. J. \& R. Zardoya. 2004. Phylogenetic relationships of Iberian Aphodiini (Coleoptera: Scarabaeidae) based on morphological and molecular data. Molecular Phylogenetics and Evolution, 31: 1084-1100.

Cabrero-Sañudo F. J., I. Martínez M. \& N. Trotta-Moreu. 2007a. Phenology, reproductive cycles, and species composition of a dung beetle community (Coleoptera: Scarabaeoidea) from a high 
mountain pasture system on the Sierra Madre Oriental (Veracruz, Mexico). Proccedings of the Entomological Society of Washington, 109: 813-828.

Cabrero-Sañudo, F. J., M. Dellacasa, I. Martínez M. \& G. Dellacasa. 2007b. Estado actual del conocimiento de los Aphodiinae mexicanos (Coleoptera: Scarabaeoidea: Aphodiidae). Pp. 69-92. In: M. Zunino and A. Melic (Eds.). Escarabajos, diversidad y conservación biológica. Ensayos en homenaje a Gonzalo Halffter. Sociedad Entomológica Aragonesa (S.E.A.), Monografías 3ercer Milenio, Vol. 7. Zaragoza, España.

Cambefort, Y. 1991. From saprophagy to coprophagy [22-35]. In: I. Hanski and Y. Cambefort (Eds.). Dung beetle ecology. Princeton University Press, Princeton, NJ, USA.

Capistrán, F. 1992. Los coleópteros Lamelicornios del Parque de la Flora y Fauna Silvestre Tropical "Pipiapan", Catemaco, Veracruz, México. Tesis de Licenciatura. Universidad Veracruzana, Facultad de Biología. Xalapa, Veracruz, México.

Carrillo-Ruiz, H. \& M. A. Morón. 2003. Fauna de Coleoptera Scarabaeoidea de Cuetzalan del Progreso, Puebla, México. Acta Zoológica Mexicana (n.s.), 88: 87-121.

Cartwright, O. L. 1957. Three new American Aphodius with notes and a key to related species (Scarabaeidae). The Coleopterists Bulletin, 11: 55-61.

Cayuela, L., D. J. Golicher, A. Newton, M. Kolb, F. S. de Alburquerque, E. J. M. M. Arets, R. M. Alkemade \& A. M. Pérez. 2009. Species distribution modelling in the tropics: Problems, potentialities, and the role of biological data for species conservation. Tropical Conservation Science 2: 319352.Chacón, A. L. 2005. Fauna de Coleoptera Lamellicornia del municipio de San Felipe Teotlalcingo, Puebla, México. Tesis de Licenciatura. Universidad Autónoma de Puebla, Puebla, México.

Chapin, E. A. 1940. A revision of the West Indian beetles of the scarabaeid subfamily Aphodiinae. Proceedings of the United States National Museum, 89: 1-41.

Chazdon, R. L., R. K. Colwell, J. S. Denslow \& M. R. Guariguata. 1998. Statistical methods for estimating species richness of woody regeneration in primary and secondary rain forests of northeastern Costa Rica. Forest biodiversity research, monitoring and modeling. Pp. 285-309. In: F. Dallmeir and J. A. Comiskey (Eds.). Conceptual background and old world case studies. Parthenon Publishing. Paris, Francia.

Clark Labs. 2003. Idrisi Kilimanjaro. Gis software package. Clark Labs, Worcester, Massachusetts, USA.

Coates, A. G., L. S. Collins, M. P. Aubry \& W. A. Berggren. 2004. The geology of the Darien, Panama, and the late Miocene-Pliocene collision of the Panama arc with northwestern South America. Geological Society of America Bulletin, 116: 1327-1344.

Colwell, R. K. 2006. EstimateS: statistical estimation of species richness and shared species from samples. Version 8. Publicado por el autor en: http://purl.oclc.org/estimates.

Colwell, R. K. \& J. A. Coddington. 1994. Estimating terrestrial biodiversity through extrapolation. Philosophical Transactions of the Royal Society of London Series B, 345: 101-118.

Cox, C. B. \& P. D. Moore. 1993. Biogeography; an evolutionary and approach, 5th ed. Blackwell Science, Oxford, Reino Unido.

Cruz, M., I. Martínez M. \& M. Alvarado. 2002. Population and reproductive features of Aphodius (Trichaphodius) opisthius Bates and Cephalocyclus hogei Bates (Coleoptera, Aphodiidae: Aphodiinae). The Coleopterists Bulletin, 56: 221-235.

Davis, A. L. V. \& C. H. Scholtz. 2001. Historical vs. ecological factors influencing global patterns of scarabaeine dung beetle diversity. Diversity and Distributions, 7: 161-174.

Dejean, P. F. M. A. 1833. Catalogue des Coleopteres de la collection de M. le Comte Dejean (2me Ed.). Mequignon-Marvis p. \& f., Paris, Francia. 
Delgado, L. L. 1989. Fauna de Coleópteros Lamellicornios de Acahuizotla, Guerrero, México. Tesis de Licenciatura. Universidad Nacional Autónoma de México, México D.F., México.

Delgado, L. \& J. Márquez. 2006. Estado del conocimiento y conservación de los coleópteros Scarabaeoidea (Insecta) del estado de Hidalgo, México. Acta Zoológica Mexicana (n.s.), 22: 57-108.

Dellacasa, G. 1986. A world-wide revision of Aphodius sharing a large scutellum (Coleoptera Scarabaeidae Aphodiinae). Frustula Entomologica, 7-8: 173-282.

Dellacasa, G. \& M. Dellacasa. 2006. Coleoptera, Aphodiidae, Aphodiinae. Fauna d'Italia XLI. Edizioni Calderini, Bologna, Italia.

Dellacasa, G. \& R. D. Gordon. 1994. North American genus-group taxa of Aphodiini and their type species (Coleoptera Aphodiidae). Frustula Entomologica, 17: 157-174.

Dellacasa, G., P. Bordat \& M. Dellacasa. 2001a. A revisional essay of world genus-group taxa of Aphodiinae (Coleoptera Aphodiidae). Memorie della Società Entomologica Italiana, 79: 1-482.

Dellacasa, M. 1987a. Contribution to a world-wide catalogue of Aegialiidae, Aphodiidae, Aulonocnemidae, Termitotrogidae. Memorie della Società Entomologica Italiana, 66: 1-456.

Dellacasa, M. 1987b. Contribution to a world-wide catalogue of Aegialiidae, Aphodiidae, Aulonocnemidae, Termitotrogidae. Supplemento Memorie della Società Entomologica Italiana, 67: 1-231.

Dellacasa, M. 1988a. Contribution to a world-wide catalogue of Aegialiidae, Aphodiidae, Aulonocnemidae, Termitotrogidae (Part II). Memorie della Società Entomologica Italiana, 67: 1-237.

Dellacasa, M. 1988b. Contribution to a world-wide catalogue of Aegialiidae, Aphodiidae, Aulonocnemidae, Termitotrogidae. Addenda et corrigenda (First Note). Memorie della Società Entomologica Italiana, 67: 291-316.

Dellacasa, M. 1991. Contribution to a world-wide catalogue of Aegialiidae, Aphodiidae, Aulonocnemidae, Termitotrogidae. Addenda et corrigenda (Second Note). Memorie della Società Entomologica Italiana, 70: 3-57.

Dellacasa, M. 1995. Contribution to a world-wide catalogue of Aegialiidae, Aphodiidae, Aulonocnemidae, Termitotrogidae. Addenda et corrigenda (Third Note). Memorie della Società Entomologica Italiana, 74: 159-232.

Dellacasa, M. \& G. Dellacasa. 2000a. Systematic revision of the genera Euheptaulacus G. Dellacasa, 1983 and Heptaulacus Mulsant, 1842 with description of the new genus Pseudoheptaulacus (Coleoptera: Scarabaeoidea: Aphodiidae). Elytron, 14: 3-37.

Dellacasa, M. \& G. Dellacasa. 2000b. Systematic revision of the genus Erytus Mulsant \& Rey, 1870, and description of the new genus Sahlbergianus (Coleoptera: Aphodiidae). Frustula Entomologica, 23: 109-130.

Dellacasa, M. \& G. Dellacasa. 2003. Review of the genus Aphodius (Coleoptera: Aphodiidae). Folia Heyrovskyana, 11: 173-202.

Dellacasa, M. \& G. Dellacasa. 2005. Comments on some systematic and nomenclatural questions in Aphodiinae with descriptions of new genera and on Italian taxa (Coleoptera Aphodiidae). Memorie della Società Entomologica Italiana, 84: 45-101.

Dellacasa, M. \& Z. Stebnicka. 2001. A new genus for Oxyomus morosus Harold, 1869 (Eupariini) and redefinition of Oxyomus setosopunctatus A. Schmidt, 1911 (Aphodiini) (Coleoptera Scarabaeidae: Aphodiinae). Acta Zoológica Mexicana (n.s.), 83: 29-34.

Dellacasa, M., G. Dellacasa \& P. Bordat. 2002a. Systematic redefinition of taxa belonging to the genera Ahermodontus Báguena, 1930 and Ammoecius Mulsant, 1842, with description of the new genus Vladimirellus (Coleoptera; Aphodiidae). Acta Zoologica Academiae Scientiarum Hungaricae, 48: 269-316.

Dellacasa, M., G. Dellacasa \& R. D. Gordon. 2007a. Systematic revision of the genus Cephalocyclus with description of eight new species from Mexico. Acta Zoológica Mexicana (n.s.), 23: 89-128. 
Dellacasa, M., G. Dellacasa \& R. D. Gordon. 2007b. Ferrerianus, new genus for Aphodius biimpressus Schmidt A., 1909 (Scarabaeoidea: Aphodiidae). Insecta Mundi, 11: 1-4.

Dellacasa, M., G. Dellacasa \& R. D. Gordon. 2008. Agrilinellus, new genus and four new species of Mexican Aphodiini (Scarabaeoidea: Scarabaeidae: Aphodiinae). Insecta Mundi, 53: 1-16.

Dellacasa, M., G. Dellacasa \& R. D. Gordon. 2009. Systematic revisión of the genus Coelotrachelus Schmidt, 1913 (Scarabaeoidea: Scarabaeidae: Aphodiinae). Insecta Mundi, 86: 1-13.

Dellacasa, M., R. D. Gordon \& G. Dellacasa. 1998. The types of Aphodius species described by Harold from Mexico with description of a new genus (Coleoptera Scarabaeoidea: Aphodiidae). Acta Zoológica Mexicana (n.s.), 74: 139-162.

Dellacasa, M., R. D. Gordon \& G. Dellacasa. 2000. Aphodius (Platyderides) pullatus A. Schmidt, 1913, another Mexican taxon to be moved into the genus Cephalocyclus and remarks on Cephalocyclus mexicanus (Harold, 1862) and Aphodius freyi Balthasar, 1941 (Coleoptera Scarabaeoidea: Aphodiidae). Acta Zoológica Mexicana (n.s.), 79: 11-15.

Dellacasa, M., R. D. Gordon \& G. Dellacasa. 2002b. Aphodiinae described or recorded by Bates in Biología Centrali-Americana (Coleoptera Scarabaeoidea: Aphodiidae). Acta Zoológica Mexicana (n.s.), 86: 155-223.

Dellacasa, M., R. D. Gordon \& G. Dellacasa. 2003. Jalisco plumipes, new genus and new species of Mexican Aphodiini (Scarabaeoidea: Aphodiidae). Insecta Mundi, 17: 69-71.

Dellacasa, M., R. D. Gordon \& G. Dellacasa. 2004a. Systematic redefinition of Calamosternus colimaensis (Hinton, 2934) and its sibling species, Calamosternus uniplagiatus (Waterhouse, 1875) (Scarabaeoidea: Aphodiidae). Folia Entomológica Mexicana, 43: 131-134.

Dellacasa, M., R. D. Gordon \& G. Dellacasa. 2004b. Neotrichonotulus, a new genus for three Mexican Aphodiini (Scarabaeoidea, Aphodiidae). Acta Zoológica Mexicana (n.s.), 20: 1-7.

Dellacasa, M., R. D. Gordon \& G. Dellacasa. 2004c. Systematic redefinition of Planolinus pratensis and Planolinus tenellus, and remarks on their sibling species Planolinus uliginosus (Coleoptera Aphodiidae). Bolletino della Societá entomologica italiana, 136: 37-45.

Dellacasa, M., R. D. Gordon \& G. Dellacasa. 2007c. Systematic review to the genus Liothorax (Coleoptera: Scarabeoidea: Scarabaeidae: Aphodiinae). Zootaxa, 1407: 23-42.

Dellacasa, M., R. D. Gordon \& G. Dellacasa. 2007d. Pseudogonaphodiellus zdzislawae, new genus and new species of Mexican Aphodiini (Scarabaeoidea: Aphodiidae). Acta Zoologica Cracoviensia, 50: $139-142$.

Dellacasa, M., R. D. Gordon, P. J. Harpootlian, Z. Stebnicka \& G. Dellacasa. 2001b. Systematic redefinition of the New World Didactyliini (Coleoptera: Scarabaeidae: Aphodiinae) with descriptions of two new species of Aidophus Balthasar. Insecta Mundi, 15: 193-216.

Deloya, C. 1987. Fauna de Coleópteros Lamelicornios del Sur de Morelos, México Tesis de Licenciatura. Universidad Nacional Autónoma de México. México D.F., México.

Deloya, C. 1988. Coleópteros Lamelicornios asociados a depósitos de detritos de Atta mexicana (Smith) (Hymenoptera: Formicidae) en el sur del estado de Morelos, México. Folia Entomológica Mexicana, 75: 77-91.

Deloya, C. 1991. Una nueva especie mexicana de Aphodius (Coelotrachelus) Schmidt 1913 (Coleoptera: Scarabaeidae: Aphodiinae) asociada con Thomomys umbrinus (Rodentia: Geomyidae). Folia Entomológica Mexicana, 81: 199-207.

Deloya, C. 1992a. Lista de las especies de Coleoptera Lamellicornia del estado de Veracruz, México (Passalidae, Trogidae, Lucanidae, Scarabaeidae y Melolonthidae). Boletín de la Sociedad Veracruzana de Zoología, 2: 19-32.

Deloya, C. 1992b. Necrophilous Scarabaeidae and Trogidae beetles of tropical deciduous forest in Tepexco, Puebla, México. Acta Zoológica Mexicana (n.s.), 52: 1-13. 
Deloya, C. 1994 Distribución del género Ataenius Harold, 1867 en México (Coleoptera: Scarabeidae: Aphodiinae, Eupariini). Acta Zoológica Mexicana (n.s.), 61: 43-56.

Deloya, C. 1995. Los Coleópteros Scarabaeidae y Trogidae necrófilos de la parte alta de la cuenca de Las Balsas (México). Memorias de la II Reunión Latinoamericana de Scarabaeoidología. Santafé de Bogotá, Colombia.

Deloya, C. 1996. Los macro-coleópteros necrófilos de Tepoztlán, Morelos, México (Scarabaeidae, Trogidae, Silphidae). Folia Entomológica Mexicana, 97: 39-54.

Deloya, C. 1998. Primer registro de Cephalocyclus mexicanus (Harold, 1862) para el estado de Morelos, México (Coleoptera: Scarabaeidae, Aphodiinae). Folia Entomológica Mexicana, 103: 101-102.

Deloya, C. 1999. Notas sobre algunos Aphodiinae de Veracruz, México (Coleoptera: Scabaeidae). Acta Zoológica Mexicana (n.s.), 78: 171-172.

Deloya, C. 2003a. Subfamilia Aphodiinae. Pp. 75-93. In: M.A. Morón (Ed.). Atlas de los escarabajos de México. Coleóptera: Lamellicornia. Vol. II Familias Scarabaeidae, Trogidae, Passalidae y Lucanidae. Argania Editio, Barcelona, España.

Deloya, C. 2003b. Coleoptera Scarabaeidae y Trogidae necrófilos de Valle de Vázquez ("Los Hornos"), Morelos, México. Folia Entomológica Mexicana, 42: 265-272.

Deloya, C. \& S. Ibáñez-Bernal. 2000. New species of Aphodiinae from Mexico and a key to species of Cephalocyclus Dellacasa, Gordon and Dellacasa (Coleoptera: Scarabaeidae). The Coleopterists Bulletin, 54: 318-324.

Deloya, C. \& J. M. Lobo. 1995. Descripción de dos nuevas especies mexicanas de Aphodius de los subgéneros Platyderides y Trichonotulus (Coleoptera: Scarabaeidae: Aphodiinae) asociadas con Pappogeomys merriami (Rodentia: Geomyidae). Folia Entomológica Mexicana, 94: 41-55.

Deloya, C. \& J. D. McCarty. 1992. Descripción de una especie nueva de Aphodius (Coelotrachelus) (Aphodiinae) y de la hembra de Parachrysina parapatrica (Rutelinae) (Coleoptera: Lamellicornia). Acta Zoológica Mexicana (n.s.), 53: 1-13.

Deloya, C. \& M. A. Morón. 1998. Scarabaeoidea (Insecta: Coleoptera) necrófagos de "Los Tuxtlas", Veracruz y Puerto Ángel, Oaxaca, México. Dugesiana, 5: 17-28.

Deloya, C., M. A. Morón \& J. M. Lobo. 1995. Coleoptera Lamellicornia (MacLeay, 1819) del sur del estado de Morelos, México. Acta Zoológica Mexicana (n.s.), 65: 1-42.

Deloya, C., V. Parra-Tabla \& H. Delfín-González. 2007. Fauna de coleópteros Scarabaeidae Laparosticti y Trogidae (Coleoptera: Scarabaeoidea) asociados al bosque mesófilo de montaña, cafetales bajo sombra y comunidades derivadas en el centro de Veracruz, México. Neotropical Entomology, 36: 5-21.

Deloya, C., A. Burgos, J. Blackaller \& J. M. Lobo. 1993. Los Coleópteros Lamelicornios de Cuernavaca, Morelos, México (Passalidae, Trogidae, Scarabaeidae y Melolonthidae). Boletín de la Sociedad Veracruzana de Zoología, 3: 15-55.

Domínguez-Domínguez, O., E. Martínez-Meyer, L. Zambrano \& G. Pérez-Ponce de León. 2006. Using ecological-niche modeling as a conservation tool for freshwater species: live-bearing fishes in central Mexico. Conservation Biology, 30: 1730-1739.

Elith, J., C. H. Graham, R. P. Anderson, M. Dudik, S. Ferrier, A. Guisan, R. J. Hijmans, F. Huettmann, J. R. Leathwick, A. Lehmann, J. Li, L. G. Lohmann, B. A. Loiselle, G. Manion, C. Moritz, M. Nakamura, Y. Nakazawa, J. M. Overton, A. T. Peterson, S. J. Phillips, K. Richardson, R. Scachetti-Pereira, R. E. Schapire, J. Soberón, S. Williams, M. S. Wisz \& N. E. Zimmermann. 2006. Novel methods improve prediction of species' distributions from occurrence data. Ecography, 29: 129-151. 
Escoto, J. 1984. Análisis de la fauna de Coleópteros Scarabaeidae y Melolonthidae de Calvillo, Estado de Aguascalientes. Tesis de Licenciatura. Universidad Autónoma de Aguascalientes. Aguascalientes, México.

Fielding, A. H. \& P. F. Haworth. 1995. Testing the generality of bird-habitat models. Conservation Biology, 9: 1466-1481.

Galante, E., Z. Stebnicka \& J. R. Verdú. 2003. The Aphodiinae and Rhyparinae (Coleoptera: Scarabaeidae) in southern states of Mexico (Chiapas, Oaxaca, Puebla and Veracruz). Acta Zoologica Cracoviensia, 46: 283-312.

García, A. 2006. Using ecological niche modelling to identify diversity hotspots for the herpetofauna of Pacific lowlands and adjacent interior valleys of Mexico. Biological Conservation, 130: 25-46.

García-Real, E. 1995. Abundancia, distribución y estructura de la comunidad de escarabajos coprófagos y necrófagos (Coleoptera: Scarabaeidae), en un gradiente altitudinal de la sierra de Manantlán, Jalisco-Colima. Master Degree Thesis. Colegio de Postgraduados. Montecillo, Estado de México, México.

Gordon, R. D. 1976. Studies on the genus Aphodius of the US and Canada IV. A taxonomic revision of Horn's group A. Proceedings of the Entomological Society of Washington, 78: 458-478.

Gordon, R. D. 1977. A new species of Aphodius (Coleoptera: Scarabaeidae) from sand dunes in Chihuahua, Mexico. Proceedings of the Biological Society of Washington, 90: 232-236.

Gordon, R. D. \& H. F. Howden. 1973. Five new species of Mexican Aphodius (Coleoptera: Scarabaeidae) associated with Thomomys umbrinus (Geomyidae). Annals of the Entomological Society of America, 66: 436-443.

Gordon, R. D. \& P. E. Skelley. 2007. A monograph of the Aphodiini inhabiting the United States and Canada (Coleoptera: Scarabaeidae: Aphodiinae). Memoirs of the American Entomological Institute, 79: $1-580$.

Guisan, A. \& N. E. Zimmermann. 2000. Predictive habitat distribution models in ecology. Ecological Modelling, 135: 147-186.

Halffter, G. 1987. Biogeography of the montane entomofauna of Mexico and Central America. Annual Review of Entomology, 32: 95-114.

Halffter, G. \& D. Edmonds. 1982. The nesting behaviour of dung beetles (Scarabaeinae). An ecological and evolutive approach. Instituto de Ecología, A.C., Xalapa, Veracruz, México.

Hanski, I. 1991. North temperate dung beetles [75-96]. In: I. Hanski and Y. Cambefort (Eds.). Dung beetle ecology. Princeton University Press, Princeton, NJ, USA.

Harold, E. von. 1862. Beitrage zur Kenntniss einiger coprophagen Lamellicornien. (Viertes Stuck). Berliner Entomologische Zeitshrift, 6: 379-403.

Hijmans, R. J., S. Cameron, J. Parra, P. Jones, A. Jarvis \& K. Richardson. 2006. World-Clim versión 1.4. Museum of Vertebrate Zoology of the University of California, CIAT, and Rainforest CRC. http://www.worldclim.org

Hinton, H. E. 1934a. Two genera of Aphodiinae new to Mexico. Pan-Pacific Entomologist, 10: 27-30.

Hinton, H. E. 1934b. New species of North American Aphodius (Col., Scarabaeidae). Stylops, 3: 188200.

Hinton, H. E. 1938. New species of Neotropical Aphodiinae (Col. Scarabaeidae). Revista de Entomología, Río de Janeiro, 8: 122-129.

Hinton, H. E. \& L. Ancona. 1934. Fauna de Coleópteros en nidos de hormigas (Atta), en México y Centro América. Anales del Instituto de Biología de la Universidad Nacional Autónoma de México, 5: 243-248. 
Hinton, H. E. \& L. Ancona. 1935. Fauna de Coleópteros en nidos de hormigas (Atta), en México y Centro América II. Anales del Instituto de Biología de la Universidad Nacional Autónoma de México, 3-4: 307-316.

Horn, G. H. 1887. A monograph of the Aphodiini inhabiting the United States. Transactions of the American Entomological Society, 14: 1-111.

Hortal, J. \& J. M. Lobo. 2006. Towards a synecological framework for systematic conservation planning. Biodiversity Informatics, 3: 16-45.

Hortal, J., J. M. Lobo \& A. Jiménez-Valverde. 2007. Limitations of biodiversity databases: case study on seed-plant diversity in Tenerife, Canary Islands. Conservation Biology, 21: 853-863.

Islas, F. 1945. Un género y tres especies nuevos de Aphodiinos mexicanos. Anales del Instituto de Biología de la Universidad Nacional Autónoma de México, 16: 451-457.

Islas, F. 1955a. Tres especies nuevas de Aphodinos mexicanos (Ins. Col. Scarabaeidae) Anales del Instituto de Biología de la Universidad Nacional Autónoma de México, 26: 493-499.

Islas, F. 1955b. Nuevas especies mexicanas del género Aphodius Ill. (Ins. Col. Scarabaeidae). Anales del Instituto de Biología de la Universidad Nacional Autónoma de México, 26: 223-227.

Islas, F. 1958. Un género y especie nuevos de la subfamilia Aphodiinae en México, (Col. Scarabaeidae). Anales del Instituto de Biología de la Universidad Nacional Autónoma de México, 26: 343-348.

Jiménez-Valverde, A., J. M. Lobo \& J. Hortal. 2008. Not as good as they seem: the importance of concepts in species distribution modelling. Diversity and Distributions, 14: 885-890.

Koçak, A. Ö. \& M. Kemal. 2008. Nomenclatural notes on the genus-group names in the order Coleoptera. Miscellaneous Papers, Centre for Entomological Studies Ankara, 144: 5.

Kohlmann, B. 1991. Dung beetles in subtropical North America. Pp. 116-132. In: Hanski, I. and Y. Cambefort (Eds.). Dung beetle ecology. Princeton University Press, Princeton, New Jersey, USA.

Lobo, J. M. 1996. Diversity, biogeographical considerations and spatial structure of a recently invaded dung beetle (Coleoptera: Scarabaeoidea) community in the Chihuahuan desert. Global Ecology and Biogeography Letters, 5: 342-352.

Lobo, J. M. 2000. Species diversity and composition of dung beetle (Coleoptera: Scarabaeoidea) assemblages in North America. The Canadian Entomologist, 132: 307-321.

Lobo, J. \& G. Halffter. 1994. Relaciones entre escarabajos (Coleoptera: Scarabaeidae) y nidos de tuza (Rodentia: Geomyidae): implicaciones biológicas y biogeográficas. Acta Zoológica Mexicana (n.s.), 62: 1-9.

Lobo, J. M. \& G. Halffter. 2000. Biogeographical and ecological factors affecting the altitudinal variation of mountainous communities of coprophagous beetles (Coleoptera: Scarabaeoidea): a comparative study. Annals of the Entomological Society of America, 93: 115-126.

Lobo, J. M. \& M. A. Morón. 1993. La modificación de las comunidades de coleópteros Melolonthidae y Scarabaeidae en dos áreas protegidas mexicanas tras dos décadas de estudios faunísticos. Giornale italiano d'Entomologia, 6: 391-406.

Márquez, J. \& J. Asiain. 2000. La colección de Coleoptera (Insecta) del Museo de Zoología “Alfonso L. Herrera", Facultad de Ciencias, UNAM, México. Acta Zoológica Mexicana (n.s.), 79: 241-255.

Martínez M., I. 2003. Spermatophore in Aphodiinae (Coleoptera: Scarabaeidae). Proceedings of the Entomological Society of Washington, 105: 982-989.

Martínez M., I. 2005. Abundancias poblaciones y ciclos reproductivos de tres especies de escarabajos estercoleros (Coleoptera: Aphodiinae: Aphodiini) del volcán Cofre de Perote, Veracruz, México. Folia Entomológica Mexicana, 44: 27-36.

Martínez M., I. \& M. Alvarado. 2001. Comportamiento de oviposición en Aphodius opisthius Bates, 1887 (Coleoptera: Scarabaeoidea: Aphodiidae). Elytron, 15: 73-78. 
Martínez M., I. \& M. Cruz. 2002. Fenología y ciclos reproductivos en Ataenius apicalis Hinton y A. sculptor Harold (Coleoptera, Aphodiidae). Bulletin de la Société Entomologique de France, 107: 177-186.

Martínez M., I. \& M. T. Suárez. 2006. Phenology, trophic preferences, and reproductive activity in some dung-inhabiting beetles (Coleoptera: Scarabaeoidea) in El Llano de las Flores, Oaxaca, Mexico. Proceedings of the Entomological Society of Washington, 108: 774-784.

Martínez M., I., M. Cruz \& J. P. Lumaret. 2000. Efecto del diferente manejo de los pastizales y del ganado sobre los escarabajos coprófagos Ataenius apicalis Hinton y Ataenius sculptor Harold (Scarabaeidae: Aphodiinae: Esupariini). Acta Zoológica Mexicana (n.s), 80: 185-196.

Martínez M., I., C. Deloya \& M. Dellacasa. 2001. Anatomical and functional data on female and male reproductive systems of some dung beetle species of Aphodiinae and Eupariinae of Mexico (Coleoptera: Scarabaeoidea: Aphodiidae). Proceedings of the Entomological Society of Washington, 103: 227-248.

Martín-Piera, F. \& J. M. Lobo. 1993. Altitudinal distribution patterns of copro-necrophage Scarabaeoidea (Coleoptera) in Veracruz, México. The Coleopterists Bulletin, 47: 321-334.

Martín-Piera, F. \& J. M. Lobo. 1996. A comparative discussion of trophic preferences in dung beetle communities. Miscellania Zoologica, 19: 13-31.

Masumoto, K. \& M. Kiuchi. 2001. A new apterous Aphodiine (Coleoptera, Scarabaeidae) from Southwest China, with proposal of a new subgenus. Elytra, 29: 119-123.

Morales, A. 1998. Análisis de la Coleopterofauna necrófila de "Las Escolleras", Alvarado, Veracruz, México. Tesis de Licenciatura. Universidad Nacional Autónoma de México. México D.F., México.

Morales, A., S. Chazaro \& J. R. Padilla. 1998. Análisis de la comunidad de Coleoptera Necrófilos de "Las Escolleras", Alvarado, Veracruz, México. Dugesiana, 5: 23-40.

Morón, M. A. 1979. Fauna de Coleópteros Lamelicornios de la Estación de Biología Tropical, "Los Tuxtlas", Veracruz, UNAM. México. Anales del Instituto de Biología de la Universidad Nacional Autónoma de México, 50: 375-454.

Morón, M. A. 1994. Fauna de Coleoptera Lamellicornia en las montañas del noreste de Hidalgo, México. Acta Zoológica Mexicana (n.s.), 63: 7-59.

Morón, M. A. \& C. Deloya. 1991. Los coleópteros lamelicornios de la Reserva de la Biosfera "La Michilia”, Durango, México. Folia Entomológica Mexicana, 81: 209-283.

Morón, M. A. \& S. Zaragoza. 1976. Coleópteros Melolonthidae y Scarabaeidae de Villa de Allende, Estado de México. Anales del Instituto de Biología de la Universidad Nacional Autónoma de México, 47: 83-118.

Morón, M. A., C. Deloya \& L. Delgado-Castillo. 1988. Fauna de Coleópteros Melolonthidae, Scarabaeidae y Trogidae de la región de Chamela, Jalisco, México. Folia Entomológica Mexicana, 77: 313-378.

Morón, M. A., F. J. Villalobos \& C. Deloya. 1985. Fauna de coleópteros lamelicornios de Boca del Chajul, Chiapas, México. Folia Entomológica Mexicana, 66: 57-118.

Morón, M. A., A. Aragón, A. M. Tapia-Rojas \& R. Rojas-García. 2000. Coleoptera Lamellicornia de la Sierra del Tentzo, Puebla, México. Acta Zoológica Mexicana (n.s.), 79: 77-102.

Morón, M. A., C. Deloya, A. Ramírez-Campos \& S. Hernández-Rodríguez. 1998. Fauna de Coleoptera Lamellicornia de la región de Tepic, Nayarit, México. Acta Zoológica Mexicana (n.s.), 75: 73-116.

Muñoz, A. 2003. Estudio de los Coleópteros Lamellicornia o Scarabaeoidea del municipio de Teziutlán, Puebla, México. Tesis de Licenciatura. Universidad Autónoma de Puebla. Puebla, México.

Muñoz, A., M. A. Morón \& A. Aragón. 2008. Coleoptera Scarabaeoidea de la región de Teziutlán, Puebla, México. Acta Zoológica Mexicana (n.s.), 24: 55-78. 
Navarrete-Heredia, J. L. 2001. Beetles associated with Atta and Acromyrmex ants (Hymenoptera: Formicidae: Attini). Transactions of the American Entomological Society, 127: 381-429.

Navarrete-Heredia, J. L. 2006. Notes on three adventive species of Coleoptera (Hydrophilidae and Scarabaeidae) from Baja California, with additional data from other Mexican states. Entomological News, 117: 211-218.

Navarrete-Heredia, J. L. \& J. Cortés. 2004. Beetles (Coleoptera) associated with the external debris of Atta mexicana (F. Smith) (Hymenoptera: Formicidae) from Ojuelos, Jalisco, México. Proceedings of the Entomological Society of Washington, 106: 481-482.

Navarrete-Heredia, J. L. \& C. Deloya. 2005. Comentarios sobre algunas especies de Aphodiinae (Coleoptera: Scarabaeidae) de Jalisco, México. Dugesiana, 12: 19-21.

Navarrete-Heredia, J. L. \& G. A. Quiroz-Rocha. 2000. Macro-coleópteros necrófilos de San José de los Laureles, Morelos, México (Coleoptera: Scarabaeidae y Silphidae). Folia Entomológica Mexicana, 110: 1-13.

Navarrete-Heredia, J. L., L. Delgado \& H. E. Fierros-López. 2001. Coleoptera Scarabaeoidea de Jalisco, México. Dugesiana, 8: 37-93.

Ochi, T. \& M. Kawahara. 2001. A new subgenus and species of the genus Aphodius Illiger from Central Japan (Coleoptera, Aphodiidae). Kogane, 2: 59-63.

Ordóñez, M. M. 2005. Colección de Coleoptera (Insecta) de la Facultad de Estudios Superiores Zaragoza, UNAM. Acta Zoológica Mexicana (n.s.), 21: 95-106.

Ortega-Huerta, M. A. \& A. T. Peterson. 2004. Modelling spatial patterns of biodiversity for conservation priorization in north-eastern Mexico. Diversity and Distributions, 10: 39-54.

Peraza, L. N. 2004. Fauna de Scarabaeidae y Trogidae (Coleoptera: Scarabaeoidea) de dos comunidades vegetales de Yucatán. Tesis de Licenciatura. Instituto Tecnológico Agropecuario $\mathrm{n}^{\circ} 2$ "Ing. José Alberto Navarrete Ruiz". Conkal, Yucatán, México.

Percino-Figueroa, S. M. 2002. Fauna de Coleóptera: Lamellicornia del municipio de Zacatlán, Puebla, Mex. Tesis de Licenciatura. Universidad Autónoma de Puebla. Puebla, México.

Peterson, A. T. 2006. Uses and requirements of ecological niche models and related distributional models. Biodiversity Informatics, 3: 59-72.

Petrovitz, R. 1961. Neue und verkannte Aphodiinae aus allen Erdteilen (Col. Scarab.) Entomologische Arbeiten aus dem Museum Georg Frey, 12: 99-135.

Phillips, S. J. \& M. Dudik. 2008. Modeling of species distributions with Maxent: new extensions and a comprehensive evaluation. Ecography, 31: 161-175.

Pineda, E. \& J. M. Lobo. 2009. Assessing the accuracy of species distribution models to predict amphibian species richness patterns. Journal of Animal Ecology, 78: 182-190.

Potts, R. \& A. K. Behrensmeyer. 1993. Late Cenozoic terrestrial ecosystems. Pp. 419-541. In: A.K. Behrensmeyer, J. D. Damuth, W. A. DiMichele, R. Potts, H. D. Sues and S. L. Wing (Eds.). Terrestrial ecosystems through time. University of Chicago Press, Chicago, USA.

Pulliam, H. R. 2000. On the relationship between niche and distribution. Ecology Letters 3: 349-361.

Rencher, A. C. 2002. Methods of Multivariate Analysis. Second edition. John Wiley \& Sons, New York, USA.

Rojas, P. 1989. Entomofauna asociada a los detritos de Atta mexicana (F. Smith) (Hymenoptera: Formicidae) en una zona árida del centro de México. Acta Zoológica Mexicana (n.s.) 33: 1-51.

Ruiz-Colorado, N. I. 2001. Los Coleópteros Scarabaeoidea (Insecta) de la Reserva Ecológica "Río Pancho Poza”, Altotonga, Veracruz, México. Tesis de Licenciatura. Universidad Veracruzana, Facultad de Biología. Xalapa, Veracruz, México.

Scotese, C. R. 2003. Paleomap project home page. http://www.scotese.com. 
Segurado, P. \& M. B. Araújo. 2004. An evaluation of methods for modelling species distributions. Journal of Biogeography 31: 1555-1569.

Skelley, P. E., M. Dellacasa, G. Dellacasa \& R. D. Gordon. 2007. Checklist of the Aphodiini of Mexico, Central and South America (Coleoptera: Scarabaeidae: Aphodiinae). Insecta Mundi, 14: 1-14.

Smith, A. B. T. 2003. Checlist of the Scarabaeoidea of the Nearctic Realm. Publicado en Internet como Papers in Entomology, por el Museum de la University of Nebraska State, Lincoln, Nebraska, USA: http://digitalcommons.unl.edu/cgi/viewcontent.cgi?article=1002\&context=entomologypapers.

Smith, A. B. T. 2006. A review of the family-group names for the superfamily Scarabaeoidea (Coleoptera) with corrections to nomenclature and a current classification. Coleopterists Society Monograph, 5: 144-204.

Soberón, J. \& A. T. Peterson. 2004. Biodiversity informatics: managing and applying primary biodiversity data. Philosophical Transactions of the Royal Society of London series B, 359: 689-698.

Soberón, J. \& A. T. Peterson. 2005. Interpretation of models of fundamental ecological niches and species' distributional areas. Biodiversity Informatics, 2: 1-10.

Sokal, R. R. 1979. Testing statistical significance of geographic variation patterns. Systematic Zoology, 28: $627-632$.

Stebnicka, Z. 2000. A new genus for Nearctic Pleurophorus ventralis Horn, 1887, with phylogenetic inferences (Coleoptera: Scarabaeidae: Aphodiinae: Aphodiini). Acta Zoologica Cracoviensia, 43: 287-291.

Stebnicka, Z. \& H. F. Howden. 1995. Revision of Australian genera in the tribes Aphodiini, Aegialiini and Proctophanini (Coleoptera: Scarabaeidae: Aphodiidae). Invertebrate Taxonomy, 9: 709-766.

Stockman, A. K., D. A. Beamer \& J. E. Bond. 2006. An evaluation of a GARP model as an approach to predicting the spatial distribution of non-vagile invertebrate species. Diversity and Distributions, 12: 81-89.

Stockwell, D. R. B. \& A. T. Peterson. 2002. Effects of sample size on accuracy of species distribution models. Ecological Modelling, 148: 1-13.

Terrón, R. A., S. Anduaga \& M. A. Morón. 1991. Análisis de la coleopterofauna necrófila de la Reserva de la Biosfera "La Michilía”, Durango, México. Folia Entomológica Mexicana, 81: 315324.

Thomas, D. B. 1993. Scarabaeidae (Coleoptera) of the Chiapanecan forests: a faunal survey and chorographic analysis. The Coleopterists Bulletin, 47: 363-408.

Trotta-Moreu, N., J. M. Lobo \& F. J. Cabrero-Sañudo. 2008. Distribución conocida y potencial de las especies de Geotrupidae (Coleoptera: Scarabaeoidea) en México. Acta Zoologica Mexicana (n.s.), 24: 39-65.

Trotta-Moreu, N. \& J. M. Lobo. 2010. Deriving a species richness distribution from the overlap of individual model predictions: The distribution of Geotrupinae (Coleoptera: Scarabaeoidea) species in Mexico. Environmental Entomology, 39: 42-49.

Vaughan, I. P. \& S. J. Ormerod. 2005. The continuing challenges of testing species distribution models. Journal of Applied Ecology, 42: 720-730.

Verdú , J.R. \& E. Galante. 1997. Aphodius brasiliensis Castelnau (Coleoptera: Aphodiidae): larval morphology and notes on biology. Coleopterists Bulletin, 51: 378-383.

Verdú, J.R. \& J. M. Lobo. 2008. Ecophysiology of thermoregulation in endothermic dung beetles: ecological and geographical implications. Pp. 1-28. In: S. Fattorini (Ed.). Insect Ecology and Conservation. Research Signpost, Kerala, India. 
Villalobos, F. J. 1985. Análisis de una comunidad de Coleópteros edafícolas de un pastizal de Laguna Verde, Veracruz. Tesis de Licenciatura. Universidad Nacional Autónoma de México. México D.F., México.

Webb, S. D. 1985. Late Cretaceous mammal dispersals between the Americas. Pp. 357-386. In: F.G. Stehli and S. D. Webb (Eds.). The great American biotic interchange. Plenum Press, New York.

Whittaker, R. J., M. B. Araújo, P. Jepson, R. J. Ladle, J. E. M. Watson \& K. J. Willis. 2005. Conservation biogeography: assessment and prospect. Diversity and Distributions, 11: 3-23.

Woodruff, R. E. \& O. L. Cartwright. 1967. A review of the genus Euparixia with description of a new species from nests of leaf-cutting ants in Louisiana (Coleoptera: Scarabaeidae). Proceedings of the United States National Museum, 123: 1-21.

Zaragoza, S. 1974. Coleópteros de algunas bromelias epífitas y doce nuevos registros de especies para la fauna mexicana. Anales del Instituto de Biología de la Universidad Nacional Autónoma de México, 29: 111-118.

Ziani, S. 2002. A new genus and species of Aphodiini (Coleoptera: Aphodiidae) inhabiting burrows of small mammals in Lebanon's mountains. Zoology in the Middle East, 27: 101-106.

Zunino, M. \& G. Dellacasa. 1989. Redescripción de Aphodius diminutus Bates con notas sobre su distribución y ecología. Bolletino della Societá entomologica italiana, 121: 59-63. 


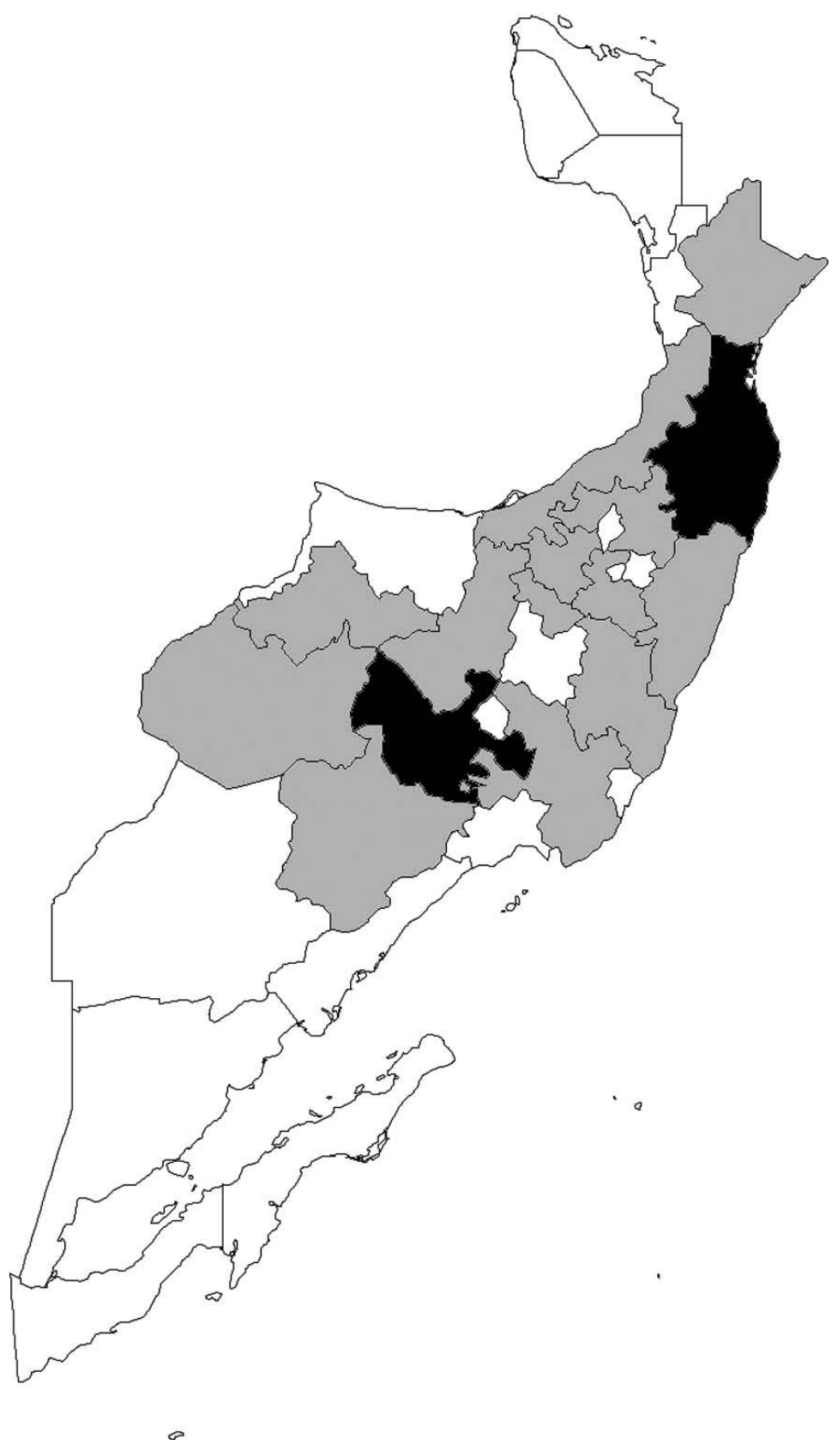

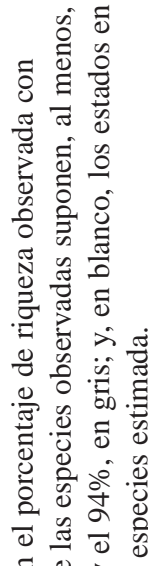

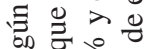

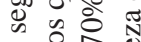

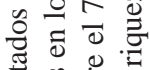

¿

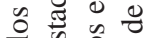

원

畹它

䒕 Оิ

灵导焉

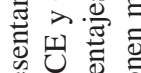

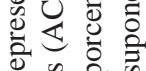

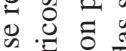

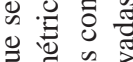

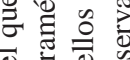

ه

ㄹํ의 엉

응. 엄

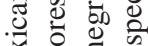

预 윰

율 氖

블을 을

Ð ฮิ ฮิ

芯氙 营

- 0

프 즐

흥 웅

क

巳ั ฝ 


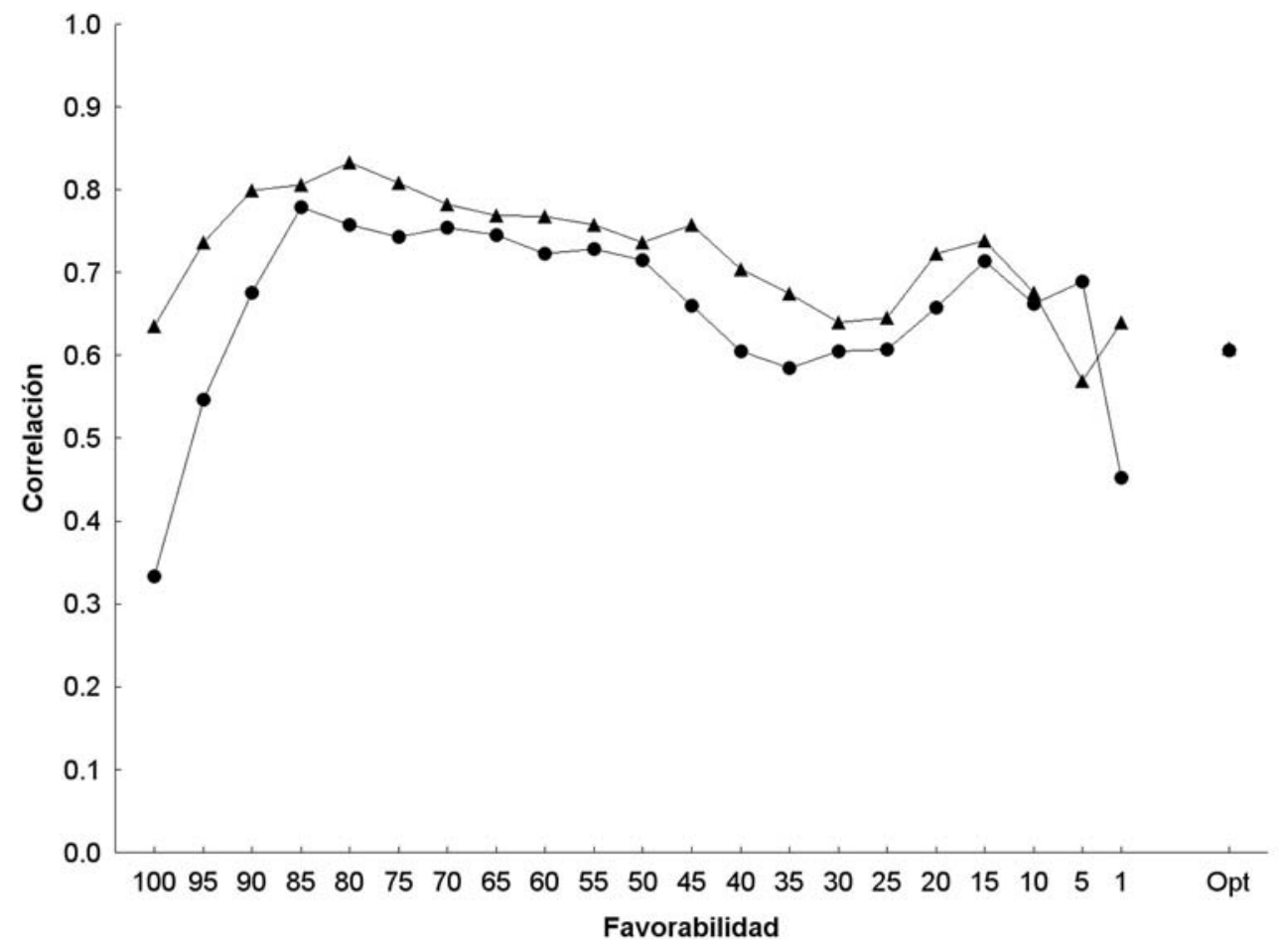

Figura 2. Valores del índice de correlación de Pearson (triángulos) entre la riqueza observada en cada estado con inventarios fiables y la riqueza predicha por la superposición de los modelos de MaxEnt, así como valores del test de Mantel (círculos) entre las composiciones faunísticas de ambos inventarios según los distintos umbrales de favorabilidad considerados para tranformar los valores continuos en binarios. El punto óptimo de corte (Opt) es aquel en el que se considera, como área de presencia, al conjunto de todas aquellas celdas con favorabilidades iguales o superiores a la menor existente en una celda con presencia observada. 

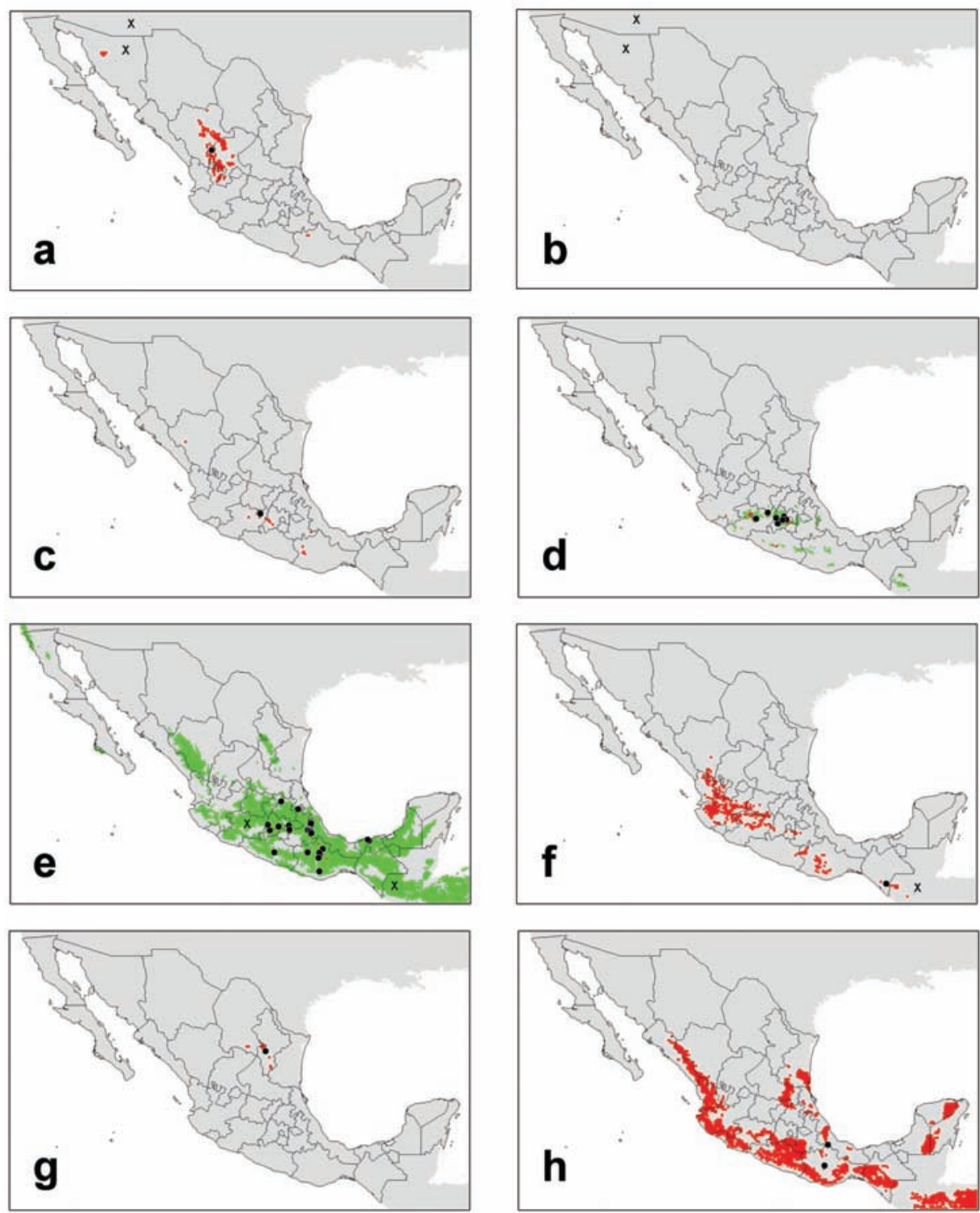

Figura 3. Mapas de distribución de Aphodiinae mexicanos. Puntos en negro: distribución observada; $\mathrm{X}$ : localizaciones (estados o países) en los que se han citado la especie, sin precisión; áreas en verde y rojo: si se utilizó MaxEnt, correspondientes al punto de corte óptimo para la especie y a una favorabilidad igual al umbral 85, respectivamente; áreas con un tono único de rojo: si se utilizó un modelo de "cobertura bioclimática”, correspondientes al área predicha por éste. a) Agoliinus cruentatus; b) Ago. plutonicus; c) Agrilinellus abbonai; d) Agr. antonioreyi; e) Agr. azteca; f) Agr. chiapasensis; g) Agr. nuriae; h) Agr. oaxacaensis. 

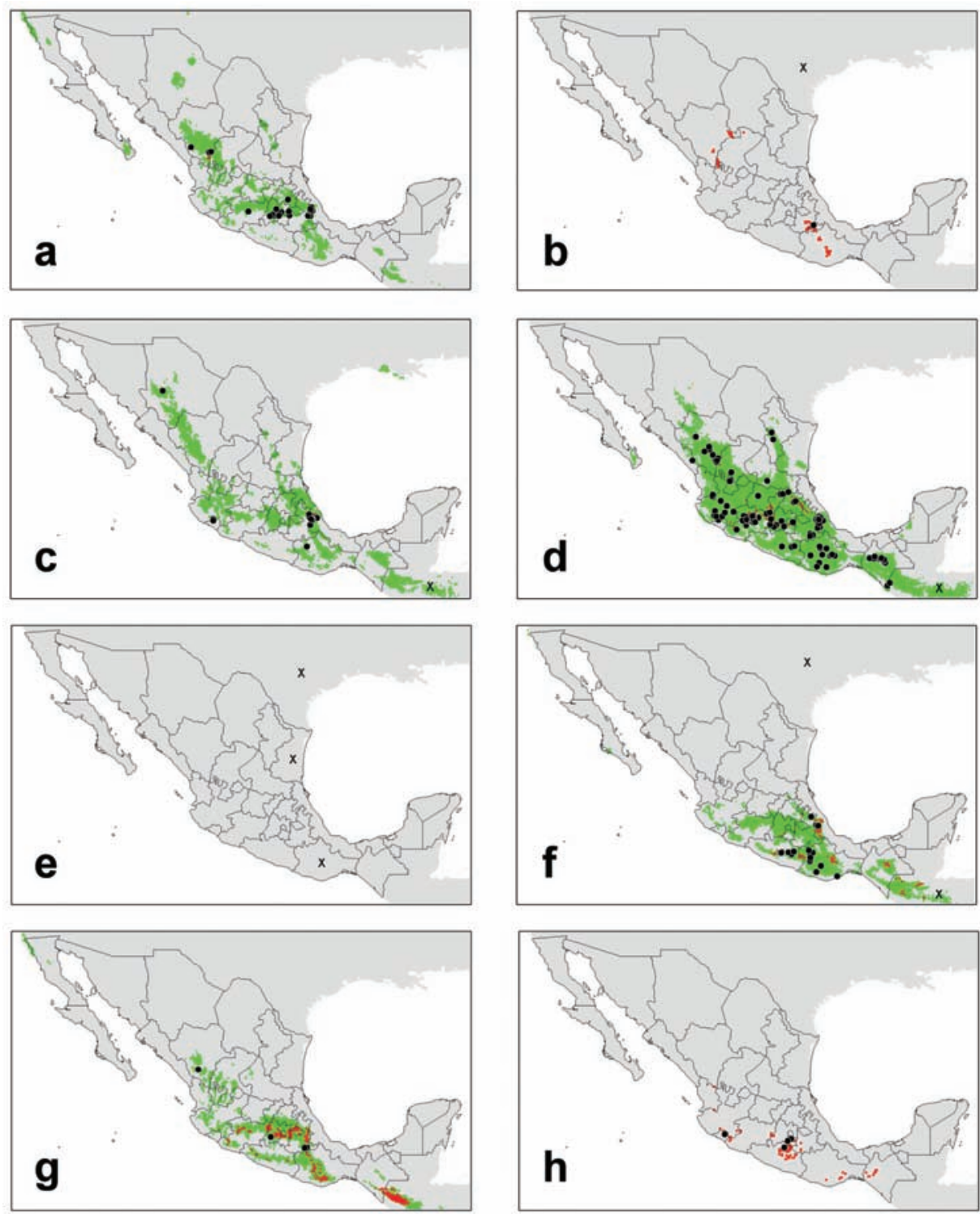

Figura 4. Mapas de distribución de Aphodiinae mexicanos. Puntos en negro: distribución observada; X: localizaciones (estados o países) en los que se han citado la especie, sin precisión; áreas en verde y rojo: si se utilizó MaxEnt, correspondientes al punto de corte óptimo para la especie y a una favorabilidad igual al umbral 85, respectivamente; áreas con un tono único de rojo: si se utilizó un modelo de "cobertura bioclimática”, correspondientes al área predicha por éste. a) Agrilinellus ornatus; b) Aphodius fimetarius; c) Blackburneus charmionus; d) B. guatemalensis; e) B. (s.l.) rubeolus; f) B. saylorea; g) B. (s.l.) saylori; h) Calamosternus colimaensis. 

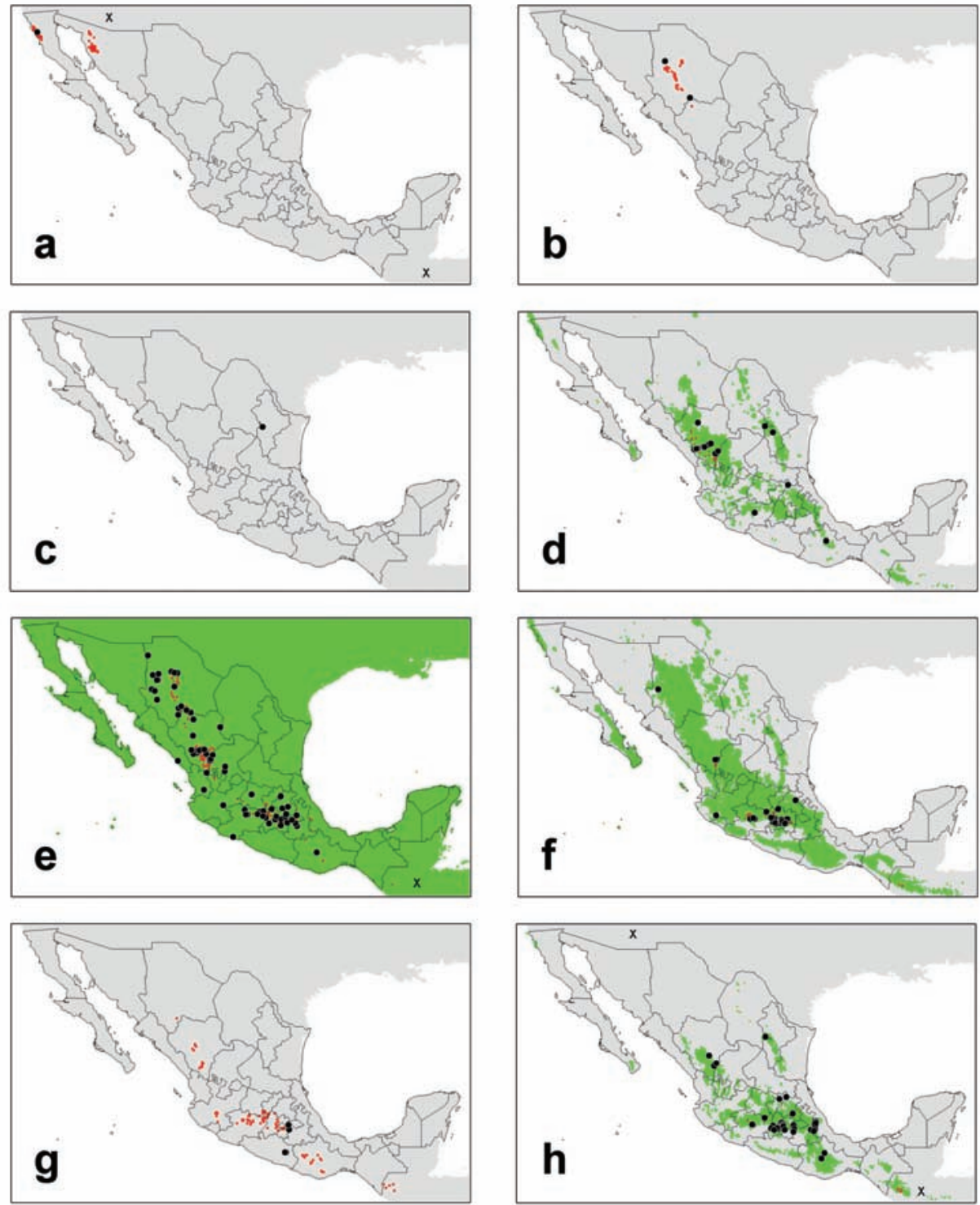

Figura 5. Mapas de distribución de Aphodiinae mexicanos. Puntos en negro: distribución observada; X: localizaciones (estados o países) en los que se han citado la especie, sin precisión; áreas en verde y rojo: si se utilizó MaxEnt, correspondientes al punto de corte óptimo para la especie y a una favorabilidad igual al umbral 85, respectivamente; áreas con un tono único de rojo: si se utilizó un modelo de "cobertura bioclimática”, correspondientes al área predicha por éste. a) Calamosternus granarius; b) Cephalocyclus bordati; c) C. carmenae; d) C. durangoensis; e) C. fuliginosus; f) C. gravidus; g) C. halffteri; h) C. hogei. 

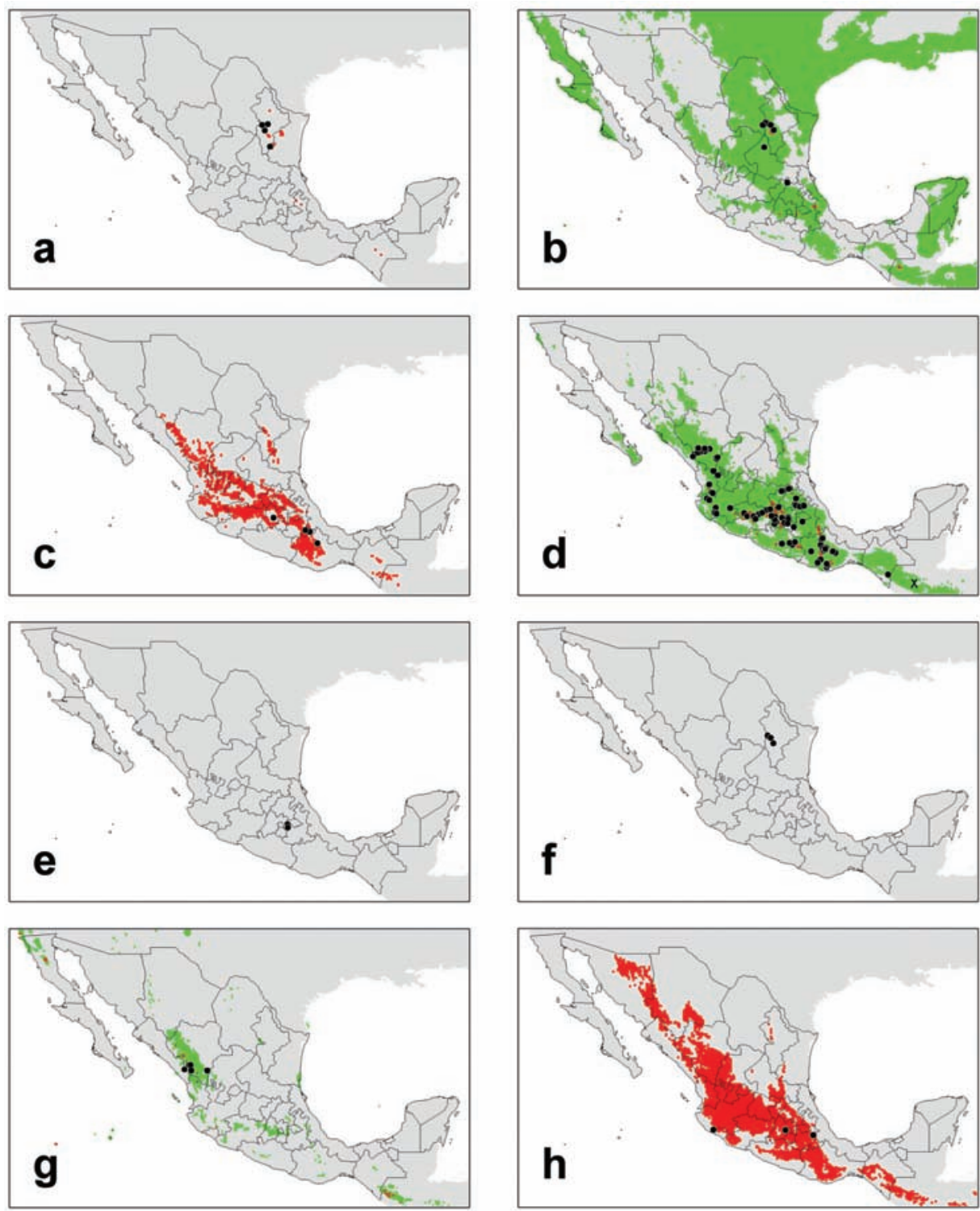

Figura 6. Mapas de distribución de Aphodiinae mexicanos. Puntos en negro: distribución observada; X: localizaciones (estados o países) en los que se han citado la especie, sin precisión; áreas en verde y rojo: si se utilizó MaxEnt, correspondientes al punto de corte óptimo para la especie y a una favorabilidad igual al umbral 85, respectivamente; áreas con un tono único de rojo: si se utilizó un modelo de "cobertura bioclimática”, correspondientes al área predicha por éste. a) Cephalocyclus howdenorum; b) C. lagoi; c) C. luridiventris; d) C. mexicanus; e) C. ordonezi; f) C. potosinus; g) C. pullatus; h) C. puncticeps. 

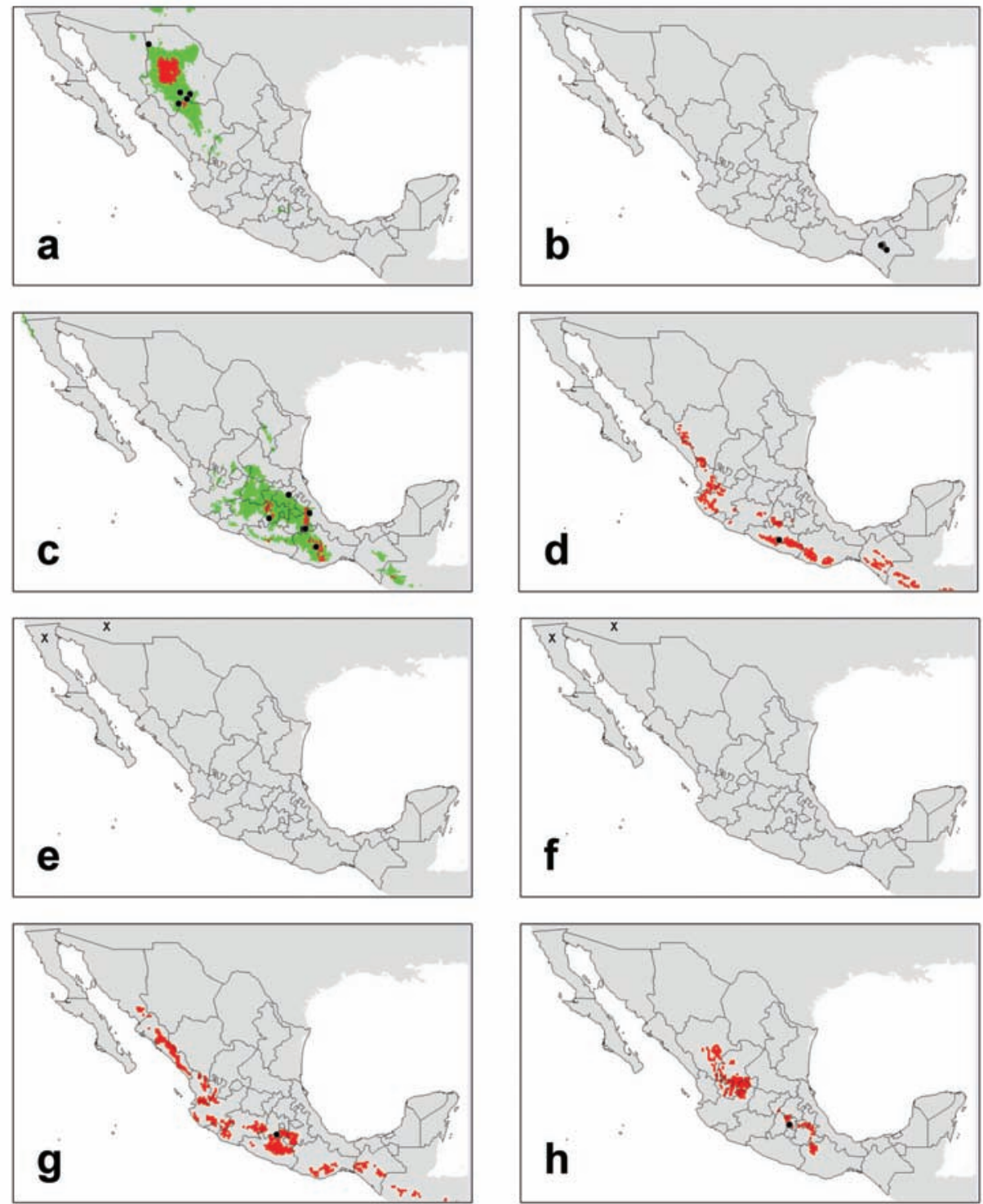

Figura 7. Mapas de distribución de Aphodiinae mexicanos. Puntos en negro: distribución observada; X: localizaciones (estados o países) en los que se han citado la especie, sin precisión; áreas en verde y rojo: si se utilizó MaxEnt, correspondientes al punto de corte óptimo para la especie y a una favorabilidad igual al umbral 85, respectivamente; áreas con un tono único de rojo: si se utilizó un modelo de "cobertura bioclimática”, correspondientes al área predicha por éste. a) Cephalocyclus rockefelleri; b) Cep. stebnickae; c) Cep. villosipes; d) Cesamexico constricticollis; e) Cinacanthus crenicollis; f) Cin. militaris; g) Coelotrachelus burgosi; h) Coe. ixtapalapaensis. 

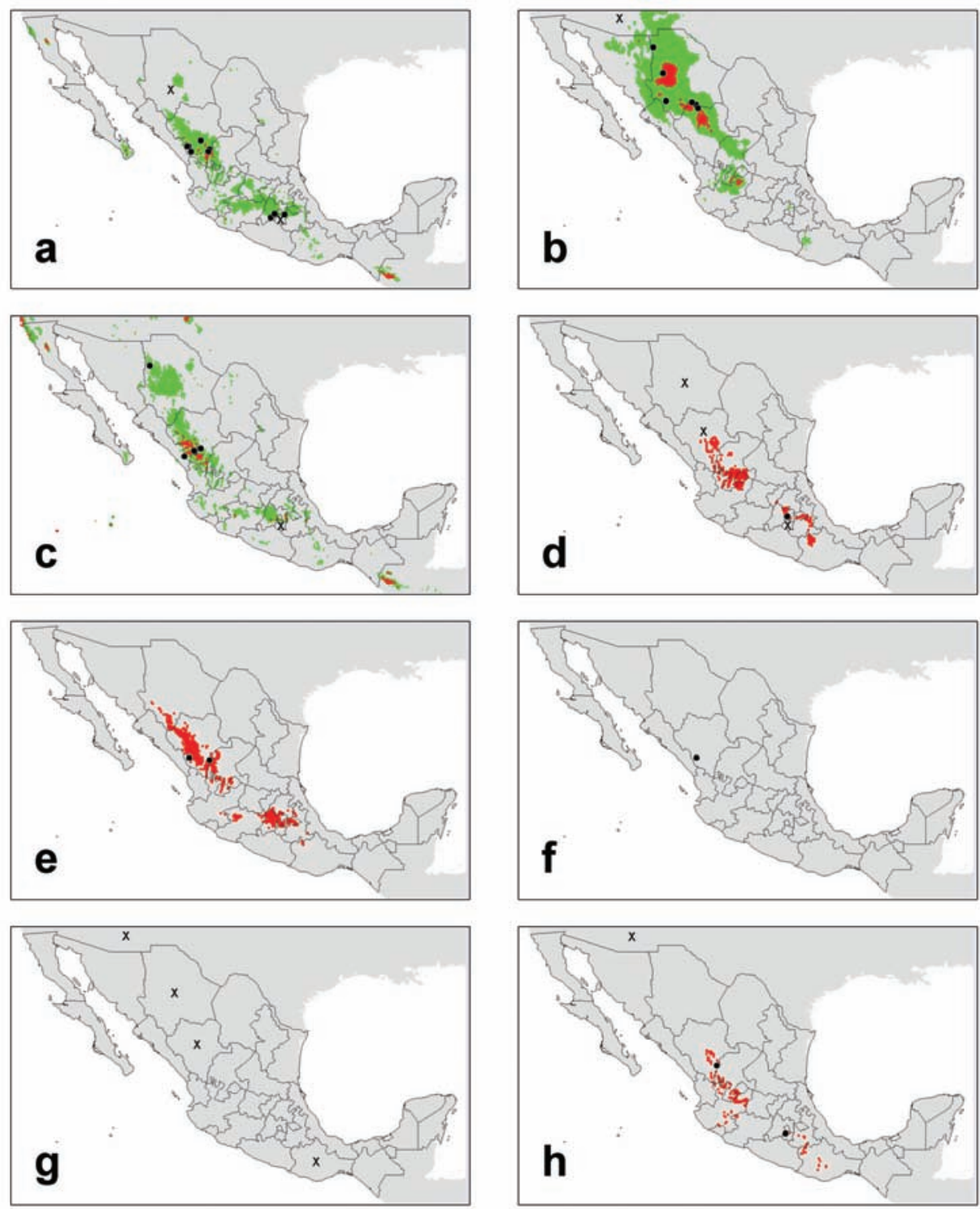

Figura 8. Mapas de distribución de Aphodiinae mexicanos. Puntos en negro: distribución observada; X: localizaciones (estados o países) en los que se han citado la especie, sin precisión; áreas en verde y rojo: si se utilizó MaxEnt, correspondientes al punto de corte óptimo para la especie y a una favorabilidad igual al umbral 85, respectivamente; áreas con un tono único de rojo: si se utilizó un modelo de "cobertura bioclimática”, correspondientes al área predicha por éste. a) Coelotrachelus kuntzeni; b) Coe. rudis; c) Coe. symbius; d) Coe. venustus; e) Cryptoscatomaseter durangoi; f) Cry. epulus; g) Dellacasiellus claudus; h) D. concavus. 

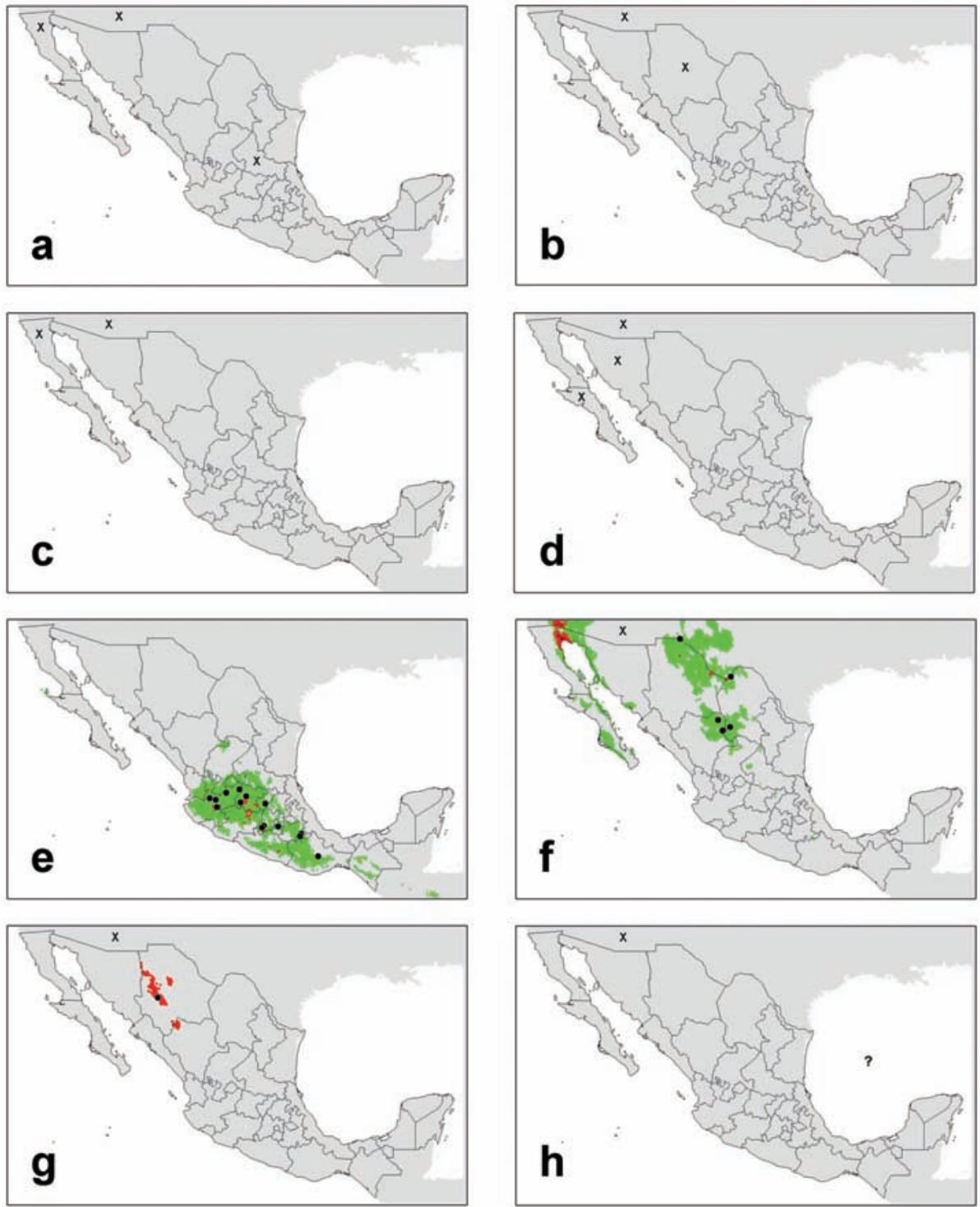

Figura 9. Mapas de distribución de Aphodiinae mexicanos. Puntos en negro: distribución observada; X: localizaciones (estados o países) en los que se han citado la especie, sin precisión; áreas en verde y rojo: si se utilizó MaxEnt, correspondientes al punto de corte óptimo para la especie y a una favorabilidad igual al umbral 85, respectivamente; áreas con un tono único de rojo: si se utilizó un modelo de "cobertura bioclimática”, correspondientes al área predicha por éste. a) Dellacasiellus fucosus; b) Del. kirni; c) Del. pseudofucosus. d) Del. ruficlarus; e) Diapterna dugesi:

f) Drepanocanthoides (s.l.) larreae; g) Flaviellus perfimbriatus; h) F. (s.l.) subtruncatus. 

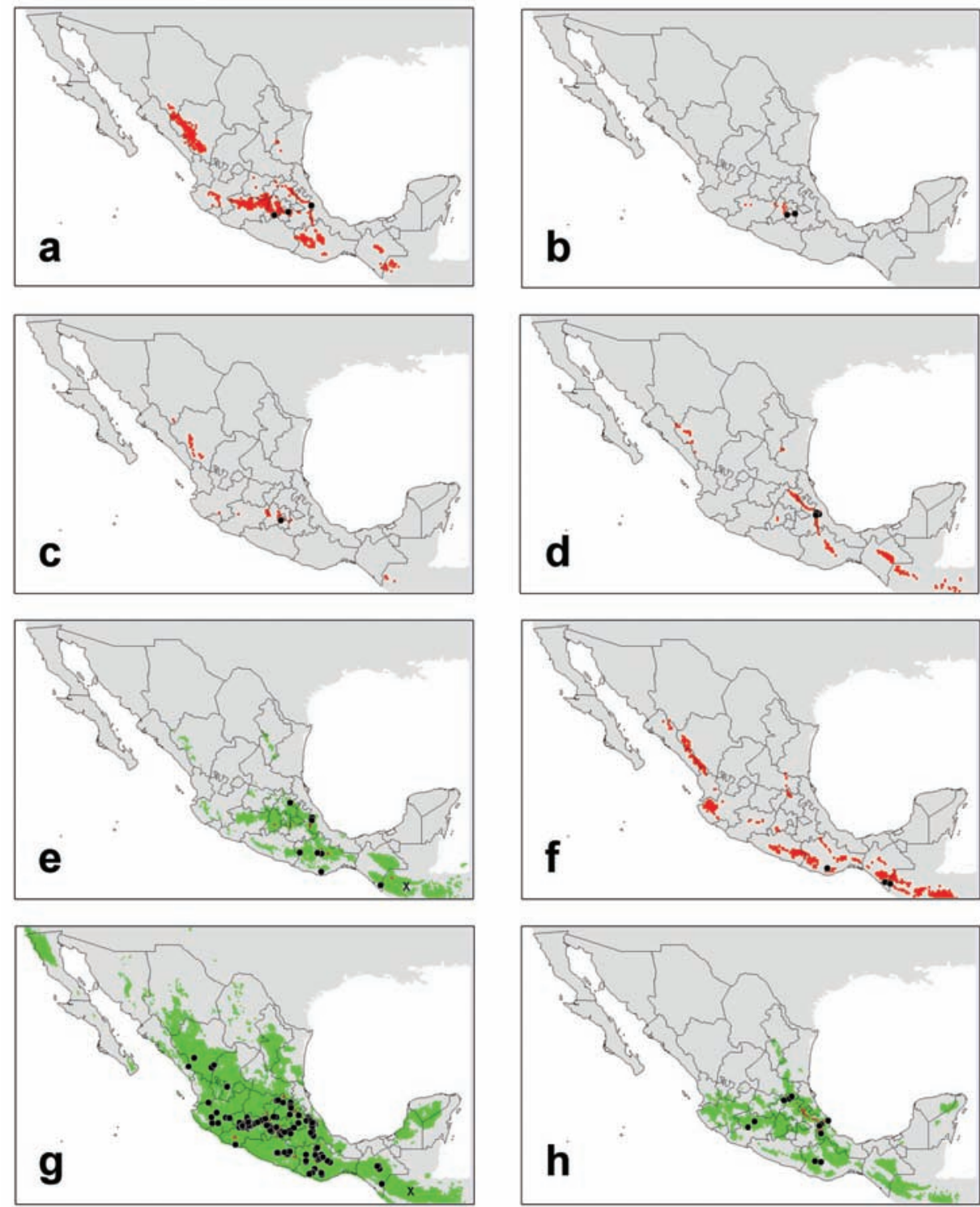

Figura 10. Mapas de distribución de Aphodiinae mexicanos. Puntos en negro: distribución observada; X: localizaciones (estados o países) en los que se han citado la especie, sin precisión; áreas en verde y rojo: si se utilizó MaxEnt, correspondientes al punto de corte óptimo para la especie y a una favorabilidad igual al umbral 85, respectivamente; áreas con un tono único de rojo: si se utilizó un modelo de "cobertura bioclimática”, correspondientes al área predicha por éste. a) Geomyphilus (s.l.) barrerai; b) Geo. (s.l.) coronadoi; c) Geo. (s.l.) macgregori; d) Geo. (s.l.) pierai; e) Gonaphodiellus bimaculosus; f) Gon. hoffmanni; g) Gon. opisthius; h) Haroldiellus lansbergei. 

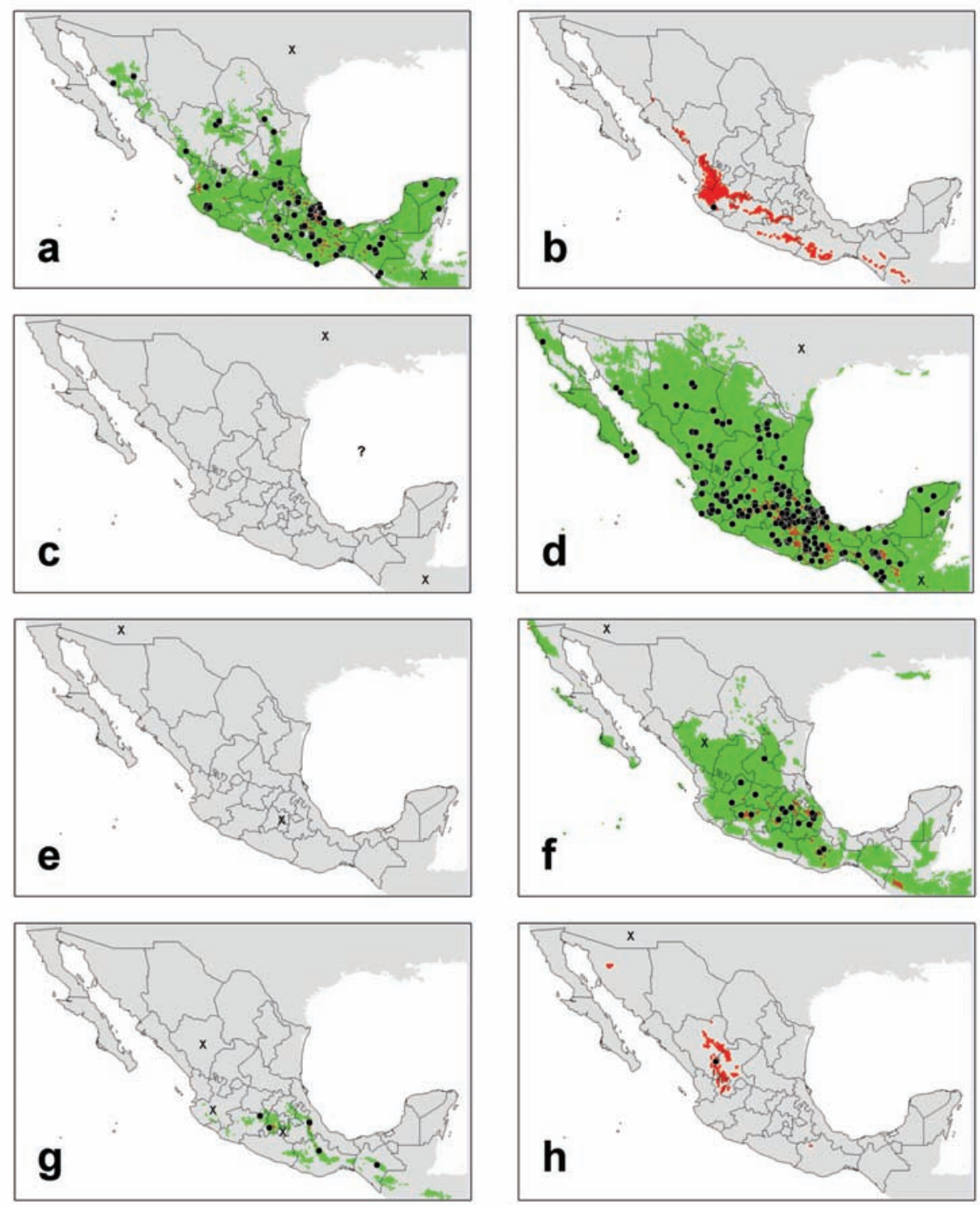

Figura 11. Mapas de distribución de Aphodiinae mexicanos. Puntos en negro: distribución observada; X: localizaciones (estados o países) en los que se han citado la especie, sin precisión; áreas en verde y rojo: si se utilizó MaxEnt, correspondientes al punto de corte óptimo para la especie y a una favorabilidad igual al umbral 85, respectivamente; áreas con un tono único de rojo: si se utilizó un modelo de "cobertura bioclimática”, correspondientes al área predicha por éste. a) Haroldiellus sallei; b) Jalisco plumipes; c) Labarrus lividus; d) Lab. pseudolividus; e) Liothorax alternatus; f) Lio. innexus; g) Lio. levatus; h) Melinopterus (s.l.) consentaneus. 

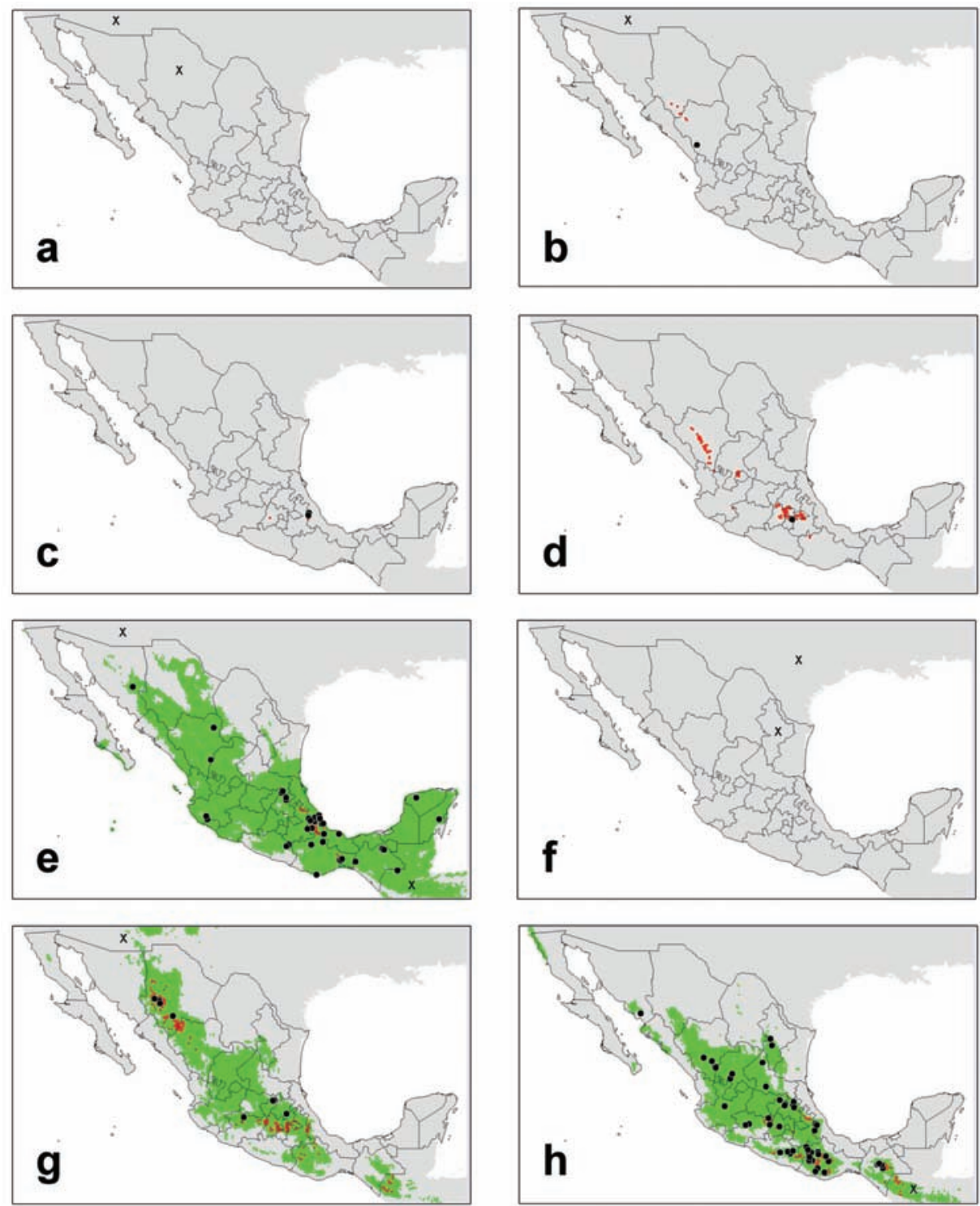

Figura 12. Mapas de distribución de Aphodiinae mexicanos. Puntos en negro: distribución observada; X: localizaciones (estados o países) en los que se han citado la especie, sin precisión; áreas en verde y rojo: si se utilizó MaxEnt, correspondientes al punto de corte óptimo para la especie y a una favorabilidad igual al umbral 85, respectivamente; áreas con un tono único de rojo: si se utilizó un modelo de "cobertura bioclimática”, correspondientes al área predicha por éste. a) Mendidius (s.l.) aculeatus; b) Neotrichonotulus inurbanus; c) Neo. perotensis; d) Neo. urangai; e) Nialaphodius nigrita; f) Oscarinus bottimeri; g) O. crassuloides; h) $O$. indutilis. 

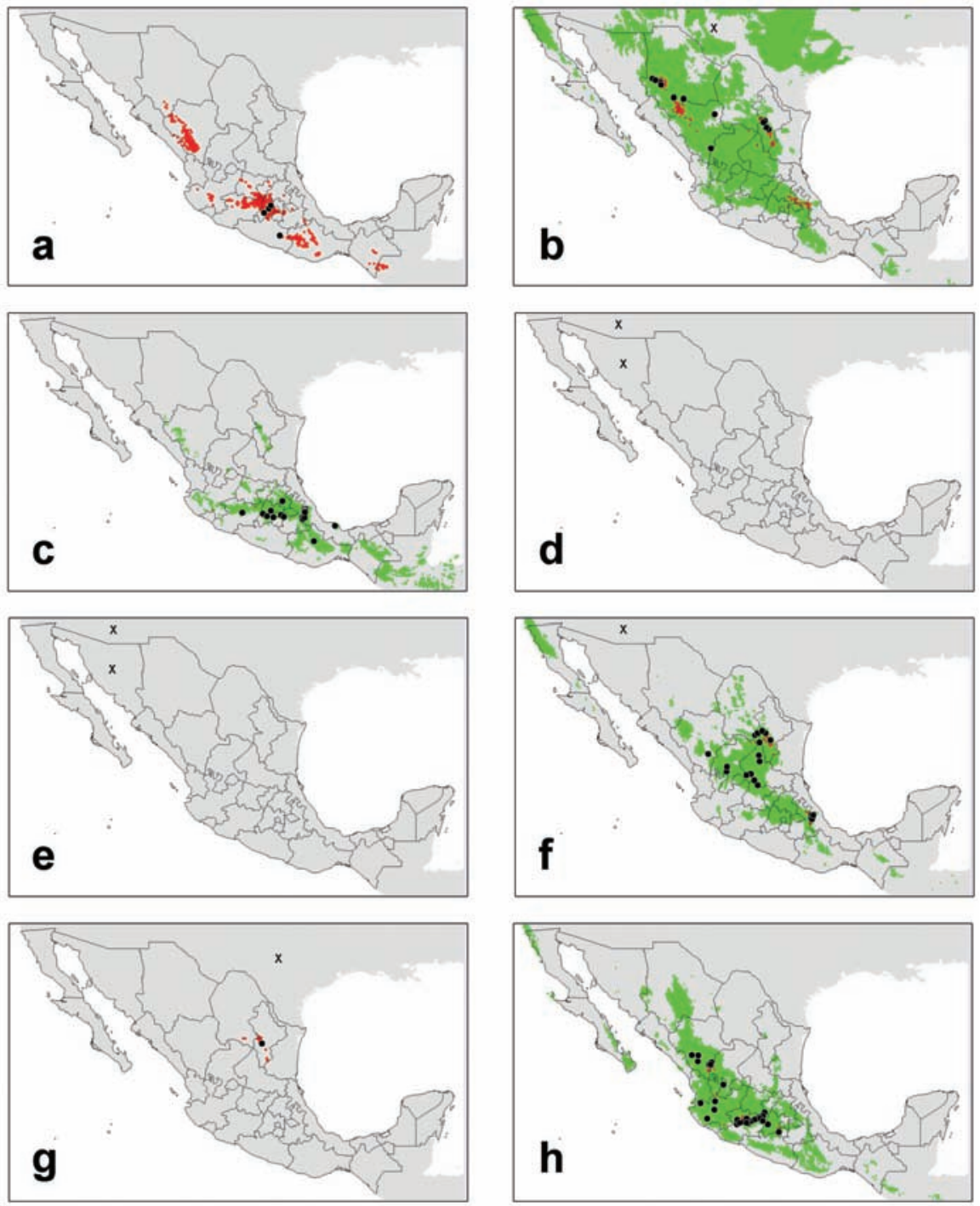

Figura 13. Mapas de distribución de Aphodiinae mexicanos. Puntos en negro: distribución observada; X: localizaciones (estados o países) en los que se han citado la especie, sin precisión; áreas en verde y rojo: si se utilizó MaxEnt, correspondientes al punto de corte óptimo para la especie y a una favorabilidad igual al umbral 85, respectivamente; áreas con un tono único de rojo: si se utilizó un modelo de "cobertura bioclimática”, correspondientes al área predicha por éste. a) Oscarinus spiniclypeus; b) Otophorus haemorrhoidalis; c) Oxyomus setosopunctatus; d) Pardalosus pardalis; e) Par. pseudopardalis; f) Par. (s.l.) pumilio; g) Par. (s.l.) serval; h) Pharaphodius (s.l.) oleosus. 

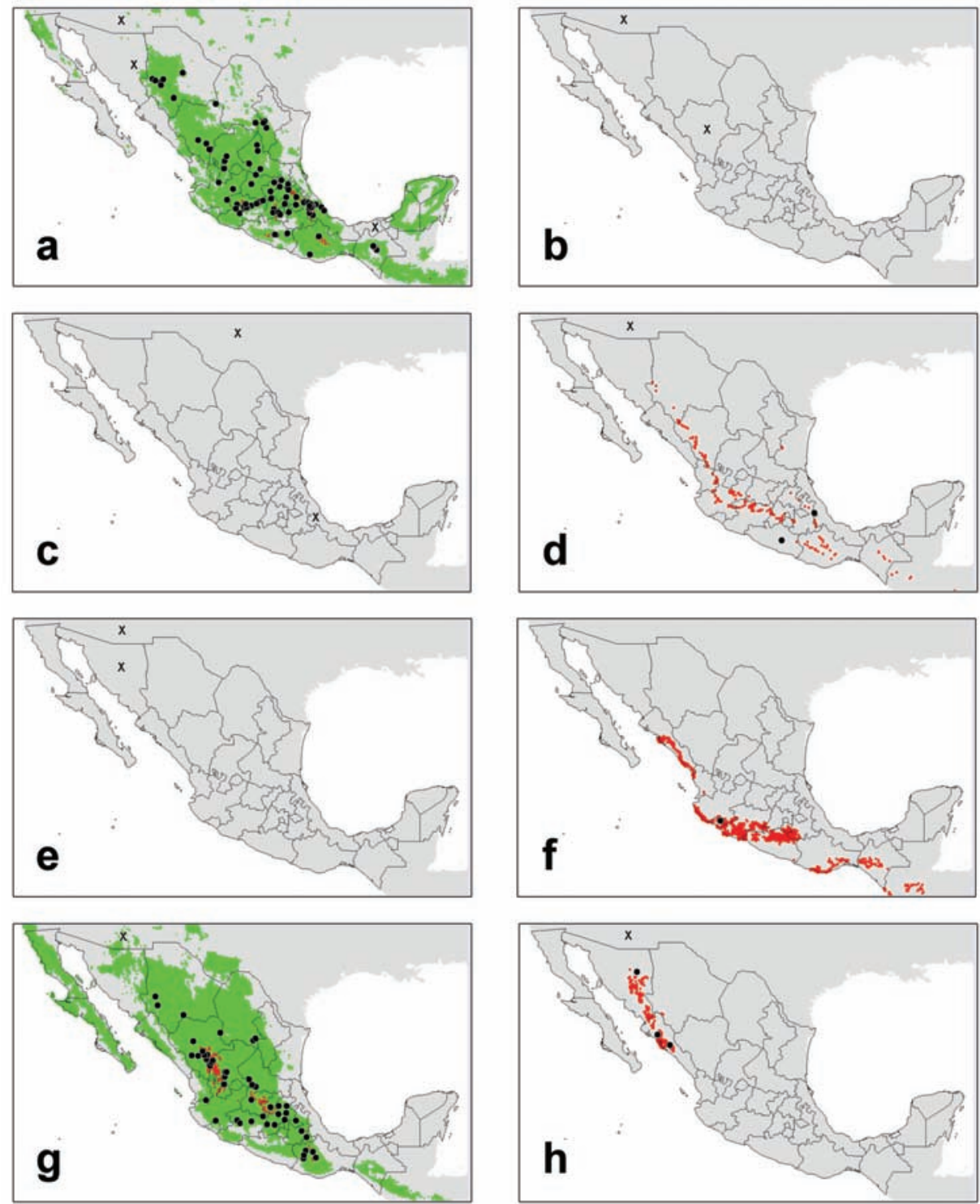

Figura 14. Mapas de distribución de Aphodiinae mexicanos. Puntos en negro: distribución observada; X: localizaciones (estados o países) en los que se han citado la especie, sin precisión; áreas en verde y rojo: si se utilizó MaxEnt, correspondientes al punto de corte óptimo para la especie y a una favorabilidad igual al umbral 85, respectivamente; áreas con un tono único de rojo: si se utilizó un modelo de "cobertura bioclimática”, correspondientes al área predicha por éste. a) Planolinellus vittatus; b) Planolinoides duplex; c) Planolinoides neotomae; d) Planolinus tenellus; e) Pseudagolius (s.l.) bicolor; f) Pse. caballeroi; g) Pse. coloradensis; h) Pse. warneri. 

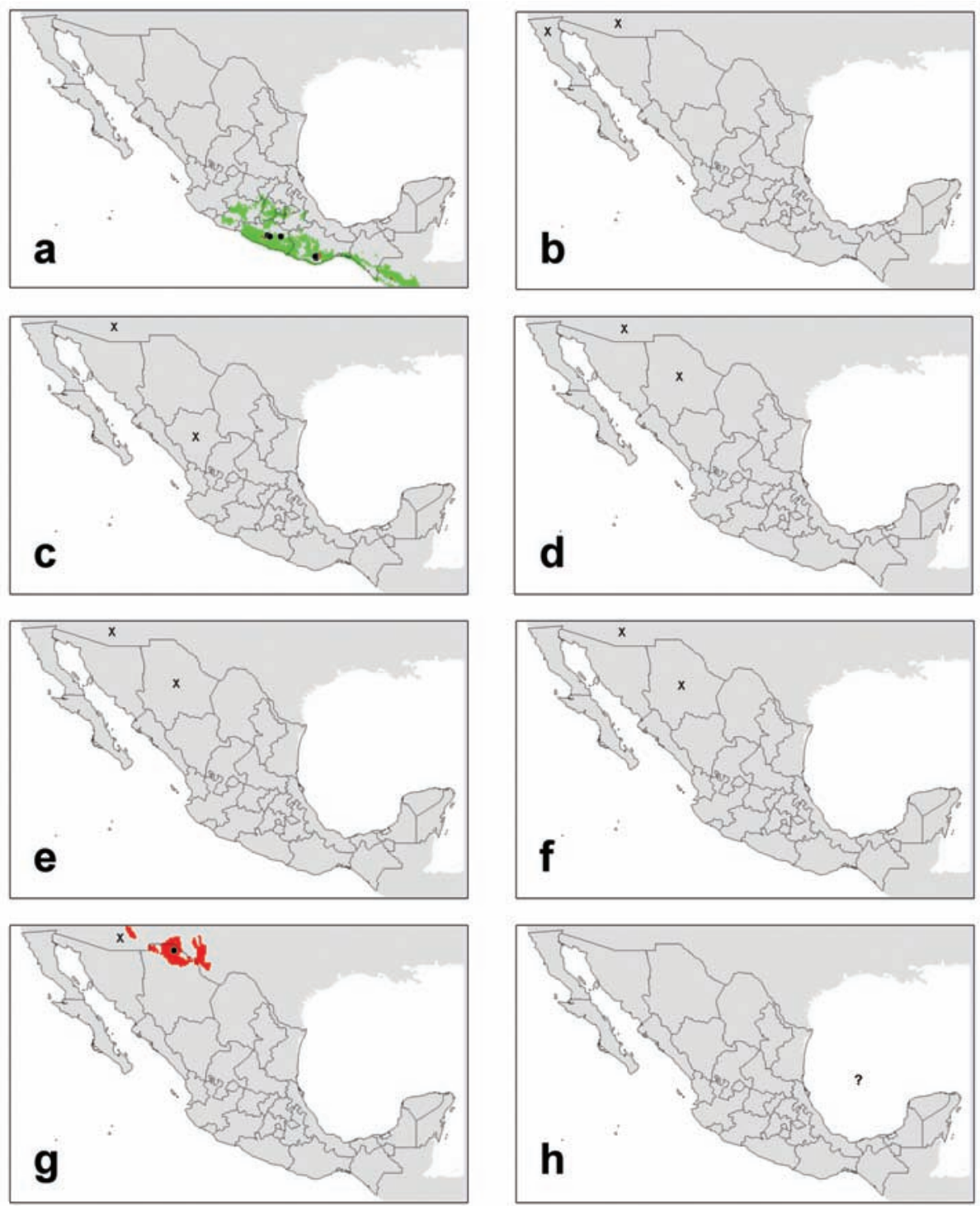

Figura 15. Mapas de distribución de Aphodiinae mexicanos. Puntos en negro: distribución observada; $\mathrm{X}$ : localizaciones (estados o países) en los que se han citado la especie, sin precisión; áreas en verde y rojo: si se utilizó MaxEnt, correspondientes al punto de corte óptimo para la especie y a una favorabilidad igual al umbral 85, respectivamente; áreas con un tono único de rojo: si se utilizó un modelo de "cobertura bioclimática”, correspondientes al área predicha por éste.

a) Pseudogonaphodiellus zdzislawae; b) Rugaphodius rugatus; c) Schaefferellus arizonensis; d) Stenotothorax sparsus; e) Tetraclipeoides (s.l.) aemulus; f) Tet. dentiger; g) Tet. (s.l.) giulianii; h) Trichaphodiellus brasiliensis. 

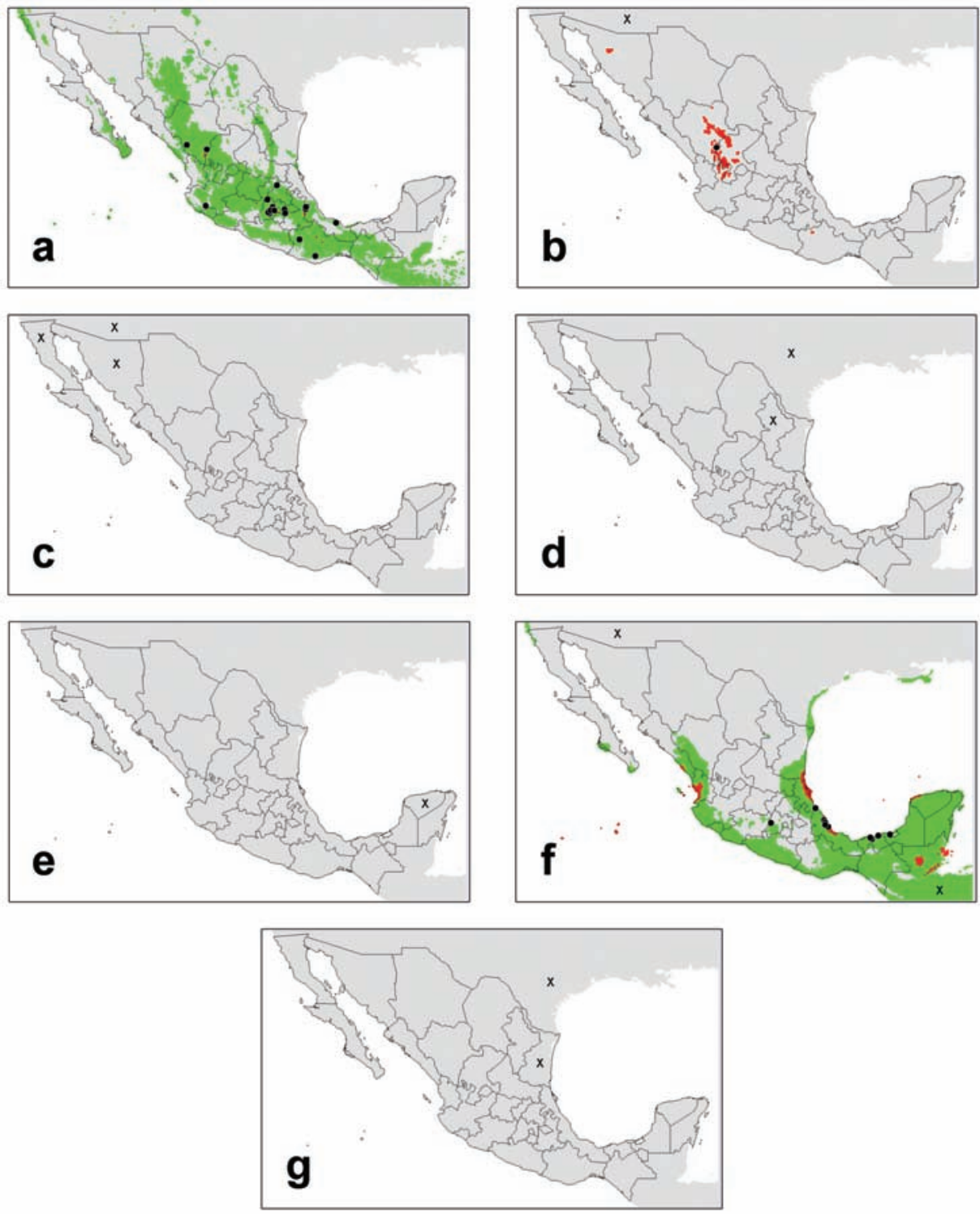

Figura 16. Mapas de distribución de Aphodiinae mexicanos. Puntos en negro: distribución observada; X: localizaciones (estados o países) en los que se han citado la especie, sin precisión; áreas en verde y rojo: si se utilizó MaxEnt, correspondientes al punto de corte óptimo para la especie y a una favorabilidad igual al umbral 85, respectivamente; áreas con un tono único de rojo: si se utilizó un modelo de "cobertura bioclimática”, correspondientes al área predicha por éste. a) Trichonotuloides glyptus; b) Xeropsamobeus (s.l.) asellus; c) X. desertus; d) X. (s.l.) scabriceps; e) Aidophus flaveolus;

f) Aid. notatus; g) Australaphodius frenchi. 


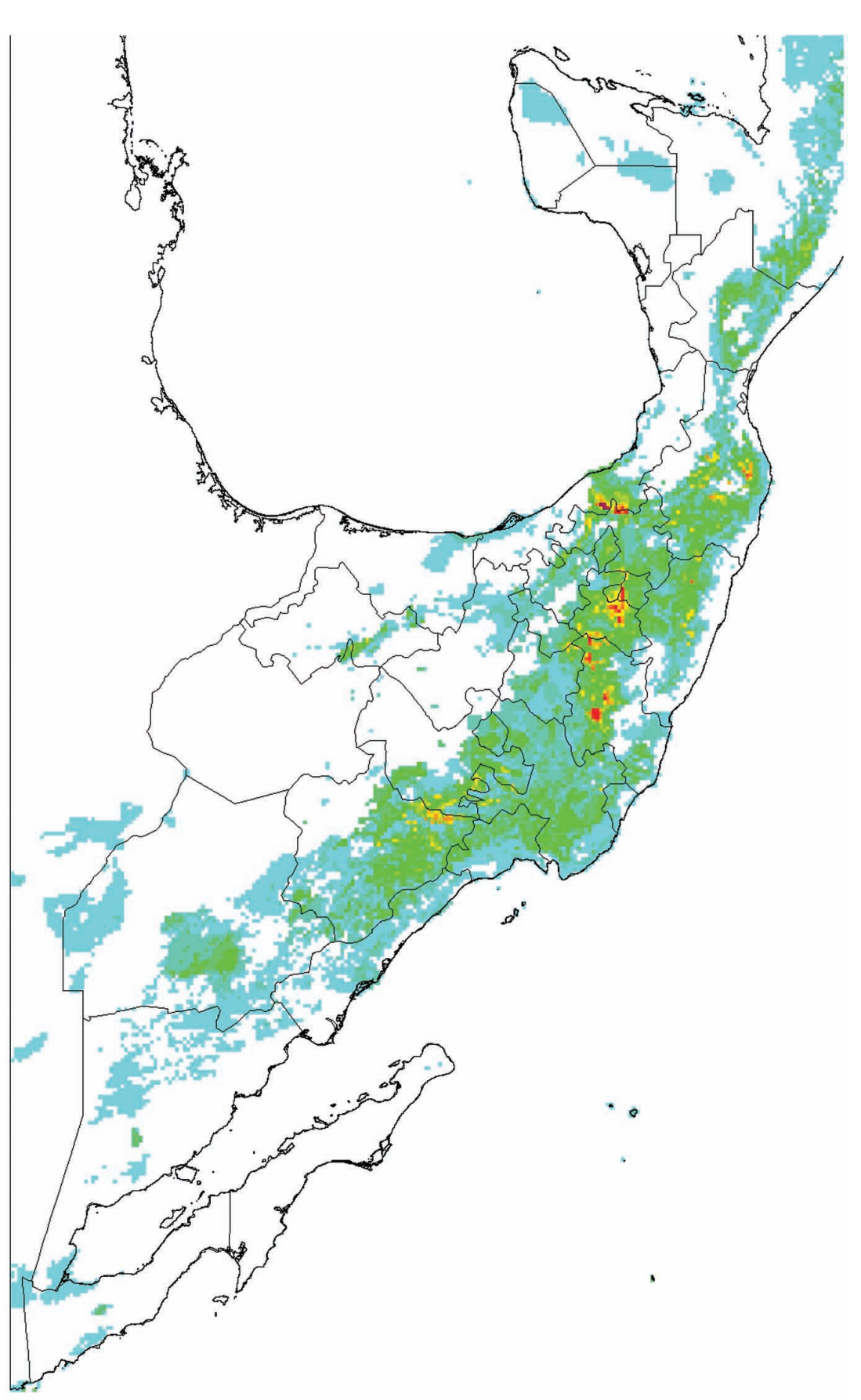

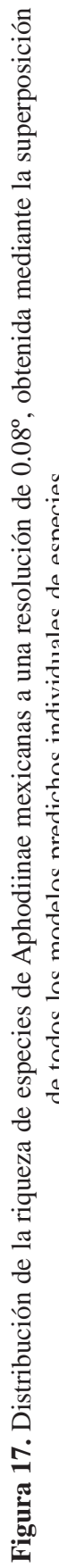


Cabrero-Sañudo et al.: Distribución de Aphodiinae en México
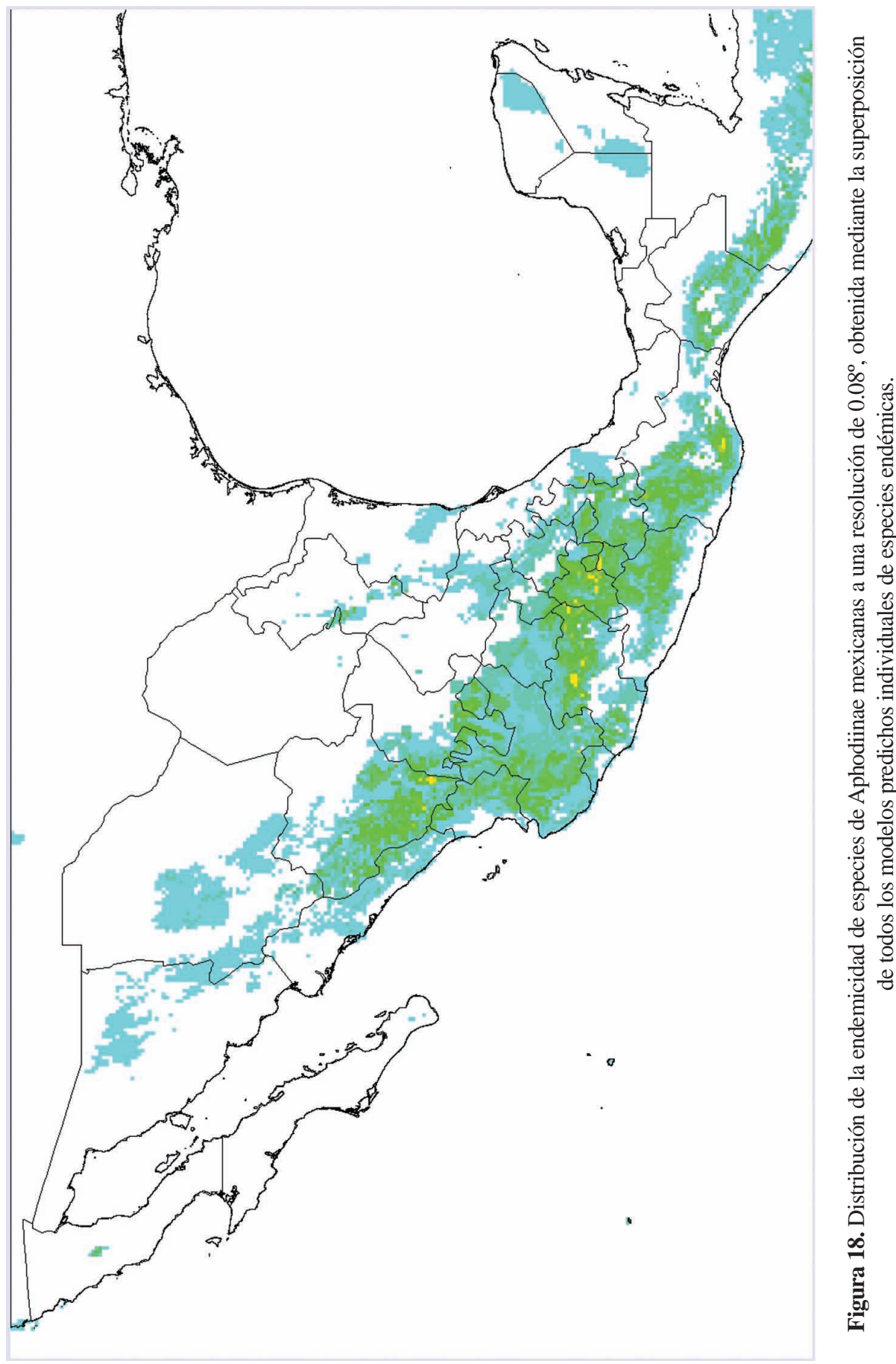


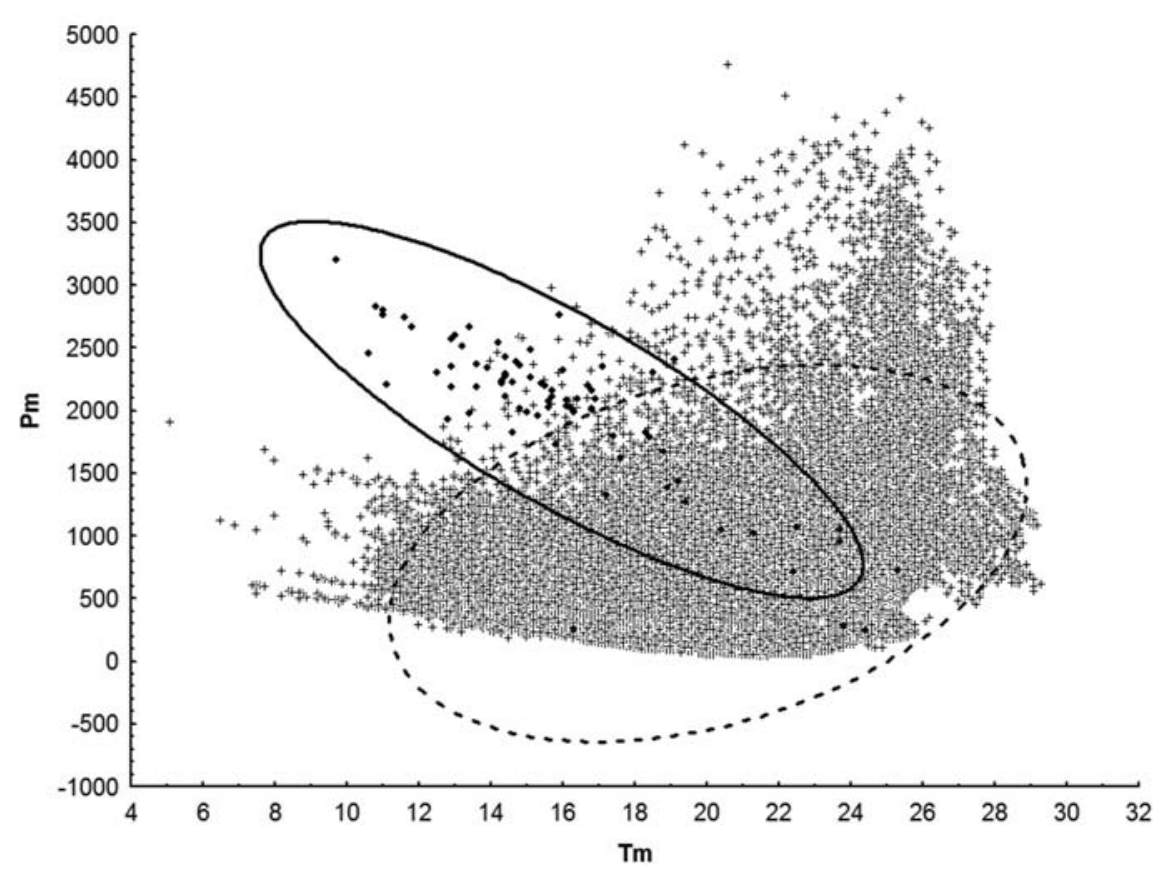

Figura 19. Extensión climática del territorio mexicano, representada por la temperatura media anual (Tm) y la precipitación anual (Pm). Las cruces indican cada una de las celdas del territorio (resolución de $0.08^{\circ}$ ) y los puntos corresponden a cada una de las especies de Aphodiinae mexicanas, de acuerdo a las características medias observadas (Tabla 4). Las elipses contienen el 95\% de los casos: i) línea discontinua: celdas del territorio mexicano; ii) línea continua: especies de Aphodiinae mexicanas. 
Apéndice 1. Listado actualizado (agosto 2009) de las especies de Aphodiinae mexicanas.

Agoliinus Schmidt, 1913

$$
\text { Subfamilia Aphodiinae }
$$

Tribu Aphodiini

Agoliinus cruentatus (LeConte, 1878)

Agoliinus plutonicus (Fall, 1907)

Agrilinellus M. Dellacasa, G. Dellacasa \& Gordon, 2008

Agrilinellus abbonai M. Dellacasa, G. Dellacasa \& Gordon, 2008

Agrilinellus antonioreyi M. Dellacasa, G. Dellacasa \& Gordon, 2008 Agrilinellus azteca (Harold, 1863)

Agrilinellus chiapasensis (Galante, Stebnicka \& Verdú, 2003)

Agrilinellus nuriae M. Dellacasa, G. Dellacasa \& Gordon, 2008

Agrilinellus oaxacaensis M. Dellacasa, G. Dellacasa \& Gordon, 2008

Agrilinellus ornatus (Schmidt, A., 1911)

Aphodius Illiger, 1798

Aphodius fimetarius (Linnaeus, 1758)

Blackburneus (s.l.) Schmidt, 1913

Blackburneus charmionus (Bates, 1887)

Blackburneus guatemalensis (Bates, 1887)

Blackburneus (s.l.) rubeolus (Palisot de Beauvois, 1805)

Blackburneus saylorea (Robinson, 1940)

Blackburneus (s.l.) saylori Hinton, 1934

Calamosternus Motschulsky, 1859

Calamosternus colimaensis (Hinton, 1934)

Calamosternus granarius (Linnaeus, 1767)

Cephalocyclus M. Dellacasa, Gordon \& G. Dellacasa, 1998

Cephalocyclus bordati M. Dellacasa, G. Dellacasa \& Gordon, 2007

Cephalocyclus carmenae M. Dellacasa, G. Dellacasa \& Gordon, 2007

Cephalocyclus durangoensis (Bates, 1887)

Cephalocyclus fuliginosus (Harold, 1863)

Cephalocyclus gravidus (Harold, 1863)

Cephalocyclus halffteri M. Dellacasa, G. Dellacasa \& Gordon, 2007

Cephalocyclus hogei (Bates, 1887)

Cephalocyclus howdenorum M. Dellacasa, G. Dellacasa \& Gordon, 2007

Cephalocyclus lagoi M. Dellacasa, G. Dellacasa \& Gordon, 2007

Cephalocyclus luridiventris (Harold, 1862)

Cephalocyclus mexicanus (Harold, 1862)

Cephalocyclus ordonezi M. Dellacasa, G. Dellacasa \& Gordon, 2007

Cephalocyclus potosinus M. Dellacasa, G. Dellacasa \& Gordon, 2007

Cephalocyclus pullatus (Schmidt A., 1913)

Cephalocyclus puncticeps (Harold, 1862) 
Cephalocyclus rockefelleri M. Dellacasa, G. Dellacasa \& Gordon, 2007

Cephalocyclus stebnickae Deloya \& Ibáñez-Bernal, 2000

Cephalocyclus villosipes (Harold, 1862)

Cesamexico Koçaz \& Kemal, 2008

Cesamexico constricticollis (Bates, 1889)

Cinacanthus Schmidt, 1913

Cinacanthus crenicollis (Fall, 1932)

Cinacanthus militaris (LeConte, 1858)

Coelotrachelus Schmidt, 1913

Coelotrachelus burgosi (Deloya \& McCarty, 1992)

Coelotrachelus ixtapalapaensis Dellacasa, Dellacasa \& Gordon, 2009

Coelotrachelus kuntzeni (Schmidt, A., 1913)

Coelotrachelus rudis (LeConte, 1878)

Coelotrachelus symbius (Gordon \& Howden, 1972)

Coelotrachelus venustus (Schmidt, A., 1911)

Cryptoscatomaseter (s.l.) Gordon \& Skelley, 2007

Crypstoscatomaseter durangoi (Gordon \& Howden, 1972)

Crypstoscatomaseter epulus (Gordon \& Howden, 1972)

Dellacasiellus Gordon \& Skelley, 2007

Dellacasiellus claudus (Fall, 1932)

Dellacasiellus concavus (Say, 1823)

Dellacasiellus fucosus (Schmidt A., 1916)

Dellacasiellus kirni (Cartwright, 1944)

Dellacasiellus pseudofucosus Gordon \& Skelley, 2007

Dellacasiellus ruficlarus (Fall, 1932)

Diapterna Horn, 1887

Diapterna dugesi (Bates, 1887)

Drepanocanthoides (s.l.) Schmidt, 1913

Drepanocanthoides (s.l.) larreae (Horn, 1887)

Flaviellus (s.l.) Gordon \& Skelley, 2007

Flaviellus perfimbriatus Gordon, 1977

Flaviellus (s.l.) subtruncatus (LeConte, 1878)

Geomyphilus (s.l.) Gordon \& Skelley, 2007

Geomyphilus (s.l.) barrerai (Islas, 1955)

Geomyphilus (s.l.) coronadoi (Islas, 1955)

Geomyphilus (s.l.) macgregori (Islas, 1955)

Geomyphilus (s.l.) pierai (Lobo \& Deloya, 1995)

Gonaphodiellus (s.l.) Schmidt, 1913

Gonaphodiellus bimaculosus (Schmidt, A., 1909)

Gonaphodiellus hoffmanni (Islas, 1945)

Gonaphodiellus opisthius (Bates, 1887)

Haroldiellus Gordon \& Skelley, 2007

Haroldiellus lansbergei (Harold, 1874) 
Cabrero-Sañudo et al.: Distribución de Aphodiinae en México

Haroldiellus sallei (Harold, 1863)

Jalisco M. Dellacasa, Gordon \& G. Dellacasa, 2004

Jalisco plumipes M. Dellacasa, Gordon \& G. Dellacasa, 2004

Labarrus Mulsant \& Rey, 1870

Labarrus lividus (Olivier, 1789)

Labarrus pseudolividus (Balthasar, 1941)

Liothorax Motschulsky, 1859

Liothorax alternatus (Horn, 1870)

Liothorax innexus (Say, 1835)

Liothorax levatus (Schmidt A., 1907)

Melinopterus (s.l.) Mulsant, 1842

Melinopterus (s.l.) consentaneus (LeConte, 1850)

Mendidius (s.l.) Harold, 1868

Mendidius (s.l.) aculeatus (Robinson, 1940)

Neotrichonotulus M. Dellacasa, Gordon \& G. Dellacasa, 2004

Neotrichonotulus inurbanus (Gordon \& Howden, 1972)

Neotrichonotulus perotensis (Deloya \& Lobo, 1996)

Neotrichonotulus urangai (Islas, 1955)

Nialaphodius Kolbe, 1908

Nialaphodius nigrita (Fabricius, 1801)

Oscarinus Gordon \& Skelley, 2007

Oscarinus bottimeri (Cartwright, 1957)

Oscarinus crassuloides (Fall, 1907)

Oscarinus indutilis (Harold, 1874)

Oscarinus spiniclypeus (Hinton, 1934)

Otophorus Mulsant, 1842

Otophorus haemorrhoidalis (Linnaeus, 1758)

Oxyomus Dejean, 1833

Oxyomus setosopunctatus Schmidt A., 1911

Pardalosus (s.l.) Gordon \& Skelley, 2007

Pardalosus pardalis (LeConte, 1857)

Pardalosus pseudopardalis Gordon \& Skelley, 2007

Pardalosus (s.l.) pumilio (A. Schmidt, 1907)

Pardalosus (s.l.) serval Say, 1835

Pharaphodius (s.l.) Reitter, 1892

Pharaphodius (s.l.) oleosus (Harold, 1871)

Planolinellus M. Dellacasa \& G. Dellacasa, 2005

Planolinellus vittatus (Say, 1825)

Planolinoides M. Dellacasa \& G. Dellacasa, 2005

Planolinoides duplex (LeConte, 1878)

Planolinoides neotomae (Fall, 1907)

Planolinus Mulsant \& Rey, 1870

Planolinus tenellus (Say, 1823) 
Pseudagolius (s.l.) Schmidt, 1913

Pseudagolius (s.l.) bicolor (Say, 1823)

Pseudagolius caballeroi (Islas, 1945)

Pseudagolius coloradensis (Horn, 1870)

Pseudagolius warneri Gordon \& Skeley, 2007

Pseudogonaphodiellus M. Dellacasa, Gordon \& G. Dellacasa, 2007

Pseudogonaphodiellus zdzislawae M. Dellacasa, Gordon \& G. Dellacasa, 2007

Rugaphodius Gordon \& Skelley, 2007

Rugaphodius rugatus (Schmidt, 1907)

Schaefferellus Gordon \& Skelley, 2007

Schaefferellus arizonensis (Schaeffer, 1907)

Stenotothorax Schmidt, 1913

Stenotothorax sparsus (LeConte, 1878)

Tetraclipeoides (s.l.) Schmidt, 1913

Tetraclipeoides (s.l.) aemulus (Horn, 1887)

Tetraclipeoides dentiger (LeConte, 1858)

Tetraclipeoides (s.l.) giulianii (Gordon, 1977)

Trichaphodiellus Schmidt, 1913

Trichaphodiellus brasiliensis (Laporte de Castelnau, 1840)

Trichonotuloides Balthasar, 1945

Trichonotuloides glyptus (Bates, 1887)

Xeropsamobeus (s.l.) Saylor, 1937

Xeropsamobeus (s.l.) asellus (Schmidt, A., 1907)

Xeropsamobeus desertus (Van Dyke, 1918)

Xeropsamobeus (s.l.) scabriceps (LeConte, 1878)

Aidophus Balthasar, 1963

Tribu Didactyliini

Aidophus flaveolus (Harold, 1867)

Aidophus notatus (Harold, 1859)

Australaphodius Balthasar, 1942

Tribu Proctophanini

Australaphodius frenchi (Blackburn, 1892) 